UNIVERSIDADE DE SÃO PAULO

ESCOLA DE ENGENHARIA DE SÃO CARLOS

DEPARTAMENTO DE HIDRÁULICA E SANEAMENTO

CLÁUDIO JÚNIOR ARAÚJO

"INFLUÊNCIA DA VELOCIDADE CROSS-FLOW NA CÂMARA DE FLOTAÇÃO NA EFICIÊNCIA DE UNIDADES DE FLOTAÇÃO POR AR DISSOLVIDO TRATANDO ÁGUA PARA ABASTECIMENTO” 
UNIVERSIDADE DE SÃO PAULO

ESCOLA DE ENGENHARIA DE SÃO CARLOS

DEPARTAMENTO DE HIDRÁULICA E SANEAMENTO

CLÁUDIO JÚNIOR ARAÚJO

\section{"INFLUÊNCIA DA VELOCIDADE CROSS-FLOW NA CÂMARA DE FLOTAÇÃO NA EFICIÊNCIA DE UNIDADES DE FLOTAÇÃO POR AR DISSOLVIDO TRATANDO ÁGUA PARA ABASTECIMENTO”}

Dissertação apresentada a Escola de Engenharia de São Carlos, da Universidade de São Paulo, como parte dos requisitos necessários para obtenção do Título de Mestre em Engenharia Hidráulica e Saneamento.

Orientador: Prof. Dr. Marco Antônio Penalva Reali

São Carlos, SP

2010 


\section{DEDICATÓRIA}

Dedico este trabalho a minha família, ao meu pai e minha mãe que me incentivam a superar todos os obstáculos da vida, com dedicação, força, coragem e humildade. A Ana Paula, minha amiga, companheira que sempre está do meu lado nas horas difíceis e alegres da vida sempre me apoiando em tudo que preciso. 


\section{AGRADECIMENTOS}

A Deus, por mais esta oportunidade de enriquecimento profissional e pessoal.

Ao Professor Marco Antonio Penalva Reali pela credibilidade depositada, orientação e sugestões na elaboração desta dissertação. Pela paciência, pelo conhecimento passado durantes estes anos de pesquisa, desde a graduação, quando fui aluno de iniciação científica, até hoje com a conclusão do mestrado. Levo comigo não só o professor, mas um amigo para toda a vida.

Aos meus pais que sempre depositaram toda confiança e incentivo na realização deste trabalho, me mostrando que nas horas difíceis a gente se supera e tira forças de onde a gente acha que não há mais nada para tirar. A educação e ética não só como um engenheiro, mas também como uma pessoa que sempre tem que respeitar o próximo.

A Ana Paula que sempre me apoiou e incentivou nas horas difíceis, sempre estando do meu lado em qualquer situação, me mostrando os caminhos onde seguir, e nunca desanimar. E pelos bons momentos que vivemos e viveremos na vida.

A Teresa, técnica do laboratório, pela paciência, orientação e ajuda nas análises realizadas, e pelas boas risadas no laboratório.

Ao Alcino, que sempre me ajudou nas reformas da piloto, não importando a hora que fosse o problema a ser solucionado.

Aos colegas Kisner, André, Aline e muitos outros, pelas sugestões, incentivos ajudas e apoio não só na pesquisa, mas também na vida.

Ao $\mathrm{CNPq}$ pela bolsa de estudo e recursos oferecidos à pesquisa. A Escola de Engenharia de São Carlos, que forneceu recursos para minha formação profissional e pessoal como Engenheiro Ambiental. 
A Sá, secretária da pós-graduação, que sempre me ajudou com documentos e prazos para que pudesse concluir tal pesquisa.

A todos que direta ou indiretamente contribuíram para a realização dessa pesquisa. 


\section{Sumário}

Resumo

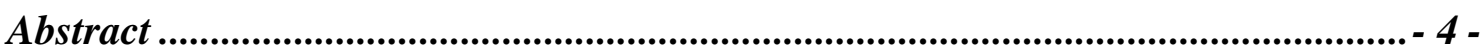

Lista de Figuras ......................................................................................................... - 5 -

Lista de Tabelas ..................................................................................................... 9 ـ

Lista de Abreviaturas....................................................................................... 12 -

1. Introdução.................................................................................................... - 14 -

2. Objetivo .......................................................................................... 17 -

3. Revisão Bibliográfica ................................................................................... 18 -

3.1 Flotação por Ar Dissolvido .........................................................................- 18 -

3.2 Alguns fatores que afetam a eficiência da FAD ...........................................- 20 -

3.2.1 Mistura Rápida ............................................................................... 20 -

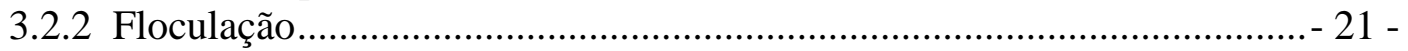

3.2.3 Geração de Bolhas ..............................................................................- 21 -

3.3 Tanque de Flotação .............................................................................................. 23 -

3.3.1 Zona de contato …………………………………........................- 23 -

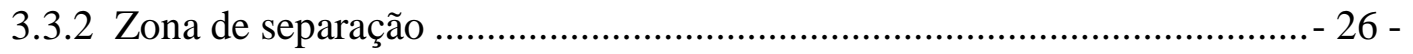

3.4 Velocidade Cross-flow.........................................................................................- 26 -



3.5.1 Colóides .....................................................................................- 31 -

3.5.2 Dupla camada elétrica (DCE) ................................................................- 32 -

3.5.3 Medidas Eletrocinéticas - Potencial Zeta....................................................- 32 -

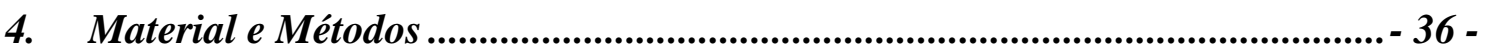

4.1 Considerações Iniciais:...................................................................................- 36 -

4.2 Descrição das Instalações a serem Utilizadas ................................................- 37 -

4.2.1 Equipamento de Escala de Laboratório - Flotateste .................................. 37 -

4.2.2 Instalação Piloto de Flotação por Ar Dissolvido de Alta Taxa ..................- 38 -

4.3 Grade de Ensaios .............................................................................................. 45 -

4.3.1 Fluxograma Geral das ETAPAS 1 e 2................................................. 45 -

4.3.2 Fluxograma da ETAPA 1 ..................................................................- 46 -

4.3.3 Fluxograma da ETAPA 2 .................................................................- 47 -

4.4 Etapa 1 - Determinação do par pH e dosagem de coagulante adequado para a flotação................................................................................................................- 48 -

4.5 Etapa 2 - Verificação da Velocidade Cross-Flow $\left(V_{C F}\right)$ na Eficiência da Flotação na Estação Piloto de Flotação por Ar Dissolvido................................... 49 -

4.6 Preparo das soluções para uso no experimento ……………………………... 52 -



5. Resultados e Discussão................................................................................... 56 - 
5.1 ETAPA 1:

5.1.1 Determinação do par Dosagem de Coagulante e pH de coagulação ......... 56 -

5.1.2 Determinação do Gradiente Médio de Floculação e o Tempo Médio de Floculação.

\subsection{ETAPA 2:}

5.2.1 Ensaio 1: Potencial Zeta Positivo e TAS na Zona de Separação igual a 7,67 $\mathrm{m} / \mathrm{h}:$

5.2.2 Ensaio 2: Potencial Zeta próximo de zero e TAS na Zona de Separação igual a $7,67 \mathrm{~m} / \mathrm{h}:$

5.2.3 Ensaio 3: Potencial Zeta positivo e TAS na Zona de Separação igual a 15 $\mathrm{m} / \mathrm{h}:$

5.2.4 Ensaio 4: Potencial Zeta próximo de zero e TAS na Zona de Separação igual a $15 \mathrm{~m} / \mathrm{h}$ : - 86 -

6. Conclusões e recomendações 96 -

7. Referências Bibliográficas . $-98-$ 


\section{Resumo}

\section{"Influência da Velocidade Cross-Flow na Câmara de Flotação na Eficiência de Unidades de Flotação por Ar Dissolvido Tratando Água para Abastecimento"}

O Reator de FAD deve propiciar condições adequadas para contato entre as microbolhas e os flocos formados no pré-tratamento e também condições para que o conjunto floco/bolha possa ser direcionado ao topo do reator, e assim ser removido. O projeto de pesquisa visou estudar condições hidrodinâmicas proporcionadas pela variação da Velocidade Cross-Flow $\left(\mathrm{V}_{\mathrm{CF}}\right)$ e assim verificar a influência na eficiência de uma Estação Piloto de Flotação por Ar Dissolvido. A $\mathrm{V}_{\mathrm{CF}}$ é importante parâmetro para concepção de unidades de FAD e é função da vazão de entrada no tanque de flotação e da área entre o nível d'água no tanque de flotação e o anteparo que separa a Zona de Contato da Zona de Separação. A Velocidade Cross-Flow constitui um parâmetro de grande importância para projetos de unidades de flotação. Nesta região de transição entre a Zona de Contato e a Zona de Separação, ocorre a passagem do conjunto floco/bolha, e turbulência excessiva pode causar o rompimento do conjunto e assim comprometer a eficiência da flotação. Além disso, o padrão de escoamento observado na Zona de Separação dos flotadores, onde ocorre a separação dos aglomerados "flocos + bolhas", depende fortemente do valor médio da Velocidade Cross-Flow, conforme comentado por Lundh et al. (2000 e 2002) e por Reali e Patrizzi (2007). Daí a necessidade de se investigar mais profundamente a influência da $V_{C F}$ na eficiência da clarificação por flotação. O projeto de pesquisa foi dividido em duas ETAPAS. Para realização das etapas foi estudado um tipo de água preparada em laboratório, através da adição de substância húmica e caulinita, para obtenção de cor aparente e turbidez, respectivamente. A água estudada possui cor aparente e turbidez moderada $(1 \mathrm{mg} / \mathrm{L} \mathrm{de}$ substância húmica e $8,5 \mathrm{mg} / \mathrm{L}$ de caulinita) resultando em valores de turbidez por volta de 7 NTU e cor aparente por volta de 40 UH. A ETAPA 1 consistiu na determinação do par, pH de coagulação e dosagem de coagulante (Sulfato de Alumínio), Gradiente Médio de Floculação e Tempo Médio de Floculação adequado para a água de estudo. Para realização da ETAPA 1 foi utilizado equipamento de flotação de bancada de regime de batelada (Flotateste), que se encontra nas dependências do Laboratório de Tratamento Avançado e Reuso de Águas - LATAR/SHS/EESC/USP. Foram mantidos fixos os seguintes parâmetros: $\mathrm{T}_{\mathrm{MR}}, \mathrm{G}_{\mathrm{MR}}, \mathrm{T}_{\mathrm{F}}, \mathrm{G}_{\mathrm{F}}, \mathrm{P}_{\mathrm{SAT}}, \mathrm{T}_{\mathrm{REC}}, \mathrm{V}_{\mathrm{FLOT}}$. Conforme preconizado por Reali et al (2007), foi variada a dosagem de coagulante. Após determinado o melhor par $\mathrm{pH}$ e dosagem de coagulante foram realizados ensaios visando determinar o melhor $\mathrm{G}_{\mathrm{F}}$ e $\mathrm{T}_{\mathrm{F}}$ para a água em estudo. Para a água de estudo foram escolhidas duas condições de Potencial Zeta, determinados na ETAPA 1 do projeto de pesquisa. A primeira condição o Potencial Zeta permaneceria com valor próximo de $0 \mathrm{mV}$ e na segunda condição o Potencial Zeta seria positivo, por volta de $+12 \mathrm{mV}$. A ETAPA 2 consistiu em variar a Velocidade Cross-Flow, através da variação da altura do vertedor de saída da água flotada de uma unidade piloto de flotação, de forma a se obter diferentes valores de $\mathrm{V}_{\mathrm{CF}}$ (mantendo-se constantes os valores de tempo de contato e taxa de aplicação superficial na Zona de Contato), para dois valores de Taxas de Aplicação Superficial (TAS) $(7,67 \mathrm{~m} / \mathrm{h}$ e $15 \mathrm{~m} / \mathrm{h})$ na Zona de Separação e os dois valores de Potencial Zeta (PZ), e com isto avaliar a sua influencia na eficiência de remoção de Sólidos Suspensos Totais, Cor e Turbidez da instalação piloto retangular de FAD.

PALAVRAS CHAVE: Flotação por Ar Dissolvido, Velocidade Cross-Flow, FAD, Potencial Zeta, Taxa de Aplicação Superficial. 


\section{Abstract}

\section{"The Influence of Cross-Flow Velocity in the Flotation Chamber on Efficiency of a Dissolved Air Flotation Unit Treating Drinking Water"}

The reactor DAF should provide adequate conditions for contact between the microbubbles and the flakes formed in the pretreatment conditions and also for the aggregate flocs / bubble can be directed to the top of the reactor, and thus be removed. The research project aimed at studying hydrodynamic conditions provided by the variation of Cross-Flow Velocity $\left(\mathrm{V}_{\mathrm{CF}}\right)$ and thus checks the influence on the efficiency of a Pilot Plant of Dissolved Air Flotation. The $\mathrm{V}_{\mathrm{CF}}$ is an important parameter to design units of DAF and is a function of input flow in the flotation tank and the area between the water level in the flotation tank and the bulkhead that separates the Contact Zone of the Zone of Separation. The Cross-Flow Velocity is a parameter of great importance to projects of flotation units. In this region of the transition zone between the Contact Zone and the Separation Zone, occurs the passage of the aggregate flocs / bubble, and excessive turbulence can cause disruption of the aggregate and thereby harm the flotation efficiency. Moreover, the pattern of flow observed in the Flotation Separation Zone, which occurs the separation of aggregates "flakes + bubbles", depends strongly on the average value of Cross-Flow Velocity as described by Lundh et al. (2000 and 2002) and Reali and Patrizzi (2007). Hence the needs to investigate further the influence of $V_{C F}$ on the clarification efficiency by flotation. The research project was divided into two steps. To perform the steps has been studied a type of water prepared in the laboratory, through the addition of humic substances and kaolin, to obtain apparent color and turbidity, respectively. The study water has moderate turbidity and apparent color $(1 \mathrm{mg}$ / L of humic substance and $8.5 \mathrm{mg} / \mathrm{L}$ of kaolin) resulting in turbidity values around 7 NTU and color apparent by 40 HU. STEP 1 consisted in the determination of the pair, coagulation $\mathrm{pH}$ and coagulant dosage (aluminum sulfate), Flocculation Gradient and Time Flocculation suitable for the study water. For the implementation of STEP 1 was used bench batch flotation system equipment (Flotatest), located on the Laboratory for Advanced Treatment and Reuse Water - LATAR / SHS / EESC / USP. Were kept fixed the following parameters: $T_{M R}, G_{M R}, T_{F}, G_{F}, P_{S A T}, T_{R E C}, V_{F L O T}$. As predicted by Reali et al (2007), was varied the dosage of coagulant. After determined the best pair of coagulant dosage and $\mathrm{pH}$ coagulation the tests were performed to determine the best $\mathrm{G}_{\mathrm{F}}$ and $\mathrm{T}_{\mathrm{F}}$ for the study water. For the study water were chosen two conditions of Zeta Potential values, determined in the Step 1 of the research project, where the first condition the Zeta Potential value kept near $0 \mathrm{mV}$ and the second condition kept a positive value of Zeta Potential, around $+12 \mathrm{mV}$. The STEP 2 consisted of varying the Cross-Flow Velocity, by varying the height of the outlet weir of the clarified water of the flotation pilot plant to obtain different values of $\mathrm{V}_{\mathrm{CF}}$ (keeping constant the values of time contact and application rate on the Contact Zone) for two values of Superficial Application Rates $(7.67 \mathrm{~m} / \mathrm{h}$ and $15 \mathrm{~m} / \mathrm{h})$ in the Zone of Separation and the two values of Zeta Potential (PZ) and then was availed the influence on removal efficiency of Total Suspended Solids, Colour and Turbidity of the rectangular pilot plant of DAF. Key Words: Dissolved Air Flotation (DAF), Cross-Flow Velocity, Zeta Potential, and Superficial Aplication Rates. 


\section{Lista de Figuras}

FIGURA 3.1 A: Fluxo Padrão identificado pelo método de ADV (Zona de Contato), Velocidade Cross-Flow de 15,2 m/h (retorno de fluxo) 26

FIGURA 3.1 B: Fluxo Padrão identificado pelo método de ADV (Zona de Contato), Velocidade Cross-Flow de $45,2 \mathrm{~m} / \mathrm{h}$ (Fluxo padrão desejável) 26

FIGURA 3. 2: Fluxo Estratificado Padrão na Zona de Separação no Processo de FAD (Fonte: Adaptado de Edzwald, 2007.) 28

FIGURA 3.3 A: Fluxo Estratificado na Zona de Separação, identificado através do método ADV. (Lundh et al., 2000) 30

FIGURA 3.3 B: Fluxo em curto-circuito na Zona de Separação, identificado através do método

ADV. 30

FIGURA 3.4: Esquema da Dupla Camada Elétrica (DCE) (Priesing 1966 apud Bratby 2006 modificado). 33

FIGURA 4.1: Fotografia do equipamento de floculação/flotação em escala de laboratório (flotateste). 39

FIGURA 4.2: Esquema do Sistema Piloto de Flotação por Ar Dissolvido situado nas dependências da EESC/USP. 40

FIGURA 4.3: Esquema da instalação piloto de flotação por ar dissolvido (Planta) (Fonte: Reali e Patrizzi,2007) 41

FIGURA 4.4: Esquema da instalação piloto de flotação por ar dissolvido (Corte) (Fonte: Reali e Patrizzi, 2007)

FIGURA 4.5: Fotos do Sistema de Tratamento de FAD 43

FIGURA 4.6: Fotos do Sistema de Tratamento de FAD 44 
FIGURA 4.7: Instalação Piloto por Ar Dissolvido. 45

FIGURA 4.8: Fluxograma caracterizando os ensaios que serão realizados na ETAPA 1 e 2 46

FIGURA 4.9: Fluxograma caracterizando os ensaios que serão realizados na ETAPA1.

FIGURA 4.10: Fluxograma caracterizando os ensaios que serão realizados na ETAPA2. 48

FIGURA 4.11: Esquema do Vertedor com Altura Variável. 51

FIGURA 4.12: Vertedor com Altura Variável. 52

FIGURA 4.13: Esquema da parede ajustável para variação de $\mathrm{L}_{Z S}$. 52

FIGURA 5.1: Diagrama de coagulação (dosagem de coagulante versus $\mathrm{pH}$ ) visando a flotação para eficiências de 90 e $95 \%$ de remoção na VFLOT de $12,8 \mathrm{~cm} / \mathrm{min}$ (TAS de $7,7 \mathrm{~m} / \mathrm{h}$ ) na zona de separação. 61

FIGURA 5.2: Diagrama de coagulação (dosagem de coagulante versus $\mathrm{pH}$ ) visando a flotação para eficiências de 90 e $95 \%$ de remoção na VFLOT de $25,1 \mathrm{~cm} / \mathrm{min}$ (TAS de $15 \mathrm{~m} / \mathrm{h}$ ) na zona de separação. 62

FIGURA 5.3: Potencial Zeta $x \mathrm{pH}$, para dosagem de $22,5 \mathrm{mg} / \mathrm{L}$ de sulfato de alumínio. $\left(\mathrm{G}_{\mathrm{MR}}\right)=800 \mathrm{~s}^{-1} ;\left(\mathrm{T}_{\mathrm{MR}}\right)=20 \mathrm{~s} ;\left(\mathrm{G}_{\mathrm{F}}\right)=90 \mathrm{~s}^{-1} ;\left(\mathrm{T}_{\mathrm{F}}\right)=12$ minutos; $\left(\mathrm{T}_{\mathrm{R}}\right)=10 \% ;\left(\mathrm{P}_{\mathrm{SAT}}\right)=$ 4,5 bar; $($ DAS $)=22,5 \mathrm{mg} / \mathrm{L} ;$ Tempo de Saturação da água recirculada $=10$ minutos. 63

FIGURA 5.4: Potencial Zeta $\mathrm{x} \mathrm{pH}$, para dosagem de $42,5 \mathrm{mg} / \mathrm{L}$ de sulfato de alumínio. $\left(\mathrm{G}_{\mathrm{MR}}\right)=800 \mathrm{~s}^{-1} ;\left(\mathrm{T}_{\mathrm{MR}}\right)=20 \mathrm{~s} ;\left(\mathrm{G}_{\mathrm{F}}\right)=90 \mathrm{~s}^{-1} ;\left(\mathrm{T}_{\mathrm{F}}\right)=12$ minutos; $\left(\mathrm{T}_{\mathrm{R}}\right)=10 \% ;\left(\mathrm{P}_{\mathrm{SAT}}\right)=$ 4,5 bar; $\mathrm{DAS}=42,5 \mathrm{mg} / \mathrm{L} ;$ Tempo de Saturação da água recirculada $=10$ minutos. 
FIGURA 5.5: Turbidez Residual (NTU) - Ensaio 1 - ETAPA 2. DSA = 42,5 mg/L; PZ $=+13,3 \pm 0,3 ; \mathrm{G}_{\mathrm{F}}=90 \mathrm{~s}^{-1} ; \mathrm{T}_{\mathrm{F}}=12$ minutos; $\mathrm{T}_{\mathrm{R}}=10 \% ; \mathrm{P}_{\mathrm{SAT}}=4,5$ bar; Variação de $\mathrm{V}_{\mathrm{CF}}: 40 ; 70 ; 100 ; 150 ; 200 ; 250 ; 350$ e $630 \mathrm{~m} / \mathrm{h}$.; $\mathrm{TAS}_{\mathrm{ZS}}=7,67 \mathrm{~m} / \mathrm{h} ; \mathrm{Q}_{\text {ent }}=4,6 \mathrm{~m}^{3} / \mathrm{h}$; $\mathrm{TAS}_{\mathrm{ZC}}=180 \mathrm{~m} / \mathrm{h} ; \mathrm{T}_{\mathrm{ZC}}=34 \mathrm{~s}$. 71

FIGURA 5.6: Cor Residual (UH) - Ensaio 1 - ETAPA 2. DSA $=42,5 \mathrm{mg} / \mathrm{L} ; \mathrm{PZ}=$ $+13,3 \pm 0,3 ; \mathrm{G}_{\mathrm{F}}=90 \mathrm{~s}^{-1} ; \mathrm{T}_{\mathrm{F}}=12$ minutos; $\mathrm{T}_{\mathrm{R}}=10 \% ; \mathrm{P}_{\mathrm{SAT}}=4,5$ bar; Variação de $\mathrm{V}_{\mathrm{CF}}$ : $40 ; 70 ; 100 ; 150 ; 200 ; 250 ; 350$ e $630 \mathrm{~m} / \mathrm{h}$.; $\mathrm{TAS}_{\mathrm{ZS}}=7,67 \mathrm{~m} / \mathrm{h} ; \mathrm{Q}_{\text {ent }}=4,6 \mathrm{~m}^{3} / \mathrm{h} ; \mathrm{TAS}_{\mathrm{ZC}}$ $=180 \mathrm{~m} / \mathrm{h} ; \mathrm{T}_{\mathrm{ZC}}=34 \mathrm{~s}$. 72

FIGURA 5.7: ABS $254 \mathrm{~nm}$ - Ensaio 1 - ETAPA 2. DSA $=42,5 \mathrm{mg} / \mathrm{L} ; \mathrm{PZ}=+13,3 \pm$ 0,$3 ; \mathrm{G}_{\mathrm{F}}=90 \mathrm{~s}^{-1} ; \mathrm{T}_{\mathrm{F}}=12$ minutos; $\mathrm{T}_{\mathrm{R}}=10 \% ; \mathrm{P}_{\mathrm{SAT}}=4,5$ bar; Variação de $\mathrm{V}_{\mathrm{CF}}: 40 ; 70$; $100 ; 150 ; 200 ; 250 ; 350$ e $630 \mathrm{~m} / \mathrm{h}$; TAS $_{\mathrm{ZS}}=7,67 \mathrm{~m} / \mathrm{h} ; \mathrm{Q}_{\mathrm{ent}}=4,6 \mathrm{~m}^{3} / \mathrm{h} ;$ TAS $_{\mathrm{ZC}}=180$ $\mathrm{m} / \mathrm{h} ; \mathrm{T}_{\mathrm{ZC}}=34 \mathrm{~s}$. 73

FIGURA 5.8: Turbidez Residual (NTU) - Ensaio 2 - ETAPA 2. DSA = 22,5 mg/L; PZ $=+0,2 \pm 0,2 ; \mathrm{G}_{\mathrm{F}}=90 \mathrm{~s}^{-1} ; \mathrm{T}_{\mathrm{F}}=12$ minutos; $\mathrm{T}_{\mathrm{R}}=10 \% ; \mathrm{P}_{\mathrm{SAT}}=4,5$ bar; Variação de $\mathrm{V}_{\mathrm{CF}}$ : $40 ; 70 ; 100 ; 150 ; 350$ e $630 \mathrm{~m} / \mathrm{h}$; TAS $_{\mathrm{ZS}}=7,67 \mathrm{~m} / \mathrm{h} ; \mathrm{Q}_{\mathrm{ent}}=4,6 \mathrm{~m}^{3} / \mathrm{h} ; \mathrm{TAS}_{\mathrm{ZC}}=180 \mathrm{~m} / \mathrm{h}$; $\mathrm{T}_{\mathrm{ZC}}=34 \mathrm{~s}$. 77

FIGURA 5.9: Cor Residual (UH) - Ensaio 2 - ETAPA 2. DSA = 22,5 mg/L; PZ = $+0,2 \pm 0,2 ; \mathrm{G}_{\mathrm{F}}=90 \mathrm{~s}^{-1} ; \mathrm{T}_{\mathrm{F}}=12$ minutos; $\mathrm{T}_{\mathrm{R}}=10 \% ; \mathrm{P}_{\mathrm{SAT}}=4,5$ bar; Variação de $\mathrm{V}_{\mathrm{CF}}$ : $40 ; 70 ; 100 ; 150 ; 350$ e $630 \mathrm{~m} / \mathrm{h}$; TAS $_{\mathrm{ZS}}=7,67 \mathrm{~m} / \mathrm{h} ; \mathrm{Q}_{\mathrm{ent}}=4,6 \mathrm{~m}^{3} / \mathrm{h} ; \mathrm{TAS}_{\mathrm{ZC}}=180 \mathrm{~m} / \mathrm{h}$; $\mathrm{T}_{\mathrm{ZC}}=34 \mathrm{~s}$. 78

FIGURA 5.10: ABS $254 \mathrm{~nm}$ residual - Ensaio 2 - ETAPA 2. DSA = 22,5 mg/L; PZ = $+0,2 \pm 0,2 ; \mathrm{G}_{\mathrm{F}}=90 \mathrm{~s}^{-1} ; \mathrm{T}_{\mathrm{F}}=12$ minutos; $\mathrm{T}_{\mathrm{R}}=10 \% ; \mathrm{P}_{\mathrm{SAT}}=4,5$ bar; Variação de $\mathrm{V}_{\mathrm{CF}}$ : $40 ; 70 ; 100 ; 150 ; 350$ e $630 \mathrm{~m} / \mathrm{h}$; TAS $_{\mathrm{ZS}}=7,67 \mathrm{~m} / \mathrm{h} ; \mathrm{Q}_{\mathrm{ent}}=4,6 \mathrm{~m}^{3} / \mathrm{h} ; \mathrm{TAS}_{\mathrm{ZC}}=180 \mathrm{~m} / \mathrm{h}$; $\mathrm{T}_{\mathrm{ZC}}=34 \mathrm{~s}$. 79

FIGURA 5.11: Turbidez Residual (NTU) - Ensaio 3 - ETAPA 2. DSA = 42,5 mg/L; $\mathrm{PZ}=+10,3 \pm 0,5 ; \mathrm{G}_{\mathrm{F}}=90 \mathrm{~s}^{-1} ; \mathrm{T}_{\mathrm{F}}=12$ minutos; $\mathrm{T}_{\mathrm{R}}=10 \% ; \mathrm{P}_{\mathrm{SAT}}=4,5$ bar; Variação de $\mathrm{V}_{\mathrm{CF}}: 40 ; 70 ; 100 ; 150 ; 350$ e $630 \mathrm{~m} / \mathrm{h} . ; \mathrm{TAS}_{\mathrm{ZS}}=15 \mathrm{~m} / \mathrm{h} ; \mathrm{Q}_{\mathrm{ent}}=4,6 \mathrm{~m}^{3} / \mathrm{h} ; \mathrm{TAS}_{\mathrm{ZC}}=180$ $\mathrm{m} / \mathrm{h} ; \mathrm{T}_{\mathrm{ZC}}=34 \mathrm{~s}$. 83 
FIGURA 5.12: Cor Residual (UH) - Ensaio 3 - ETAPA 2. DSA = 42,5 mg/L; PZ = $+10,3 \pm 0,5 ; \mathrm{G}_{\mathrm{F}}=90 \mathrm{~s}^{-1} ; \mathrm{T}_{\mathrm{F}}=12$ minutos; $\mathrm{T}_{\mathrm{R}}=10 \% ; \mathrm{P}_{\mathrm{SAT}}=4,5$ bar; Variação de $\mathrm{V}_{\mathrm{CF}}$ : $40 ; 70 ; 100 ; 150 ; 350$ e $630 \mathrm{~m} / \mathrm{h}$; $\operatorname{TAS}_{\mathrm{ZS}}=15 \mathrm{~m} / \mathrm{h} ; \mathrm{Q}_{\mathrm{ent}}=4,6 \mathrm{~m}^{3} / \mathrm{h} ; \mathrm{TAS}_{\mathrm{ZC}}=180 \mathrm{~m} / \mathrm{h}$; $\mathrm{T}_{\mathrm{ZC}}=34 \mathrm{~s}$. 84

FIGURA 5.13: ABS $254 \mathrm{~nm}$ residual - Ensaio 3 - ETAPA 2. DSA = 42,5 mg/L; PZ = $+10,3 \pm 0,5 ; \mathrm{G}_{\mathrm{F}}=90 \mathrm{~s}^{-1} ; \mathrm{T}_{\mathrm{F}}=12$ minutos; $\mathrm{T}_{\mathrm{R}}=10 \% ; \mathrm{P}_{\mathrm{SAT}}=4,5$ bar; Variação de $\mathrm{V}_{\mathrm{CF}}$ : $40 ; 70 ; 100 ; 150 ; 350$ e $630 \mathrm{~m} / \mathrm{h}$; TAS $_{\mathrm{ZS}}=15 \mathrm{~m} / \mathrm{h} ; \mathrm{Q}_{\mathrm{ent}}=4,6 \mathrm{~m}^{3} / \mathrm{h} ; \mathrm{TAS}_{\mathrm{ZC}}=180 \mathrm{~m} / \mathrm{h}$; $\mathrm{T}_{\mathrm{ZC}}=34 \mathrm{~s}$. 85

FIGURA 5.14: Turbidez Residual (NTU) - Ensaio 4 - ETAPA 2. DSA = 22,5 mg/L; $\mathrm{PZ}=+0,3 \pm 0,2 ; \mathrm{G}_{\mathrm{F}}=90 \mathrm{~s}^{-1} ; \mathrm{T}_{\mathrm{F}}=12$ minutos; $\mathrm{T}_{\mathrm{R}}=10 \% ; \mathrm{P}_{\mathrm{SAT}}=4,5$ bar; Variação de $\mathrm{V}_{\mathrm{CF}}: 40 ; 70 ; 100 ; 150 ; 350$ e $630 \mathrm{~m} / \mathrm{h} . ; \mathrm{TAS}_{\mathrm{ZS}}=15 \mathrm{~m} / \mathrm{h} ; \mathrm{Q}_{\mathrm{ent}}=4,6 \mathrm{~m}^{3} / \mathrm{h} ; \mathrm{TAS}_{\mathrm{ZC}}=180$ $\mathrm{m} / \mathrm{h} ; \mathrm{T}_{\mathrm{ZC}}=34 \mathrm{~s}$. 89

FIGURA 5.15: Cor Residual (UH) - Ensaio 4 - ETAPA 2. DSA = 22,5 mg/L; PZ = $+0,3 \pm 0,2 ; \mathrm{G}_{\mathrm{F}}=90 \mathrm{~s}^{-1} ; \mathrm{T}_{\mathrm{F}}=12$ minutos; $\mathrm{T}_{\mathrm{R}}=10 \% ; \mathrm{P}_{\mathrm{SAT}}=4,5$ bar; Variação de $\mathrm{V}_{\mathrm{CF}}$ : $40 ; 70 ; 100 ; 150 ; 350$ e $630 \mathrm{~m} / \mathrm{h}$; $\operatorname{TAS}_{\mathrm{ZS}}=15 \mathrm{~m} / \mathrm{h} ; \mathrm{Q}_{\mathrm{ent}}=4,6 \mathrm{~m}^{3} / \mathrm{h} ; \mathrm{TAS}_{\mathrm{ZC}}=180 \mathrm{~m} / \mathrm{h}$; $\mathrm{T}_{\mathrm{ZC}}=34 \mathrm{~s}$. 90

FIGURA 5.16: ABS $254 \mathrm{~nm}$ Residual - Ensaio 4 - ETAPA 2. DSA = 22,5 mg/L; PZ = $+0,3 \pm 0,2 ; \mathrm{G}_{\mathrm{F}}=90 \mathrm{~s}^{-1} ; \mathrm{T}_{\mathrm{F}}=12$ minutos; $\mathrm{T}_{\mathrm{R}}=10 \% ; \mathrm{P}_{\mathrm{SAT}}=4,5$ bar; Variação de $\mathrm{V}_{\mathrm{CF}}$ : $40 ; 70 ; 100 ; 150 ; 350$ e $630 \mathrm{~m} / \mathrm{h}$; TAS $_{\mathrm{ZS}}=15 \mathrm{~m} / \mathrm{h} ; \mathrm{Q}_{\mathrm{ent}}=4,6 \mathrm{~m}^{3} / \mathrm{h} ; \mathrm{TAS}_{\mathrm{ZC}}=180 \mathrm{~m} / \mathrm{h}$; $\mathrm{T}_{\mathrm{ZC}}=34 \mathrm{~s}$. 91

FIGURA 5.17: Comparativo entre as Velocidades Cross-Flow analisadas, TAS na zona de separação e os valores de Potencial Zeta em relação a Turbidez remanescente(NTU). 93

FIGURA 5.18: Comparativo entre as Velocidades Cross-Flow analisadas, TAS na zona de separação e os valores de Potencial Zeta em relação à Cor remanescente(UH). 95 


\section{Lista de Tabelas}

TABELA 3.1: Velocidade Cross-flow (Parâmetros para projeto) 29

TABELA 4.1: Análise e Leituras para monitoramento da ETAPA 2. 55

TABELA 5.1: Caracterização da Água Bruta para ensaios em laboratório (flotateste)_58

TABELA 5.2: resultados dos ensaios realizados no flotateste em relação a remoção de turbidez e cor da Água I - $\left(\mathrm{G}_{\mathrm{MR}}\right)=800 \mathrm{~s}^{-1} ;\left(\mathrm{T}_{\mathrm{MR}}\right)=20 \mathrm{~s} ;\left(\mathrm{G}_{\mathrm{F}}\right)=90 \mathrm{~s}^{-1} ;\left(\mathrm{T}_{\mathrm{F}}\right)=12$ minutos; $\left(\mathrm{T}_{\mathrm{R}}\right)=10 \% ;\left(\mathrm{P}_{\mathrm{SAT}}\right)=4,5$ bar; $\mathrm{V}_{\mathrm{FLOT}}=12,8 \mathrm{~cm} / \mathrm{min}(7,7 \mathrm{~m} / \mathrm{h})$ e $25,1 \mathrm{~cm} / \mathrm{min}$ $(15 \mathrm{~m} / \mathrm{h})$; Tempo de Saturação da água recirculada $=10$ minutos. 58

TABELA 5.3: resultados do gradiente médio e tempo de floculação para a água tipo I estudada e dosagem de Sulfato de Alumínio de 22,5 mg/L. 65

TABELA 5.4: resultados do gradiente médio e tempo de floculação para a água tipo I estudada e dosagem de Sulfato de Alumínio de 42,5 mg/L. 66

TABELA 5.5: Parâmetros para realização do Ensaio 1 na Instalação Piloto de Flotação por Ar Dissolvido da ETAPA 2 68

TABELA 5.6: Caracterização da Água I do Ensaio 1 da ETAPA 2 69

TABELA 5.7: Caracterização da água coagulada do ensaio 1 da ETAPA 2, para dosagem de Sulfato de Alumínio de 42,5 mg/L. 69

TABELA 5.8: Velocidades Cross-flow analisadas no Ensaio 1 da ETAPA 2 70

TABELA 5.9: Resultados das análises das amostras compostas do Ensaio 1 da ETAPA2. 70

TABELA 5.10: Resultados de SST da amostra flotada e floculada do Ensaio 1 da ETAPA2. 74

TABELA 5.11: Parâmetros para realização do Ensaio 2 na Instalação Piloto de Flotação por Ar Dissolvido da ETAPA 2 
TABELA 5.12: Caracterização da Água I do Ensaio 2 da ETAPA 2 75

TABELA 5.13: Caracterização da água coagulada do ensaio 2 da ETAPA 2, para dosagem de Sulfato de Alumínio de 22,5 mg/L. 75

TABELA 5.14: Velocidades Cross-flow analisadas no Ensaio 2 da ETAPA 2 76

TABELA 5.15: Resultados das análises das amostras compostas do Ensaio 2 da ETAPA2 76

TABELA 5.16: Resultados de SST da amostra flotada e floculada do Ensaio 2 da ETAPA2. 79

TABELA 5.17: Parâmetros para realização do Ensaio 3 na Instalação Piloto de Flotação por Ar Dissolvido da ETAPA 2 81

TABELA 5.18: Caracterização da Água I do Ensaio 3 da ETAPA 2 81

TABELA 5.19: Caracterização da água coagulada do ensaio 3 da ETAPA 2, para dosagem de Sulfato de Alumínio de 42,5 mg/L 81

TABELA 5.20: Velocidades Cross-flow analisadas no Ensaio 3 da ETAPA 2 82

TABELA 5.21: Resultados das análises das amostras compostas do Ensaio 3 da ETAPA2. 82

TABELA 5.22: Resultados de SST da amostra flotada e floculada do Ensaio 3 da ETAPA2. 86

TABELA 5.23: Parâmetros para realização do Ensaio 4 na Instalação Piloto de Flotação por Ar Dissolvido da ETAPA 2 87

TABELA 5.24: Caracterização da Água I do Ensaio 4 da ETAPA 2 87

TABELA 5.25: Caracterização da água coagulada do ensaio 3 da ETAPA 2, para dosagem de Sulfato de Alumínio de 22,5 mg/L. 87

TABELA 5.26: Velocidades Cross-flow analisadas no Ensaio 4 da ETAPA 2 88 
TABELA 5.27: Resultados das análises das amostras compostas do Ensaio 4 da ETAPA2. 88

TABELA 5.28: Resultados de SST da amostra flotada e floculada do Ensaio 4 da ETAPA2. 92

TABELA 5.29: Discussão em relação à remoção da turbidez, analisando as variações de TAS na zona de separação, as variações de $\mathrm{V}_{\mathrm{CF}}$ e de PZ. 94

TABELA 5.30: Conclusão em relação à remoção de cor, analisando as variações de TAS na zona de separação, as variações de $\mathrm{V}_{\mathrm{CF}}$ e de $\mathrm{PZ}$. 96 


\section{Lista de Abreviaturas}

${ }^{\circ} \mathrm{C} \quad-\quad$ Graus Celsius;

ABS - Absorbância.

ADV - Acoustic Doppler Velocimeter;

C.V. - $\quad$ Coeficiente de variância;

DSA - $\quad$ Dosagem de Sulfato de Alumínio;

FAD - $\quad$ Flotação por Ar Dissolvido;

g/L $\quad-\quad$ Gramas por litro;

$\mathrm{g} / \mathrm{m}^{3} \quad$ - Gramas por metro cúbico;

$\mathrm{G}_{\mathrm{F}} \quad$ - Gradiente Médio de Floculação;

$\mathrm{G}_{\mathrm{MR}} \quad$ - $\quad$ Gradiente Médio de Mistura Rápida;

h $\quad-\quad$ Hora;

$\mathrm{h}^{*} \quad$ - $\quad$ Altura sobe o anteparo que separa a Zona de Contato da Zona de Separação no flotador;

HSL $_{\mathrm{CZ}} \quad$ - $\quad$ Taxa de Aplicação Superficial na Zona de Contato;

$\mathrm{L}_{\mathrm{SZ}} \quad$ - Comprimento da Zona de Separação;

$\mathrm{m} / \mathrm{h} \quad-\quad$ Metro por hora;

$\mathrm{m}^{3} / \mathrm{h} \quad$ - Metro cúbico por hora;

$\mathrm{mg} / \mathrm{L} \quad$ - $\quad$ Miligramas por litro;

min. - $\quad$ Minutos;

$\mathrm{mV} \quad-\quad$ Milivolts;

NTU - $\quad$ Nephelometric Turbidity Unity (unidade de turbidez Nephelométrica);

$\mathrm{P}_{\mathrm{SAT}} \quad$ - Pressão de Saturação da Câmara de Contato;

$\mathrm{PZ} \quad$ - Potencial Zeta;

Q ent $\quad$ - Vazão de entrada;

S $\quad-\quad$ Segundos;

S.D. - - Desvio padrão;

SST - Sólidos Suspensos Totais;

TAS - $\quad$ Taxa de Aplicação Superficial;

TAS - $\quad$ Taxa de Aplicação Superficial; 
TAS $_{Z C} \quad$ - Taxa de Aplicação Superficial na Zona de Contato;

TAS $_{Z S} \quad$ - Taxa de Aplicação Superficial na Zona de Separação;

$\mathrm{T}_{\mathrm{CZ}} \quad$ - $\quad$ Tempo de Residência na Zona de Contato;

$\mathrm{T}_{\mathrm{F}} \quad$ - $\quad$ Tempo de Floculação;

$\mathrm{T}_{\mathrm{MR}} \quad$ - $\quad$ Tempo de Mistura Rápida;

$\mathrm{T}_{\mathrm{REC}} \quad$ - $\quad$ Taxa de Recirculação;

$\mathrm{T}_{\mathrm{ZC}} \quad$ - $\quad$ Tempo de Residência na Zona de Contato;

UH $\quad-\quad$ Unidades Hazen;

$\mathrm{V} \quad$ - Volume;

$\mathrm{V}_{\mathrm{CF}} \quad-\quad$ Velocidade Cross-Flow;

$V_{\text {FLOT }} \quad$ - Velocidade de Flotação;

$\mathrm{Z} \quad$ - Altura; 


\section{Introdução}

A ocupação desordenada das cidades e a expansão predatória da agricultura e pecuária degradam áreas de preservação permanente que circundam os corpos d'água e assim os deixam mais susceptíveis à poluição e conseqüentemente piora na qualidade da água. Esta piora na qualidade da água dos mananciais faz com que os sistemas de tratamento de água para abastecimento gerem mais dispêndios em relação ao tratamento, com unidades de tratamento avançados para que a qualidade final da água tratada não seja comprometida e assim obedeça aos padrões de potabilidade. Assim estudos são desenvolvidos em relação a melhorias de tecnologias de tratamento de águas para abastecimento, visando alcançar condições adequadas para consumo da água clarificada final, com menores custos para o tratamento.

A Flotação por Ar Dissolvido (FAD), consolidada tecnologia no tratamento de águas para abastecimento, é processo de tratamento de estudo desta pesquisa, que visou identificar condições hidrodinâmicas adequadas, variando a Velocidade Cross-flow entre a Zona de Contato e a Zona de Separação no processo de tratamento de Flotação por Ar Dissolvido (FAD), tratando água para abastecimento.

A flotação por ar dissolvido é uma tecnologia de separação amplamente usada no tratamento de água e águas residuárias. O processo utiliza microscópicas bolhas de ar para remover partículas suspensas da água (Leppinen e Dalziel, 2004).

Reali (1991) apresenta algumas vantagens da flotação em relação à sedimentação, e que são citadas:

- O lodo produzido apresenta elevado teor de sólidos em suspensão, precedido de unidades adicionais de espessamento de lodo; 
- Constitui processo de alta taxa, apresentando grande rapidez para entrada em regime;

- Na maior parte dos casos requer menores dosagens de coagulantes;

- Requer tempos de floculação da água significativamente menores, resultando em unidades de floculação menores;

- Pode promover arraste de substâncias voláteis porventura presente na água a ser tratada.

Segundo Edzwald (1995) a configuração do reator FAD deve propiciar condições para o contato e a agregação entre as partículas em suspensão no meio líquido (micro-bolhas de ar e flocos) assim como condições favoráveis para que os agregados sejam conduzidos até a parte superior do reator onde podem ser removidos.

Nos últimos 10 anos muita atenção tem sido dada aos aspectos hidrodinâmicos das unidades de flotação de última geração, onde se pode citar Lundh (2000 e 2002), Reali e Patrizi (2007), com vistas a se obter eficiências de clarificação elevadas aliadas a valores de taxas de aplicação superficial cada vez mais elevadas e tempo de floculação vez menores, resultando em unidades mais compactas e eficientes.

Nessa linha, estudos recentes demonstraram que o projeto adequado da zona de contato e da altura do anteparo que define a área de passagem dessa zona para a zona de separação dos flotatores influi marcadamente no desempenho geral da flotação (Reali e Patrizi, 2007). Para uma determinada vazão, as dimensões dessa área de passagem entre as duas zonas citadas definem uma velocidade de passagem designada na literatura por "Cross-Flow Velocity" e aqui designada por Velocidade Cross-Flow $\left(\mathrm{V}_{\mathrm{CF}}\right)$.

Essa velocidade depende da configuração geométrica geral das Zonas de Contato e de Separação dos flotadores, constituindo, portanto, importante parâmetro de projeto dos flotadores. Estudos recentes desenvolvidos por Lundh et. al. (2000 e 2002) e 
por Reali e Patrizzi (2007) demonstraram que o valor de $\mathrm{V}_{\mathrm{CF}}$ influi no padrão de escoamento estratificado verificado na Zona de Separação, situada a jusante do anteparo, que separa a Zona de Contato e a Zona de Separação dos flotadores.

Este escoamento padrão se torna estratificado devido à elevada concentração de micro-bolhas de ar presentes na água junto à saída da Zona de Contato, e o padrão de estratificação é muito dependente do valor de $\mathrm{V}_{\mathrm{CF}}$ resultante da concepção e do projeto da unidade.

Segundo Edzwald (2007) a obtenção do escoamento estratificado na Zona de Separação é muito desejável, tendo em vista que esta estratificação proporciona condições hidrodinâmicas que possibilitem a adoção de taxas de aplicação superficial na zona de separação com valores cada vez maiores (até $40 \mathrm{~m} / \mathrm{h}$ nas unidades de última geração).

Este projeto de pesquisa teve intuito de verificar a influência da Velocidade Cross-Flow na eficiência do processo de flotação, de uma Instalação Piloto de Flotação por Ar Dissolvido (FAD), implantada nas dependências da Escola de Engenharia de São Carlos da Universidade de São Paulo. Assim, foi investigada a influência da Velocidade Cross-Flow na eficiência global de separação da unidade piloto de flotação, submetida a dois diferentes valores de taxa de aplicação superficial (TAS) e a dois diferentes valores de Potencial Zeta (PZ).

Deve-se salientar que não se tem conhecimento da existência na literatura de estudos que forneçam informações conclusivas acerca do valor ou da faixa de valores recomendável para o projeto de flotadores. 


\section{Objetivo}

Avaliar o desempenho de uma unidade de flotação por ar dissolvido (FAD) retangular tratando água sintética para abastecimento, associado à variação da Velocidade Cross-flow juntamente com a variação de duas taxas de aplicação superficial na zona de separação e dois potencias zeta. 


\section{Revisão Bibliográfica}

\subsection{Flotação por Ar Dissolvido}

O primeiro uso relatado do processo de FAD no tratamento de água foi na Finlândia (ADKA e Sveen-Pedersen), durante a década de 1920 (Haarhoff, 2007). Segundo Schofield (2001) há centenas de unidades de FAD em todo o mundo, sendo mais de 90 unidades tratando água no Reino Unido, 37 na Finlândia, 26 na Austrália, 26 na África do Sul, 20 nos Estados Unidos, 15 na Suécia, 5 na Noruega, 6 no Canadá, 7 na França, 5 na Holanda, 3 na Bélgica e 1 na Nova Zelândia. Patrizzi (2002) relata que na América Latina há em torno de 20 unidades FAD em operação.

Segundo Lundh (2000) o mecanismo de flotação por ar dissolvido é descrito por pequenas bolhas de ar que se aderem às partículas suspensas presentes na água, cuja idéia é gerar aglomerados com menor densidade que a água, causando a ascensão do floco até a superfície, podendo ser removido no lodo.

Aspectos positivos do processo de FAD são citados por vários autores:

- A FAD utiliza tanques menores comparados com os tanques da sedimentação, gerando menos gastos para construção (Edzwald, 1992);

- $\quad$ Sistema compacto que utiliza altas taxas (Zabel, 1985; Schofield, 2001);

- $\quad$ A FAD utiliza tanques de floculação menores (Edzwald, 1992) e com isto o tempo de detenção durante o processo de floculação é menor (Mooyoung et al., 2007); 
- $\quad$ Rápido start up (Zabel, 1985; Schofield, 2001);

- Dosagens de coagulantes e floculantes poderão ser menores (Edzwald, 1992);

- $\quad$ A FAD fornece melhor remoção de partículas de pequena densidade e algas (Zabel, 1985; Edzwald, 1992);

- $\quad$ A FAD é particularmente mais efetiva para o tratamento de água que contem grandes quantidades de algas, ou águas de baixa turbidez e altos valores de cor em relação ao processo de sedimentação (Zabel, 1985);

- $\quad$ Quando a FAD é associada com filtros, taxas de filtração maiores ou carreiras de filtração mais longas podem ser obtidas, quando comparadas com a sedimentação associada aos filtros (Edzwald, 1992);

- Melhor qualidade da água tratada quando comparada com a sedimentação (Zabel, 1985);

- É obtida maior concentração de sólidos no lodo proveniente da flotação, quando comparado com a sedimentação (Edzwald, 1992); produção de lodo mais espesso (Zabel, 1985; Reali, 1991);

- $\quad$ Sistema FAD é robusto as variações hidráulicas e na qualidade da água bruta (Schofield, 2001);

- $\quad$ Air Stripping de substancias voláteis (Reali, 1991)

Dentre os aspectos negativos do processo de FAD, Edzwald (1992) cita-se o alto consumo de energia elétrica proveniente da bomba de recirculação, porém os gastos com energia podem ser compensados com o reduzido uso de coagulantes e floculantes, pelo melhor tratamento do lodo (mais desaguado) e com isto menor custo para sua disposição. 
A FAD exige mão-de-obra mais qualificada, pois a complexidade e a quantidade de equipamentos são maiores o que torna a operação mais delicada em relação à sedimentação.

\subsection{Alguns fatores que afetam a eficiência da FAD}

\subsubsection{Mistura Rápida}

A água pode conter uma variedade de impurezas, destacando-se partículas coloidais, substancias húmicas e organismos em geral. Tais impurezas apresentam carga superficial negativa, impedindo que as mesmas se aproximem uma das outras, permanecendo no meio líquido se suas características não forem alteradas (Bratby, 2006). Para que as impurezas possam ser removidas é preciso alterar algumas características da água. A coagulação resulta em dois fenômenos: o primeiro essencialmente químico que consiste nas reações do coagulante com a água formando espécies hidrolisadas com carga positiva e depende da concentração do metal e pH final da mistura; o segundo, fundamentalmente físico, consiste no transporte das espécies hidrolisadas para que haja contato entre as impurezas presentes na água.

Shawwa e Smith (2000) relatam que a desestabilização das partículas ocorre durante o estágio de mistura rápida, depois da adição de coagulantes químicos. O coagulante é misturado de forma homogênea e rápida causando a desestabilização das partículas coloidais na água bruta. Portanto é necessária uma eficiente mistura, de forma que haja a desestabilização das partículas, para que não venha a prejudicar as etapas seguintes da flotação por ar dissolvido. 


\subsubsection{Floculação}

Segundo Shawwa e Smith (2000), o principal foco do processo de floculação é transportar as partículas desestabilizadas e promover colisões para a formação de flocos. A formação de flocos ocorre em situações de mistura lenta.

Moruzzi (2005) descreve que estudos desenvolvidos na década de 90, mostraram os benefícios do uso de câmaras de floculação em série ( 2 ou 3 câmaras em série). Segundo Schofield (2001), os trabalhos iniciais sobre a FAD utilizavam as mesmas condições de floculação da sedimentação convencional. Hoje em dia os gradientes e o tempo de floculação foram otimizados visando a FAD. Gradientes de velocidade na floculação de $70 \mathrm{~s}^{-1}$, aproximadamente, são recomendados. O tempo de floculação foi reduzido de 20 a 30 minutos para um tempo de 10 minutos ou menor, o que tem produzido flocos entre 10 e $100 \mu \mathrm{m}$ de diâmetro que são mais eficientemente separados pela FAD.

\subsubsection{Geração de Bolhas}

O tamanho das bolhas é muito importante na flotação, onde se prefere a formação de bolhas na faixa de 10 e $100 \mu \mathrm{m}$ de diâmetro, por apresentarem maior eficiência na remoção de partículas (Edzwald, 1995).

Pequenas bolhas de ar (100 $\mu \mathrm{m}$ ou menores) são formadas pela injeção da água recirculada pressurizada no tanque de flotação usando bocais especiais ou válvulas agulha (Edzwald, 1995). Isto é causado pela diferença de pressão entre a água pressurizada recirculada (geralmente a pressões da ordem de 5 bar), inserida no tanque de flotação, situado à pressão atmosférica. Assim ocorrerá o desprendimento das bolhas fazendo com que estas entrem em contato com os flocos proveniente dos floculadores. 
Bolhas entre 10 e $100 \mu \mathrm{m}$ de diâmetro produzem um tratamento estável (Takahashi et al., 1979; Zabel, 1984; De Rijk et al., 1994 apud Edzwald, 1995). Edzwald (1995) cita que tamanhos de bolhas razoáveis para o tratamento são de $40 \mu \mathrm{m}$ de diâmetro. Na câmara de saturação, em pressões acima de 5 bar tem-se um efeito muito pequeno sobre o tamanho das bolhas (Heinanen et al., 1992; De Rijk et al., 1994 apud Edzwald, 1995). Segundo Edzwald (1995), para se obter bolhas pequenas, a pressão na câmara de saturação deve estar compreendida entre 4 e 6 bar.

Edzwald (1992) cita que duas variáveis a respeito do ar fornecido são importantes: Porcentagem de água recirculada e a concentração em volume de bolhas de ar. A porcentagem de água recirculada é um parâmetro simples e prático usado em projetos e no controle operacional. O volume de bolhas é um parâmetro controlado pela pressão da câmara de saturação, temperatura da água e porcentagem de água recirculada. É relacionada às colisões entre floco e bolha de ar visando reduzir a densidade do floco.

Reali et al. (2001) relatam que é importante que a "nuvem" de micro-bolhas de ar produzidas na entrada das unidades FAD seja uniformemente distribuída, permitindo que essas micro-bolhas exerçam seu papel com o máximo de eficiência. A principal função das micro-bolhas de ar no processo FAD é, conforme já comentado, diminuir a densidade dos conjuntos flocos/bolhas em relação à densidade da água e, dessa forma, quanto maior o volume de bolhas ligadas aos flocos (ou sólidos), menor a densidade relativa e maior a velocidade ascendente dos conjuntos flocos/bolhas. 


\subsection{Tanque de Flotação}

Segundo Edzwald (1995), o tanque se flotação é dividido em duas partes: a zona de reação (zona de contato) onde há o contato e o aderimento das bolhas com os flocos; e a zona de separação onde são promovidas condições para a ascensão do conjunto floco/bolha à superfície. A Zona de Contato caracteriza-se como uma região de mistura visando a colisão e a agregação entre as micro-bolhas e os flocos. A Zona de Separação por sua vez, é a região onde as condições de escoamento devem favorecer a manutenção da ligação e propiciar a ascensão do conjunto micro-bolhas e flocos. (Lundh et al., 2002).

\subsubsection{Zona de contato}

O propósito da zona de Contato é promover colisões entre as micro-bolhas e os flocos e assim causar a agregação entre ambos (Lundh et al., 2002; Edzwald, 2009).

Segundo Moruzzi e Reali (2007) a zona de contato exerce papel fundamental na eficiência da flotação por ar dissolvido e vem despertando grande interesse nos pesquisadores. Uma das etapas mais importantes da FAD ocorre nesta zona: formação de agregados flocos/bolhas estáveis os quais dependem de diversos fatores que definem a eficiência da colisão e aderência. Entre estes fatores, a distribuição do tamanho das bolhas possui grande importância. Ainda na zona de contato são relatados por Reali e Moruzzi (2007) que o pH, a razão de recirculação e o tempo de detenção na zona de contato são fatores que podem modificar a distribuição de tamanho das micro-bolhas depois do ponto em que são injetadas e assim interferir na formação dos agregados flocos + micro-bolhas. 
Reali e Patrizzi (2007) produziram importante pesquisa para o desenvolvimento de flotadores. Nesta pesquisa foram estudados os principais parâmetros da composição da Zona de Contato: A influência do tempo de detenção hidráulico e a Taxa de Aplicação Superficial aplicada na Zona de Contato, observando não só a estrutura do fluxo na Zona de Contato, mas também a eficiência de remoção de cor e turbidez no processo de clarificação de água pela FAD, associando a condição de fluxo aplicado na Zona de Contado com a eficiência na clarificação pelo processo de flotação. Foi utilizado o método de ADV (Acoustic Doppler Velocimeter) para realização de medidas do fluxo. Para execução do projeto foi utilizada água bruta preparada em laboratório, tendo cor aparente de $52 \pm 3$ Pt-Co e turbidez de $11 \pm 2$ NTU. A altura e a espessura do anteparo que separa a Zona de Contato da Zona de Separação do flotador foi variada 8 vezes, produzindo diferentes tempos de detenção hidráulico e diferentes taxas de aplicação superficial na Zona de Contato. O sistema de flotação foi alimentado com uma vazão de $4,6 \mathrm{~m}^{3} / \mathrm{h}$ a uma taxa de aplicação superficial na zona de separação de 8,43 $\mathrm{m} / \mathrm{h}$. Dentre os resultados, vale destacar a formação de um fluxo padrão descontrolado acima da Zona de Contato quando a Velocidade "Cross-Flow" variou de 9,4 a 15,2 m/h. Além disso, houve um retorno de fluxo indesejável proveniente da Zona de Separação para a parte superior da Zona de Contato, logo acima do anteparo (Figura 3.1a). Em Velocidades "Cross-Flow" maiores $(45,2 \mathrm{~m} / \mathrm{h})$ houve a formação de um fluxo padrão desejável, onde o fluxo e as velocidades foram dirigidos para cima e para frente acima da Zona de Contato (Figura 3.1b). O ensaio que obteve melhores condições de remoção de cor e turbidez teve valores de: tempo de detenção na Zona de Contato: 34 s; Taxa de aplicação na Zona de Contato: $180 \mathrm{~m} / \mathrm{h}$; Velocidade "Cross-Flow": $45 \mathrm{~m} / \mathrm{h}$. Nos ensaios onde houve retorno do fluxo, provenientes da Zona de Separação para a Zona de Contato, obtiveram eficiências menores em relação à remoção de cor e turbidez. 
Segundo Reali e Patrizzi (2007) mais pesquisas são necessárias para verificar mais profundamente: a influência das $\mathrm{V}_{\mathrm{CF}}$ sobre o desempenho de unidade de FAD e; a influência da TAS na zona de separação.


Figura 3.1: Fluxo Padrão identificado pelo método de ADV (Zona de Contato).

a) Velocidade Cross-Flow de $15,2 \mathrm{~m} / \mathrm{h}$ (retorno de fluxo) e;

b) Velocidade Cross-Flow de 45,2 m/h (Fluxo padrão desejável).

(Fonte: Reali e Patrizzi, 2007)

Lundh et al. (2002) concluiu que a geometria da zona de contato não influencia a estrutura de fluxo na zona de separação, exceto a altura do anteparo que separa a zona de contato da zona de separação. Se o anteparo é muito pequeno, fazendo com que haja uma distancia muito grande entre o topo anteparo e a superfície da água, a estrutura de fluxo não resultará em um fluxo estratificado. Isto significa que anteparos com maiores alturas podem gerar um fluxo plug-flow na maior parte da zona de separação, o que não ocorre com anteparos de pequena altura. Por isso, a Velocidade Cross-Flow parece ter uma maior significância no desenvolvimento do fluxo estratificado. 


\subsubsection{Zona de separação}

Após a passagem na Zona de Contato, a água contendo a suspensão de agregados de flocos+bolhas, as bolhas livres e os flocos não agregados às bolhas são encaminhados a outra parte do tanque, a zona de separação. Neste local, bolhas livres e agregados de flocos+bolhas deverão subir a superfície da zona de separação formando o lodo, que será coletado e removido do tanque de flotação (Edzwald, 2009).

Para que seja alcançada eficiência satisfatória no processo de flotação, o valor da taxa de aplicação superficial (TAS) na Zona de Separação depende basicamente da velocidade de ascensão do conjunto floco/bolha e que por sua vez depende do tamanho, densidade dos flocos e do volume de bolhas aderidas (Reali,1991).

\subsection{Velocidade Cross-flow}

Segundo Haarhoff e van Vuuren (1995) três parâmetros são considerados importantes para a flotação na zona de separação, onde o primeiro parâmetro citado é a Velocidade Cross-flow, vindo da zona de contato (onde há o contato entre o ar dissolvido e o afluente) para o tanque de flotação. Ainda citam que velocidade Crossflow excessivamente alta pode induzir um desenho de circulação na zona de flotação (zona de separação), e excessiva turbulência pode romper o aglomerado floco/bolha. Lundh et al. (2002) relatam que a velocidade Cross-flow tem grande importância no desenvolvimento de um fluxo de estrutura estratificada, o que é desejável para que se tenha uma boa eficiência na FAD.

Uma simples ilustração do fluxo estratificado padrão é mostrada na Figura 3.2. 


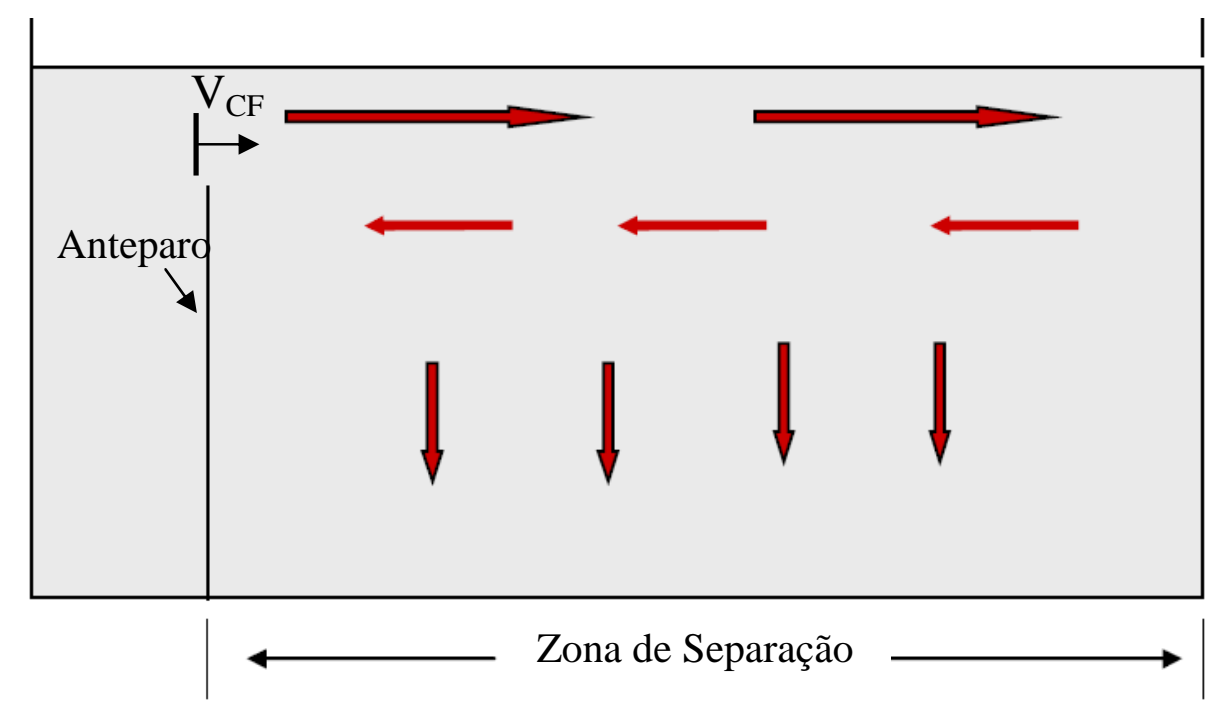

Figura 3. 2: Fluxo Estratificado Padrão na Zona de Separação no Processo de FAD (Fonte: Adaptado de Edzwald, 2007).

Edzwald (2007) ainda relata que o fluxo estratificado padrão na Zona de Separação é o fator chave na remoção de agregados de flocos + bolhas, devido ao fato de haver um aumento na área de clarificação.

Segundo Edzwald (2007) a obtenção do escoamento estratificado na Zona de Separação é muito desejável, tendo em vista que esta estratificação proporciona condições hidrodinâmicas favoráveis à flotação.

Tanques de FAD, especialmente aqueles que possuem alta taxa de aplicação superficial, exibem um fluxo estratificado movendo-se horizontalmente próximo ao topo da Zona de Separação até o final da parede e depois volta horizontalmente abaixo deste fluxo, antes de se dirigir ao fundo do tanque (Kiuru, 2000; Lundh et al., 2000 apud Edzwald, 2007).

Usando a Figura 3.2 para ilustrar, o escoamento horizontal próximo ao topo da Zona de Separação promove a área de separação entre as partículas (agregados flocos + micro-bolhas) e o efluente clarificado, a qual é duplicada com o escoamento retornando 
logo abaixo e horizontalmente e finalmente triplicada com o escoamento vertical seguindo ao fundo do tanque (Edzwald, 2009).

Segundo Edzwald (2007) e conforme relatado anteriormente por Edzwald (2009) este fluxo padrão estratificado triplica eficazmente a área Zona de Separação, em que para uma TAS aplicada na Zona de Separação de $40 \mathrm{~m} / \mathrm{h}$ indica na realidade uma TAS aplicada de $13,3 \mathrm{~m} / \mathrm{h}$, reduzindo assim a TAS em três vezes para a flotação. Isto faz com que taxas de aplicação superficial na Zona de Separação cada vez maiores possam ser aplicadas para uma mesma eficiência de clarificação, desde que o fluxo padrão estratificado seja conseguido.

Velocidades Cross-flow são sugeridas por alguns autores, onde são apresentadas na Tabela 3.1:

Tabela 3.1: Velocidade Cross-flow (Parâmetros para projeto)

\begin{tabular}{|c|c|c|}
\hline \multicolumn{3}{|c|}{ Velocidade Cross-flow (m/h)* } \\
\hline \multirow{2}{*}{$\begin{array}{c}\text { Pesquisas na África } \\
\text { do Sul** }\end{array}$} & Mínimo & 14 \\
\cline { 2 - 3 } & Médio & 38 \\
\cline { 2 - 3 } & Maximo & 210 \\
\hline Haarhoff e van & Mínimo & 20 \\
\cline { 2 - 3 } Vuuren (1995) & Maximo & 100 \\
\hline Lundh et al. (2000) & $\geq$ & 37 \\
\hline
\end{tabular}

* Pesquisas na África do Sul foram baseadas no escoamento total (incluindo a recirculação) e a área de flotação efetiva.

** Fonte: Haarhoff e van Vuuren (1995).

Não só a Velocidade Cross-Flow é importante para que se obtenha uma zona de circulação estratificada como relatado por Lundh et al. (2002), deve ser destacado que a geometria e o tamanho da zona de separação possui grande importância para a formação desta estratificação.

Estudos realizados por Lundh et al. (2000) nos mostra que a Taxa de Aplicação Superficial e a Taxa de Recirculação da água saturada influenciam na formação do fluxo estratificado na Zona de Separação. Baixas Taxas de Recirculação associadas a 
altas Taxas de Aplicação Superficial (TAS) na Zona de Separação causam a transformação do fluxo estratificado em curtos-circuitos (Figura 3.3 b). Em certas condições o fluxo estratificado é formado, como mostra a Figura 3.3 a.

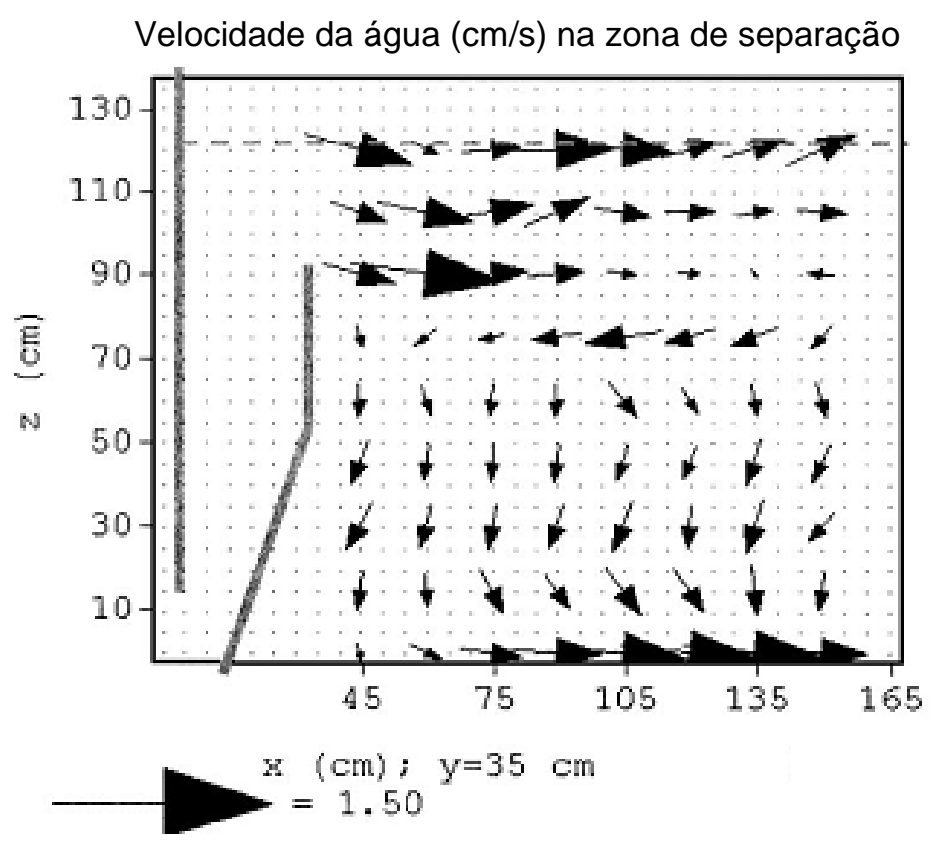

Figura 3.3 a: Fluxo Estratificado na Zona de Separação, identificado através do método ADV. (Lundh et al., 2000)

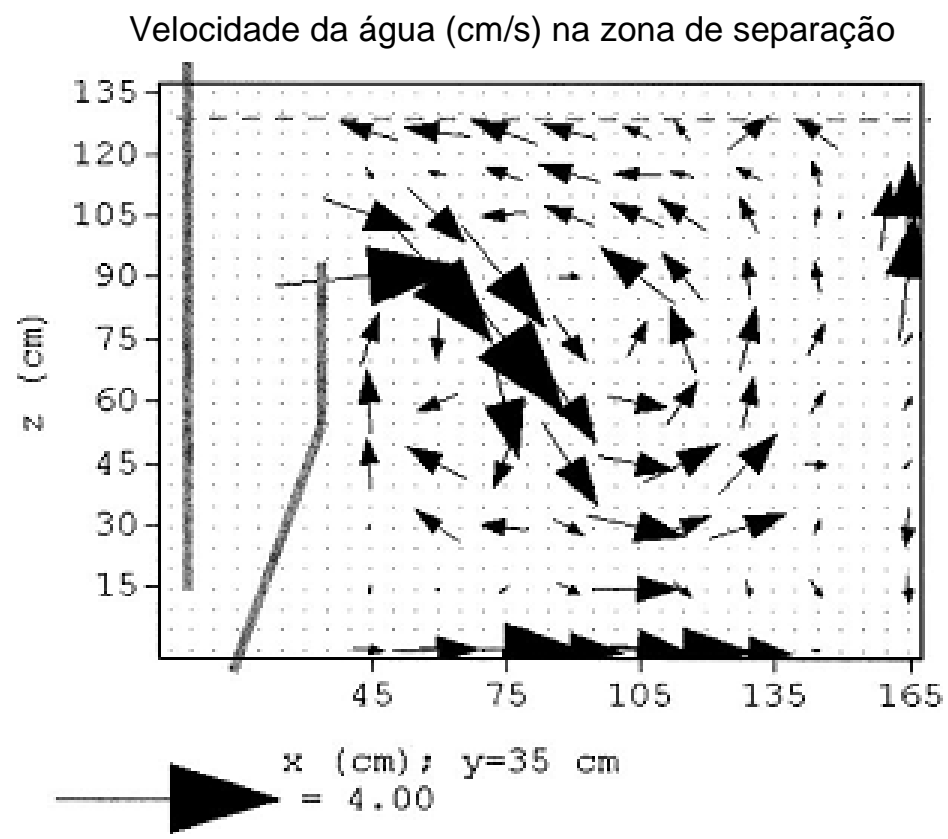

Figura 3.3 b: Fluxo em curto-circuito na Zona de Separação, identificado através do método ADV. 


\subsection{Coagulação}

A coagulação é o processo pelo qual a desestabilização de uma dada suspensão ou solução é afetada, em que a função da coagulação é superar os fatores que conferem a estabilidade de um certo sistema, transformando de um estado estável para um estado instável de estabilidade (Bratby, 2006).

No tratamento de águas para abastecimento, a coagulação possui um papel extremamente importante. Cleasby et al. (1989) apud Bratby (2006) concluiu que o prétratamento químico antecedendo a filtração é fator de maior importância para se obter uma melhor qualidade da água tratada. Portanto o pré-tratamento químico é mais crítico ao sucesso da clarificação de águas do que as instalações físicas da planta do sistema de tratamento.

A coagulação é essencial para favorecer a formação de agregados de flocos+micro-bolhas, sendo a mais importante variável de controle de operação que pode afetar a performance da flotação. A coagulação depende da dose do coagulante e do pH. Sem a coagulação não ocorre a formação de agregados flocos+micro-bolhas, pois a as partículas possuem carga negativa e são geralmente hidrofílicas (Edzwald, 2009).

Faust e Aly (1998) apud Bratby (2006) mencionam o uso de coagulante pelos romanos em 77 D.C.; em 1757 o alumínio foi usado como coagulante no tratamento de água na Inglaterra, e mais formalmente no tratamento de água para abastecimento em 1881. 


\subsubsection{Colóides}

Segundo Bratby (2006), materiais suspensos presentes em águas cujo tamanho é menor que $10^{-5} \mathrm{~mm}$ são considerados colóides. Material coloidal inclui substancias minerais, pequenos agregados de precipitados, silte, bactérias, plâncton, vírus, biopolímeros e macromoléculas.

Partículas coloidais ou de dimensões menores possuem a habilidade de se manterem dispersos o que tal característica inerente promove sua estabilidade (Bratby, 2006)

Bratby (2006) cita que para os colóides, o termo estabilidade descreve a habilidade de partículas individuais se manterem separadas, ou seja, manterem em estado disperso. A estabilidade de materiais coloidais surge da predominância de forças associadas à interface sólido-líquido. Estas forças que promovem a estabilidade de uma dispersão coloidal surgem da:

- presença de uma superfície de cargas na interface entre colóide e líquido;

- hidratação das camadas superficiais do colóide.

Há dois tipos de colóides, os hidrofílicos e os hidrofóbicos. Hidrofílicos indicam uma forte afinidade por moléculas de água nas camadas superficiais do colóide, enquanto que os hidrofóbicos indicam forte repulsão em relação á água provenientes das camadas superficiais do colóide (Bratby, 2006).

Usualmente é difícil classificar o material suspenso de uma água em particular como sendo uma suspensão coloidal hidrofílica ou hidrofóbica. Ambos podem coexistir em um sistema, em alguns casos áreas hidrofóbicas e hidrofílicas podem existir em um colóide conjuntamente (Bratby, 2006). Bratby (2006) ainda cita que no tratamento de água, o material coloidal quase sempre possui superfície de carga negativa. 


\subsubsection{Dupla camada elétrica (DCE)}

A carga superficial juntamente com a movimentação Browniana conduz a formação da Dupla Camada Elétrica (DCE), formada pelas cargas superficiais e pelo excesso de íons com carga oposta adsorvidos na partícula, deixando o meio circundante eletricamente neutro e mais distante da superfície da partícula, e por íons de mesma carga distribuídos de maneira difusa no meio polar. Outra forma de apresentar a DCE foi dividindo a dupla camada em duas regiões: camada compacta (CC) e camada difusa (CD). A distância onde o potencial elétrico decresce exponencialmente passando pelas fronteiras das camadas compacta e difusa é conhecido como Potencial Zeta (PZ).

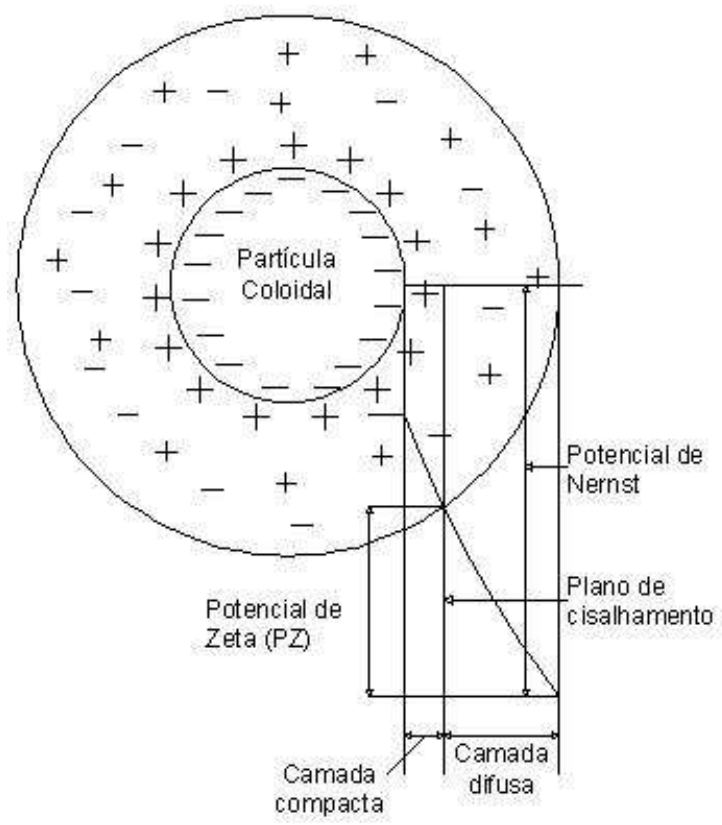

Figura 3.4: Esquema da Dupla Camada Elétrica (DCE)

\subsubsection{Medidas Eletrocinéticas - Potencial Zeta}

O potencial entre o plano de cisalhamento e o líquido que cerca a partícula é chamado de potencial zeta. Seu uso pode ser viável se o mecanismo de desestabilização do sistema é predominantemente devido à conseqüência do efeito de cargas. No entanto, 
em muitos casos, embora tenham seu papel na desestabilização, a neutralização de cargas não é o principal mecanismo para que ocorra desestabilização do sistema.

A medição do potencial zeta é vantajoso, não só para testar as teorias da dupla camada (particularmente em relação a estabilidade dos sólidos hidrofóbicos) mas também para as seguintes aplicações:

- Estabilidade do colóide;

- Estudos de adsorção de íons;

- Caracterização da superfície das partículas.

Em certos casos, valores de potencial zeta (por exemplo, zero) não conduzem necessariamente à desestabilização, portanto a desestabilização não pode ser prevista por nenhum valor específico de potencial zeta. (Ockershausen e Peterman 1964, Packhan e Sheiham 1977, Stumm e O’Melia 1968 apud Bratby 2006)

Bratby (2006) ainda cita que alguns pesquisadores, como Gupta et al. (1975), apresentaram resultados onde medidas de potencial zeta inferiram no ponto isoelétrico, ou seja, potencial zeta igual a zero, como sendo condições ótimas de coagulação. Bratby (2006) menciona que isto pode ser ilusório, desde que foi considerado como mecanismo de desestabilização somente a neutralização de cargas, o que pode ser uma simplificação grosseira em alguns casos.

Apesar da neutralização de cargas não ser necessariamente um pré-requisito para a desestabilização, a ocorrência de carga de superfície pode ser resposta como um meio de controlar o desempenho de certos processos gerando assim a desestabilização (Bratby, 2006). Um exemplo citado por Letterman e Tanner (1974) apud Bratby (2006) relata o controle de um processo de filtração direta por medidas de potencial zeta, onde os valores do potencial deveriam manter aproximadamente $14 \mathrm{mV}$ para que o processo obtivesse sucesso para este caso em específico. 
Ótimas condições para atingir a desestabilização para aplicações na prática são adequadamente encontradas por técnicas como o jarteste. A aplicação das medidas eletrocinéticas para efeito de controle é possível depois de uma adequada correlação entre os resultados de jarteste, instalação piloto, ou algum outro método de controle (Bratby, 2006).

Trabalho realizado por Han e Dockko (2001) foi avaliado a eficiência de colisão entre partícula e bolha, onde foram analisados os potenciais zeta de ambos e assim construídos diagramas de eficiência de colisão. Também foram analisados tempos de floculação $(0,10,20,30$ minutos de tempo de floculação com rotação de $25 \mathrm{rpm})$ e sua influência no potencial zeta das partículas. A água experimental foi preparada com suspensão de caulinita, mantendo turbidez em torno de 40 NTU. A partícula de caulinita não tratada possui potencial zeta de $-13 \mathrm{mV}$. O potencial zeta ficou menos negativo assim que foi adicionado o alumínio (coagulante usado), tornando-se zero sob uma dosagem de 10 ppm de alumínio.

Como resultados, potenciais zeta baixos $(-10 \mathrm{mV})$, a eficiência de remoção de partículas foi muito pobre. Em potenciais altos (acima de $+15 \mathrm{mV}$ ) a eficiência de remoção de partículas também foi baixa, onde a dosagem de coagulante correspondente se situa na região do diagrama em que a coagulação corresponde ao mecanismo de varredura. A maior remoção de partículas ocorreu no momento em que o potencial zeta tornou-se ligeiramente positivo. A dosagem ótima de alumínio foi de $15 \mathrm{ppm}$, obtendo um potencial zeta de $+10 \mathrm{mV}$ com melhor remoção de partículas no tempo de floculação de 5 minutos. Também foram conseguidas ótimas eficiências de remoção de partículas quando os potenciais zeta ficaram ligeiramente positivos com tempos de floculação excedendo 10 minutos. A teoria prediz que melhores condições de colisão são obtidas quando partículas carregadas positivamente colidem-se com bolhas 
carregadas negativamente. A eficiência de colisão possui relação direta tanto ao tamanho de partículas quanto o potencial zeta. Ambas as teorias de eficiência de colisão, tamanho de partículas e potencial zeta demonstraram que são importantes parâmetros e que afetam a eficiência de remoção de partículas (Han e Dockko, 2001). 


\section{Material e Métodos}

\subsection{Considerações Iniciais:}

Foi estudado 1 tipo de água preparada em laboratório. A Água de estudo foi preparada adicionando-se 1,0 mg/L de ácido húmico comercial (Aldrich 675-2) para obter cor aparente, e 8,5 mg/L de Kaolin (Fluka 60609) para obtenção de turbidez. As características conseguidas na água de estudo foram as seguintes: turbidez de 7,5 NTU, cor aparente de $43 \mathrm{UH}, \mathrm{pH}$ de 6,6 UpH e alcalinidade de $26 \mathrm{mg} \mathrm{CaCO}_{3} / \mathrm{L}$.

O projeto de pesquisa foi dividido em duas etapas. Na Primeira Etapa foi determinado o par, $\mathrm{pH}$ de coagulação e dosagem de coagulante adequado para a água estudada. Para concretização desta etapa foi utilizado equipamento de escala de laboratório - Flotateste - montado no Laboratório de Tratamento Avançado e Reuso de Águas (LATAR) do Departamento de Hidráulica e Saneamento (SHS) da Escola de Engenharia de São Carlos (EESC) da Universidade de São Paulo (USP). Foi utilizado como coagulante Sulfato de Alumínio PA, da marca VETEC. Como alcalinizante, para variação do pH, foi utilizado Carbonato de Sódio (barrilha) da marca Genco com 99,5\% de pureza.

Na Segunda Etapa foi variada a Velocidade Cross-Flow para duas taxas de aplicação superficial (TAS) na Zona de Separação e para dois valores de Potencial Zeta para a água estudada, verificando suas influências na eficiência de remoção de cor, turbidez e sólidos suspensos totais da flotação. Para realização da Segunda Etapa foi utilizada a Instalação Piloto de Flotação por Ar Dissolvido, situado nas dependências da Escola de Engenharia de São Carlos. A Instalação Piloto de FAD passou por devidas modificações e ajustes para que a Velocidade Cross-Flow e a TAS na zona de separação pudessem ser variadas e as condições fossem mantidas adequadas ao ensaio. 


\subsection{Descrição das Instalações a serem Utilizadas}

Todas as instalações que serão utilizadas se encontram nas dependências da Escola de Engenharia de São Carlos da Universidade de São Paulo (EESC-USP).

\subsubsection{Equipamento de Escala de Laboratório - Flotateste}

A etapa de mistura rápida (desestabilização do efluente) foi efetuada em béqueres com agitadores rápidos. Nesta fase foram realizados ensaios no Jarteste. O Flotateste é constituído por quatro câmaras onde cada uma possui agitador próprio (responsáveis por promoverem a floculação) É válido ressaltar que o aparelho de Flotateste é operado em regime descontínuo, ou seja, em batelada. Com este equipamento foi determinado o par $\mathrm{pH}$ de coagulação e dosagem de coagulante de melhor eficiência para as águas estudadas. Estas câmaras estão interligadas à câmara de saturação onde foi promovida aeração do volume de água a ser recirculada. Terminado o período de floculação abriram-se as válvulas agulhas situadas ao fundo de cada câmara de flotação no flotateste, promovendo a entrada da água já aerada ocorrendo a flotação dos flocos formados durante a etapa de floculação.

A coleta das amostras foi promovida com o auxílio de frascos (aproximadamente 30ml de volume unitário), coletadas em pontos situados em posições adequadas ao cálculo das curvas de distribuição de velocidade de flotação (curvas de flotação) conforme metodologia proposta por Reali (1991). 


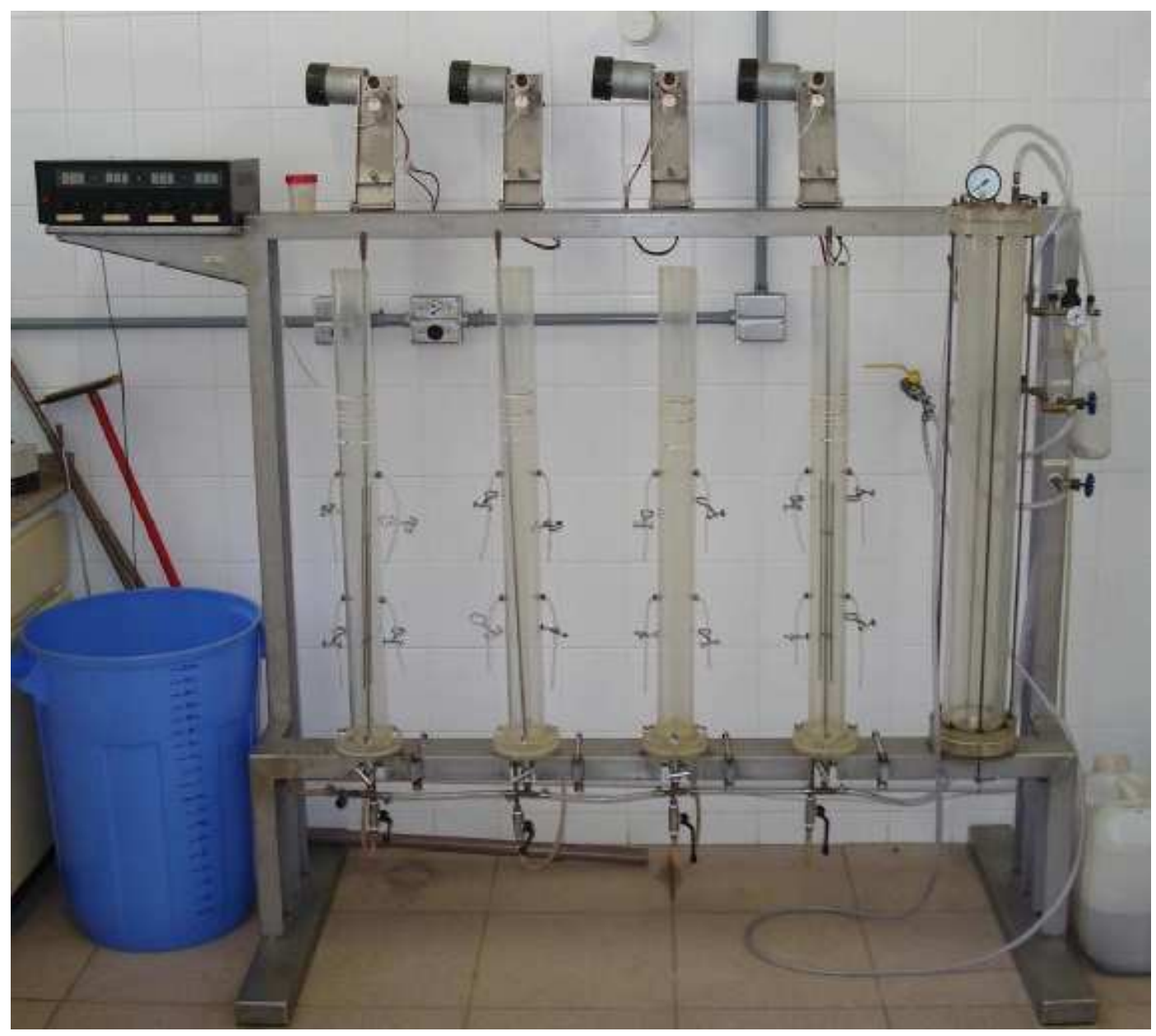

Figura 4.1: Fotografia do equipamento de floculação/flotação em escala de laboratório (flotateste) (modificado Reali, 1991).

\subsubsection{Instalação Piloto de Flotação por Ar Dissolvido de Alta Taxa}

A Instalação Piloto de Flotação por Ar Dissolvido (FAD) é composta por 2 Câmaras de Floculação em série (cada câmara nos dá um tempo de floculação de 6 minutos), onde cada câmara possui motores associados à pás responsáveis por promover o gradiente necessário para efetuar a floculação com eficiência. É composto também pela Câmara de Flotação a qual possui um "manifold” na parte inferior, e faz com que a água coletada seja encaminhada a um vertedor triangular e assim alimente a Câmara de Saturação. 
Além destes compartimentos a instalação piloto possui um canal entre as Câmaras de Floculação e a Câmara de Flotação onde está localizado um dispositivo de despressurização da água saturada, proveniente da Câmara de Saturação, e assim a água saturada encontra a água floculada, fazendo com que inicie a ascensão do conjunto floco + bolhas até a superfície da Câmara de Flotação. O Esquema do sistema piloto de flotação é apresentado na Figura 4.2:

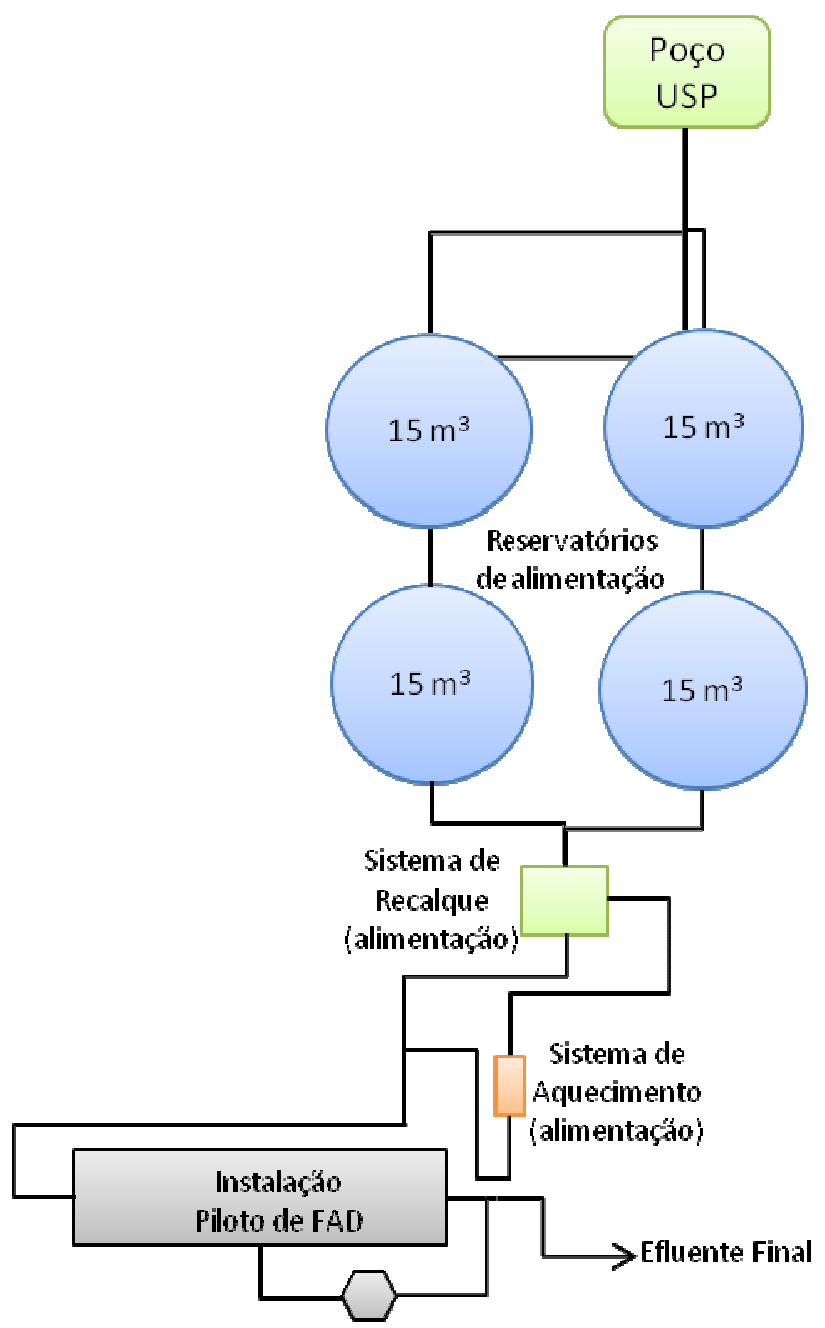

Figura 4.2: Esquema do Sistema Piloto de Flotação por Ar Dissolvido situado nas dependências da EESC/USP. 


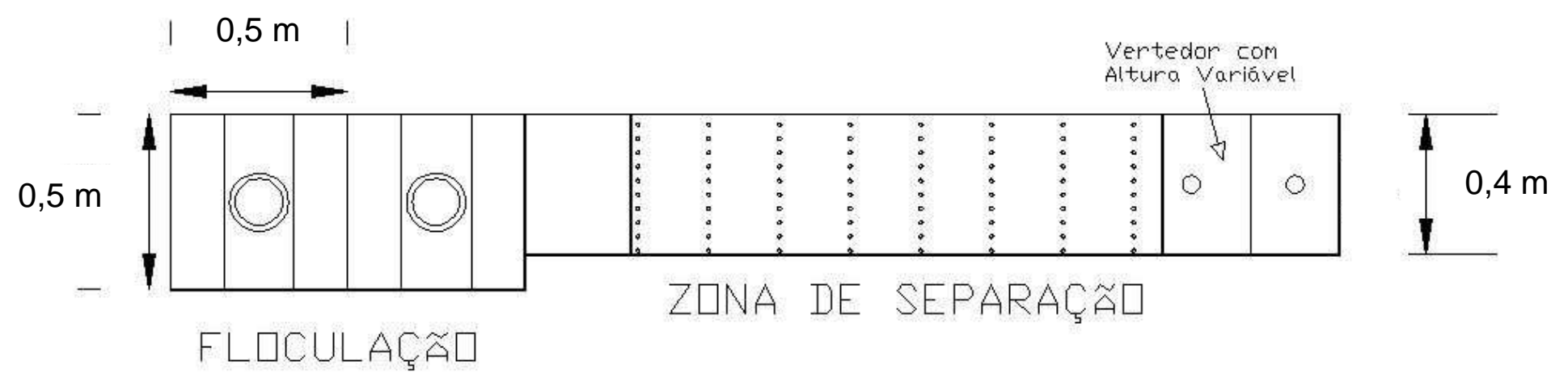

Figura 4.3: Esquema da instalação piloto de flotação por ar dissolvido (Planta) (Fonte: Reali e Patrizzi,2007)

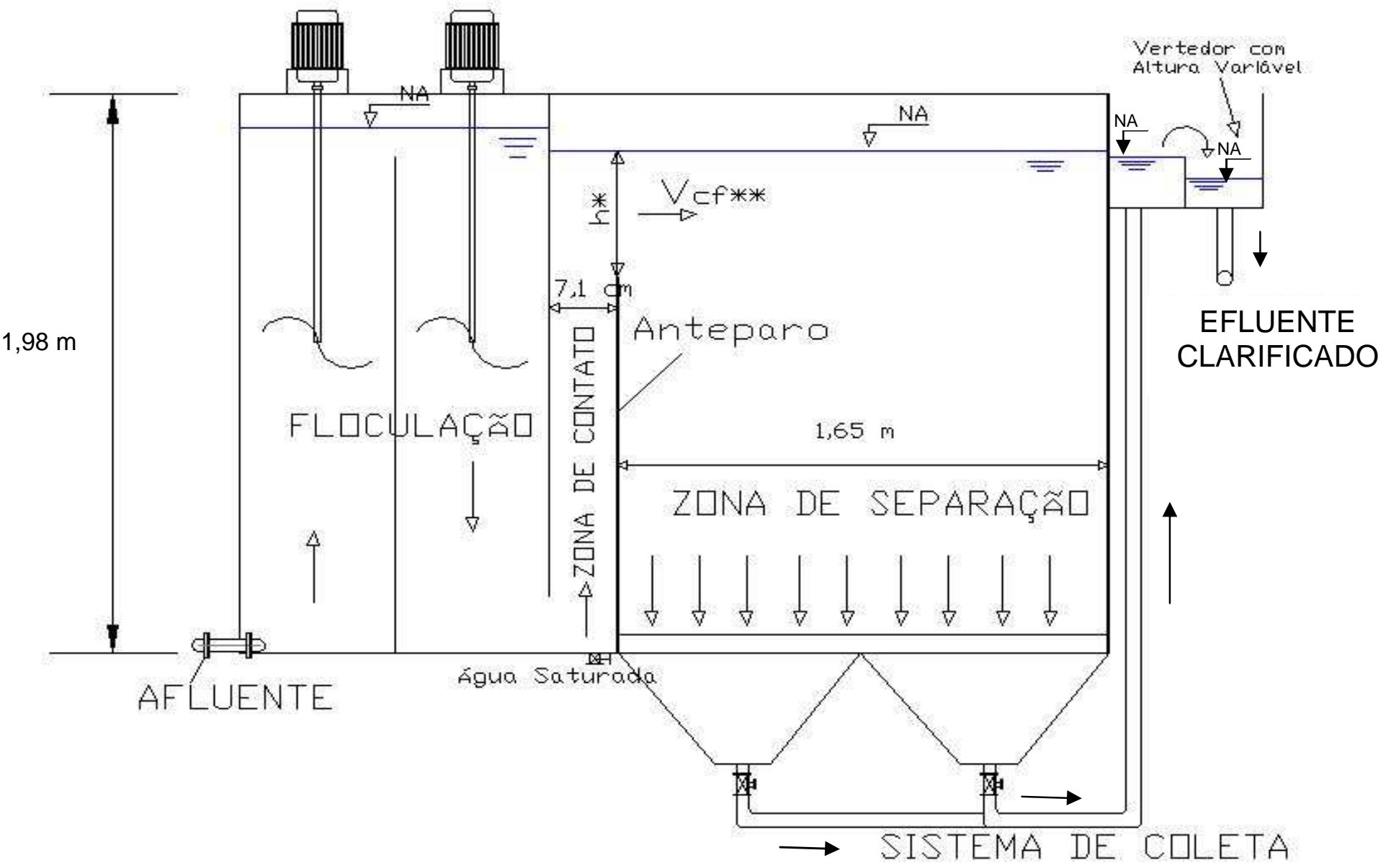

$* \mathrm{~h}=$ altura sobre o anteparo a que define o valor de $\mathrm{V}_{\mathrm{CF}}$, para uma determinada vazão do flotador; $* * \mathrm{~V}_{\mathrm{CF}}=$ Velocidade "Cross-Flow";

Figura 4.4: Esquema da instalação piloto de flotação por ar dissolvido (Corte) (Fonte: Reali e Patrizzi, 2007) 
O sistema piloto de FAD é composto por quatro reservatórios de água com capacidade de $15 \mathrm{~m}^{3}$ cada um os quais eram alimentados com água de poço situado nas dependências da USP. Nestes reservatórios foi adicionada a substância húmica comercial e a caulinita em dosagens já mencionadas anteriormente, para que fossem obtidas as características da água de estudo. Os reservatórios são compostos por agitadores de eixo vertical e moto-redutor para que se mantenha a água sob constante agitação durante o ensaio mantendo maior homogeneidade.

A instalação Piloto de FAD possui sistema de alimentação composto por duas bombas centrífugas, caixa de controle da carga d'água proveniente dos reservatórios. Sistema de aquecimento de parte da vazão de alimentação, composto por um aquecedor a gás, para que obtivesse o mínimo de variação de temperatura no sistema. A instalação piloto também possui reservatório e bomba dosadora de coagulante (sulfato de alumínio) e reservatório e bomba dosadora de alcalinizante (barrilha). A mistura rápida é efetuada na linha da tubulação (in line) e a floculação é realizada em duas câmaras contendo agitadores verticais e moto-redutor. A instalação piloto de FAD possui tanque de flotação e câmara de saturação onde a água saturada é injetada através de três bocais difusores situados no fundo da zona de contato. Medidores de vazão eletromagnético e hidráulico (rotâmetros) situados na tubulação de alimentação da Instalação Piloto de FAD e na tubulação de alimentação da câmara de saturação. 


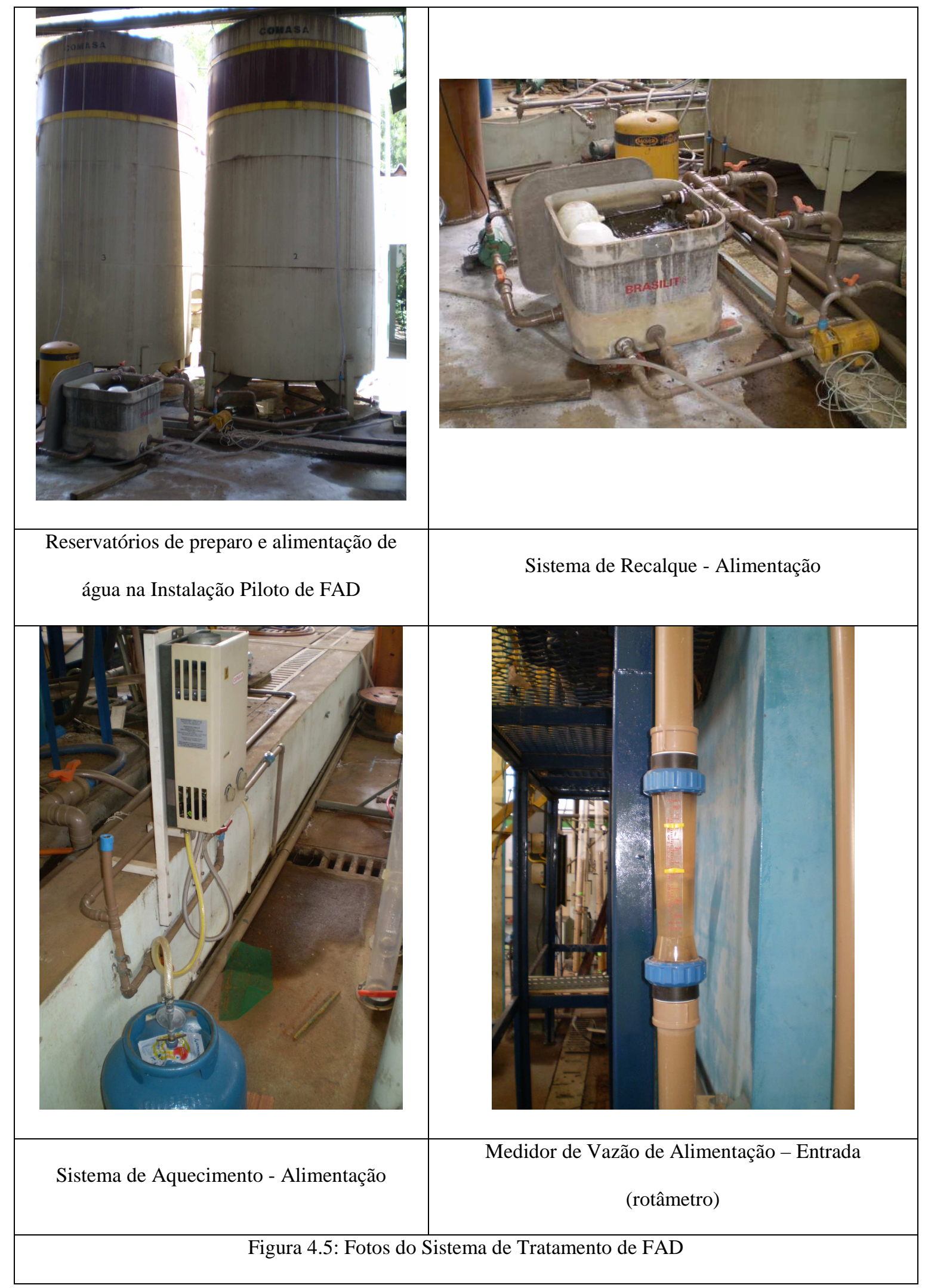




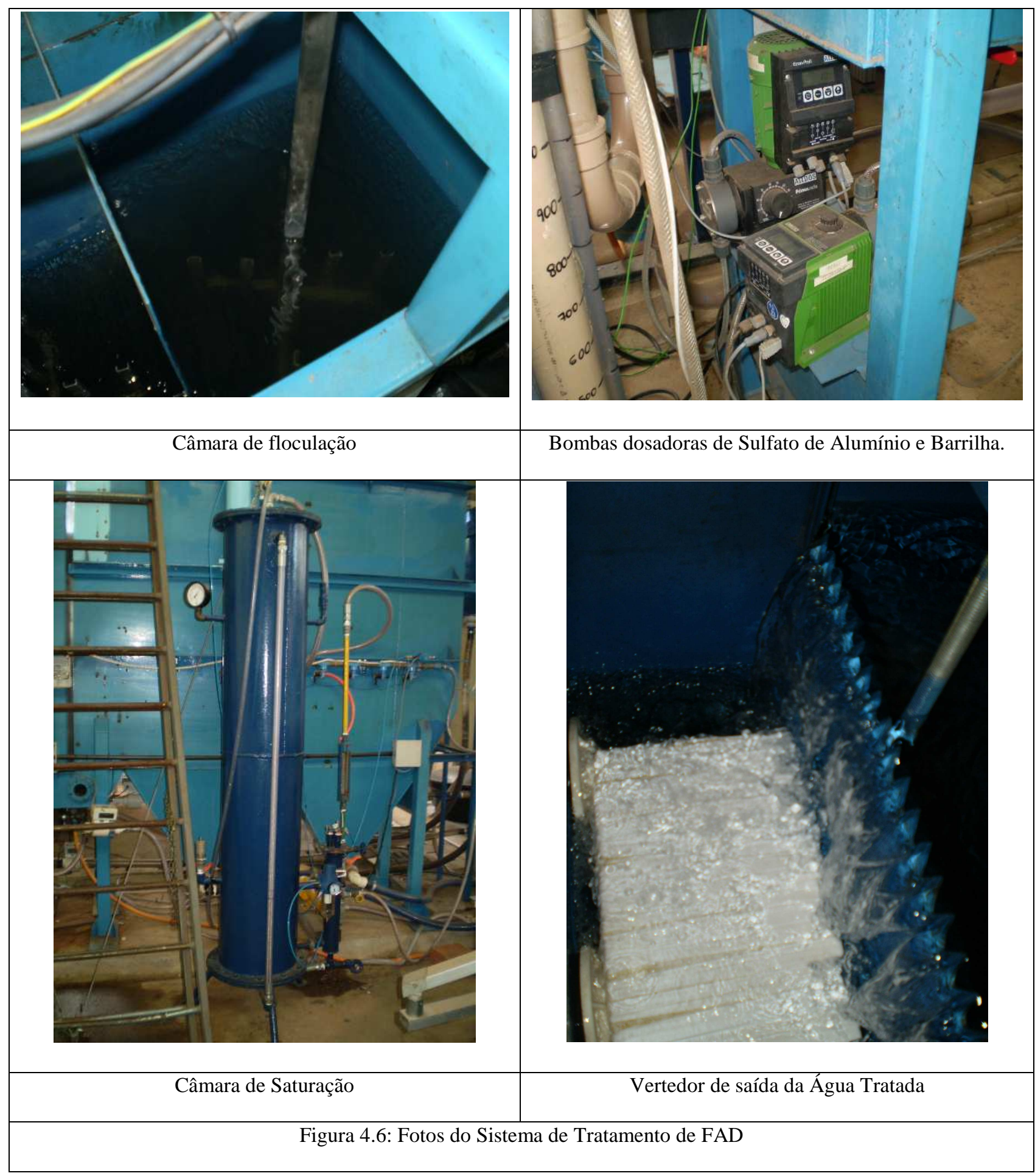




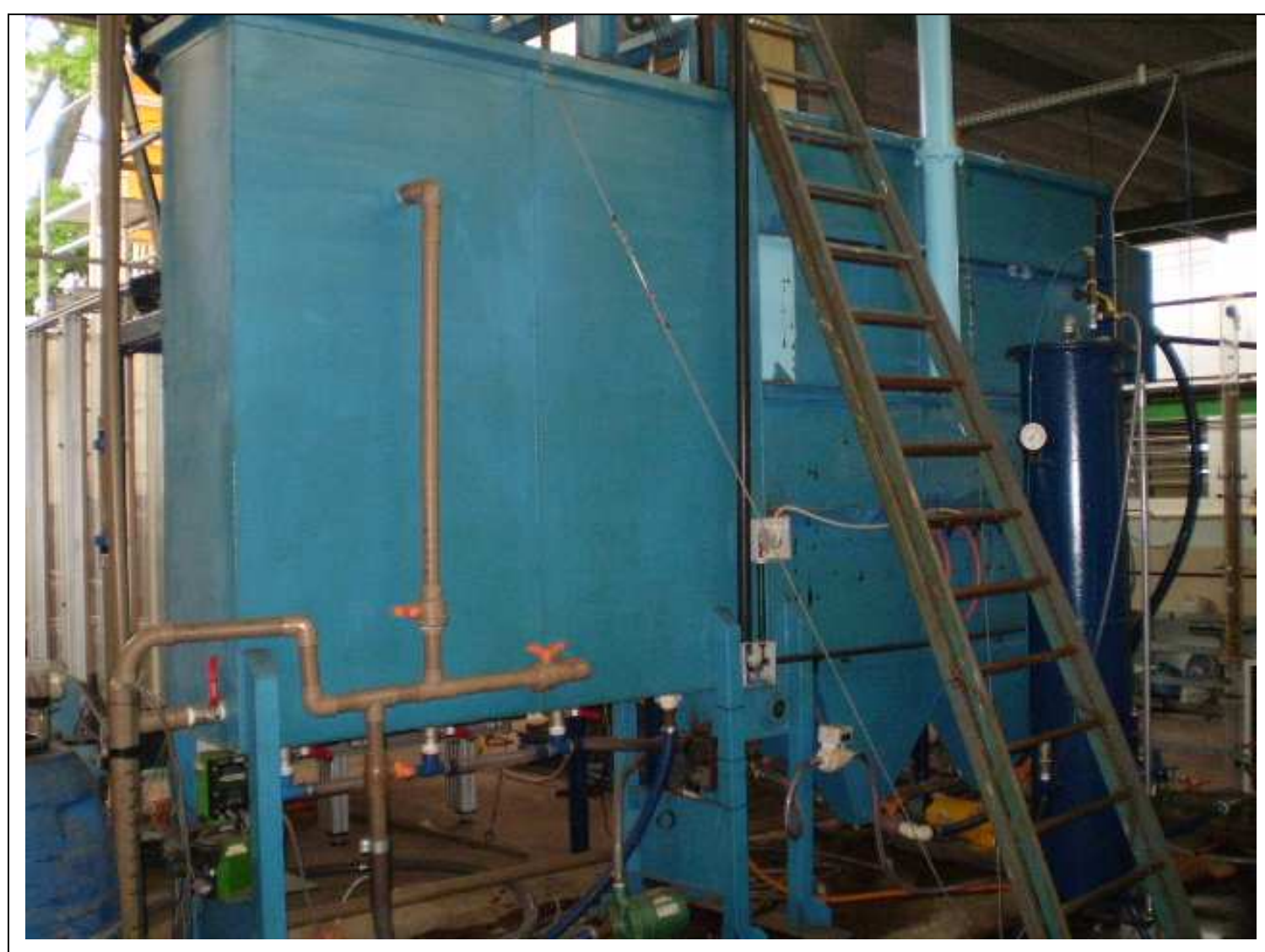

Figura 4.7: Instalação Piloto por Ar Dissolvido 


\subsection{Grade de Ensaios}

\subsubsection{Fluxograma Geral das ETAPAS 1 e 2}

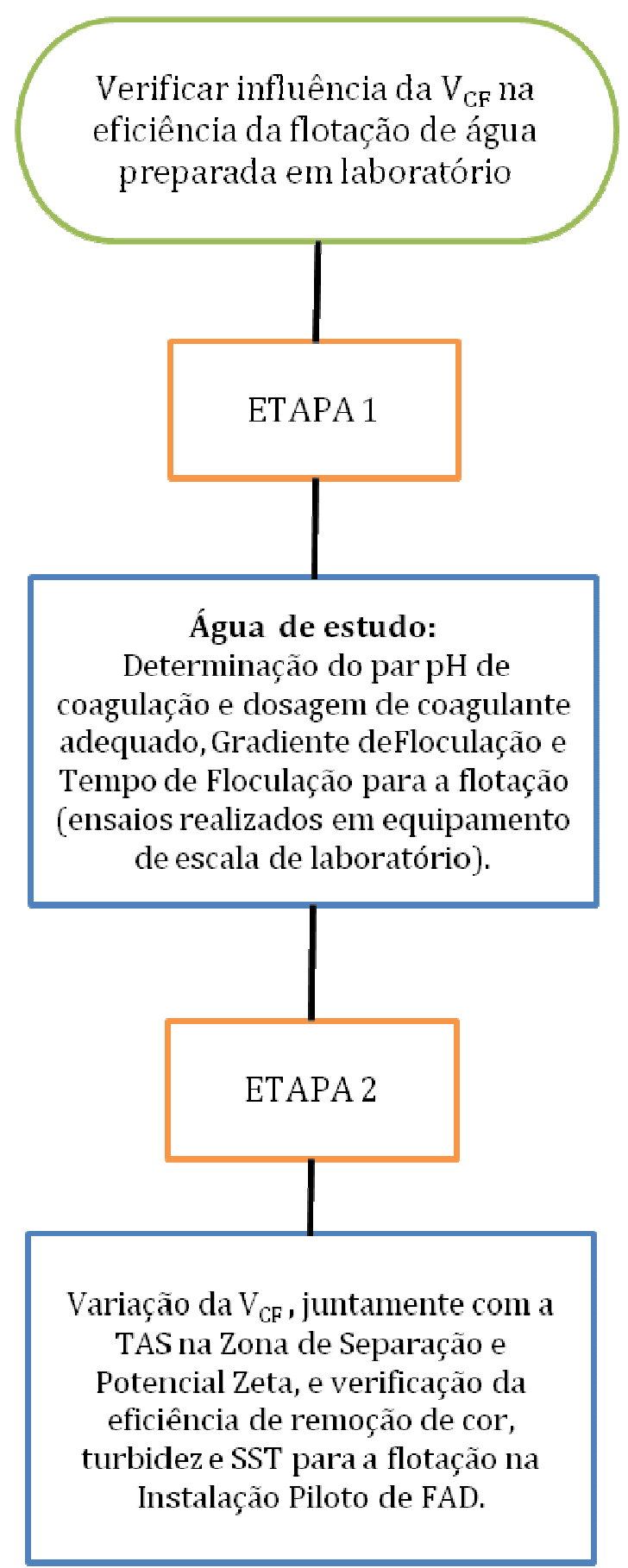

Figura 4.8: Fluxograma caracterizando os ensaios que serão realizados na ETAPA 1 e 2. 


\subsubsection{Fluxograma da ETAPA 1}

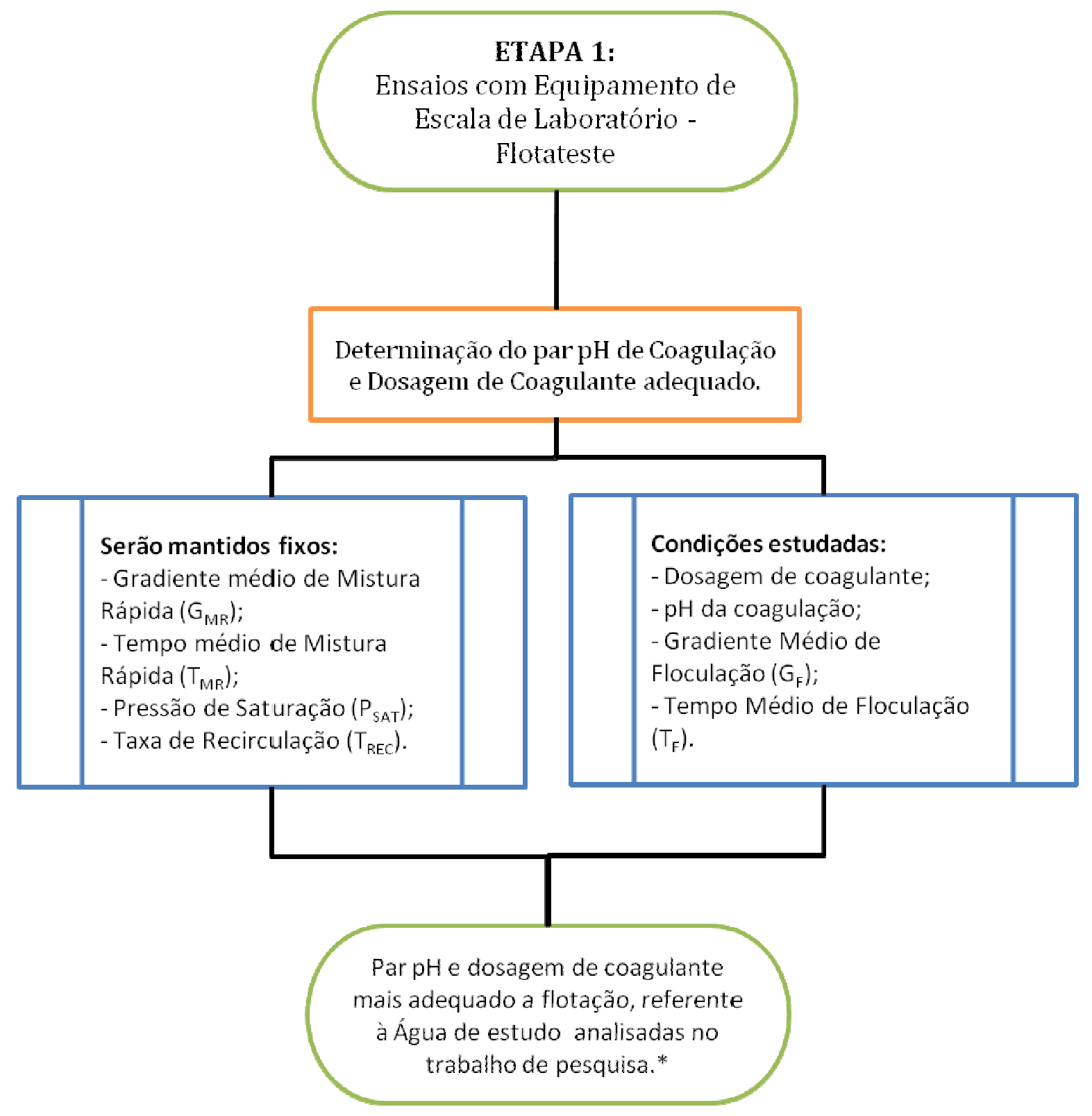

*Estes resultados serão usados para os ensaios com a Estação Piloto de Flotação com Ar Dissolvido, para verificação da influência da Velocidade Cross-Flow na eficiência da flotação.

Figura 4.9: Fluxograma caracterizando os ensaios que serão realizados na ETAPA 1. 


\subsubsection{Fluxograma da ETAPA 2}

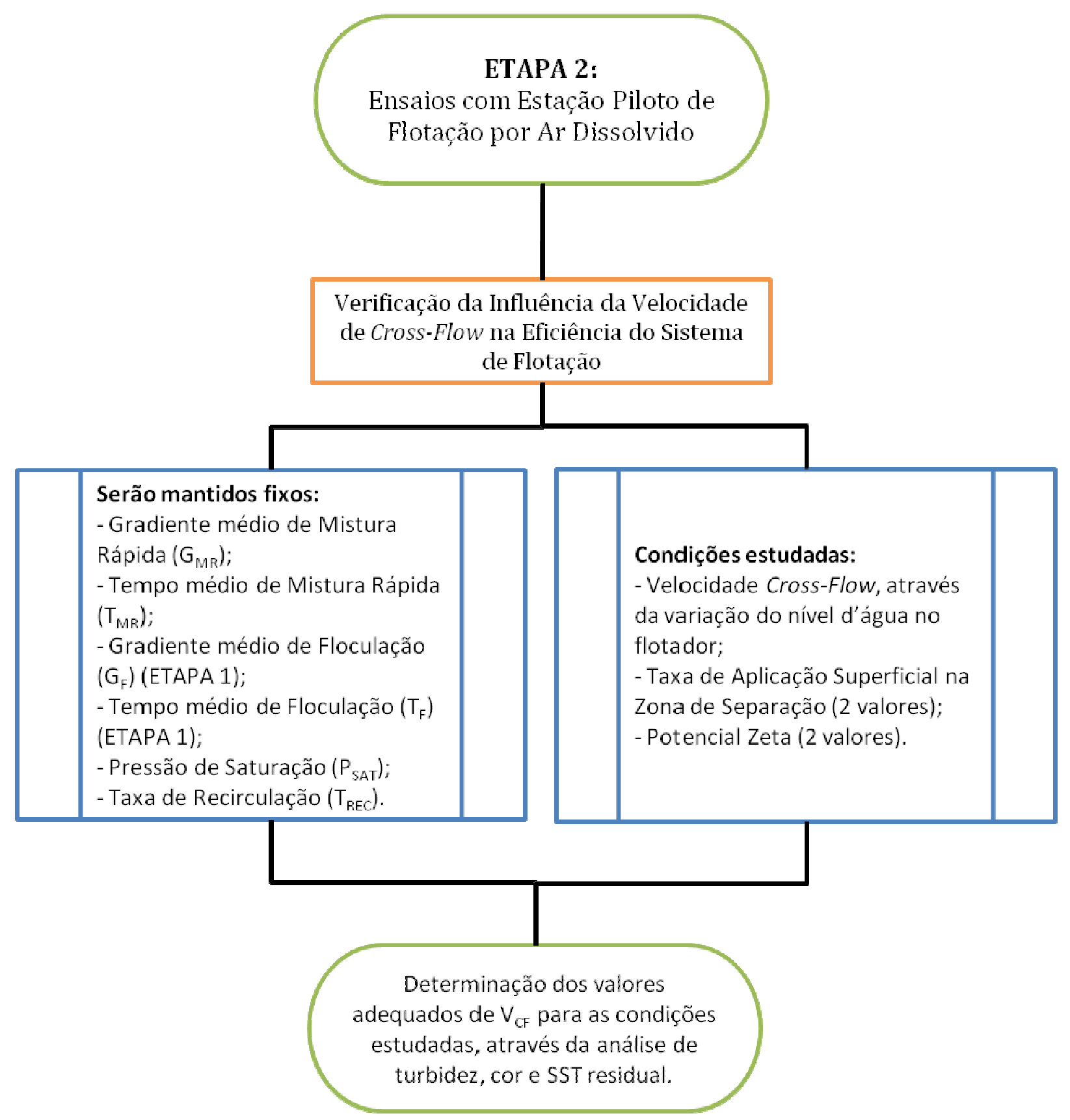

Figura 4.10: Fluxograma caracterizando os ensaios que serão realizados na ETAPA 2. 


\subsection{Etapa 1 - Determinação do par pH e dosagem de coagulante adequado para a flotação.}

Os ensaios realizados na ETAPA 1 serviram para determinar o par $\mathrm{pH}$ de coagulação e dosagem de coagulante adequado, neste caso o Sulfato de Alumínio PA da marca VETEC, para a Água de estudo. Assim foram realizados ensaios variando-se a dosagem de coagulante de 2,5 mg/L em 2,5 mg/L, da dosagem de 7,5 mg/L até a dosagem de $50 \mathrm{mg} / \mathrm{L}$. Em cada dosagem será variado o $\mathrm{pH}$ em valores diferentes, a fim de que houvesse uma varredura do $\mathrm{pH}$ entre os valores 5,5 e 7,0.

Nesta primeira parte da ETAPA 1, que foram determinados o par $\mathrm{pH}$ de Coagulação e dosagem de Sulfato de Alumínio, foram mantidos fixos os seguintes parâmetros:

- $\quad$ Tempo de saturação na Câmara de contato = 10 minutos;

- $\mathrm{G}_{\mathrm{MR}}$ (gradiente médio de velocidade de mistura rápida) $=800 \mathrm{~s}^{-1}$;

- $\quad \mathrm{T}_{\mathrm{MR}}($ tempo médio de mistura rápida $)=20 \mathrm{~s}$;

- $\quad \mathrm{G}_{\mathrm{f}}$ (gradiente médio de floculação $)=90 \mathrm{~s}^{-1}$;

- $\quad \mathrm{T}_{\mathrm{f}}($ tempo médio de floculação) $=12 \mathrm{~min}$;

- $\quad$ Temperatura $=24{ }^{\circ} \mathrm{C}$;

- $\quad \mathrm{P}_{\mathrm{SAT}}$ (pressão na câmara de saturação) $=4,5$ bar;

- $\quad \mathrm{R}$ (porcentagem de recirculação na flotação) $=10 \%$;

- $\quad \mathrm{V}_{\mathrm{F}}$ (velocidade de flotação) $=7,67 \mathrm{~m} / \mathrm{h}$ e $15 \mathrm{~m} / \mathrm{h}^{*}$.

Foram variados os seguintes parâmetros:

- $\quad$ Dosagem de coagulante $(2,5 \mathrm{mg} / \mathrm{L}$ em $2,5 \mathrm{mg} / \mathrm{L}$, entre 7,5 e $50 \mathrm{mg} / \mathrm{L})$;

- $\quad \mathrm{pH}$ da coagulação (entre 5,5 e 7,0).

É importante relatar que as características da Água analisada já foram estudadas anteriormente por Reali e Patrizzi (2007), portanto o par, pH de coagulação e dosagem 
de coagulante, já são conhecidos para esta água. Mesmo assim foram feitos ensaios para a Água analisada para determinação do par pH de coagulação e dosagem de coagulante.

Assim, determinados o melhor $\mathrm{pH}$ de coagulação juntamente com a melhor dosagem de coagulante para a Água de estudo, foram feitos ensaios da segunda parte da ETAPA 1 para determinação do Gradiente Médio de Floculação e do Tempo Médio de Floculação. Assim foi variado o Gradiente Médio de Floculação de $70 \mathrm{~s}^{-1}$ até $110 \mathrm{~s}^{-1}$, variando de $10 \mathrm{em} 10 \mathrm{~s}^{-1}$. Para cada gradiente foi variado o Tempo Médio de Floculação em 12,16 e 20 minutos.

Com o par pH de coagulação e Dosagem de Coagulante, o Gradiente Médio de Floculação e o Tempo Médio de Floculação determinados, partiu-se com estes dados para a Instalação Piloto de Flotação por Ar Dissolvido para verificação da influência da Velocidade Cross-Flow na eficiência da flotação.

\subsection{Etapa 2 - Verificação da Velocidade Cross-Flow $\left(V_{C F}\right)$ na Eficiência da Flotação na Estação Piloto de Flotação por Ar Dissolvido.}

Terminada a ETAPA 1, foram feitos ensaios na Instalação Piloto de Flotação por Ar Dissolvido onde foram variadas as Velocidades Cross-Flow com a intenção de verificar a influência que esta velocidade proporcionará a flotação da água analisada.

Para obtenção das várias $\mathrm{V}_{\mathrm{CF}}$ analisadas, foi variada a altura do vertedor da água já flotada, de modo que este venha variar a altura da água de dentro da Câmara de Flotação. Portanto com a variação da altura do vertedor fez com que a altura da lâmina líquida no interior na câmara de flotação variasse, e com isso obtivesse os vários valores da $V_{\text {CF. }}$

Condições a serem fixadas na ETAPA 2 (Reali e Patrizzi, 2007): 
- $\quad \operatorname{Vazão}(\mathrm{Q})=4,6 \mathrm{~m}^{3} / \mathrm{h}$;

- $\quad$ Gradiente Médio da Floculação = determinado na ETAPA 1;

- $\quad$ Tempo Médio de Floculação = determinado na ETAPA 1;

- $\quad$ Pressão na Câmara de Saturação = 4,5 bar;

- $\quad$ Taxa de recirculação $=10 \%$;

- $\quad$ Temperatura da água $=26 \pm 2{ }^{\circ} \mathrm{C}$.

A Velocidade e o Tempo na Zona de Contato foram mantidos os mesmos identificados como os que apresentaram melhores resultados na flotação por Reali e Patrizzi (2007):

- $\quad$ Taxa de Aplicação Superficial na Zona de Contato = $180 \mathrm{~m} / \mathrm{h}$;

- $\quad$ Tempo de Detenção Hidráulica na Zona de Contato = $34 \mathrm{~s}$.

Além destes parâmetros, foi mantida fixa a Velocidade de Entrada da Zona de Contato. O aluno Kisner Anderson Maia e orientador Marco Antônio Penalva Reali possuem pesquisa intitulada: "Influência da Velocidade de Entrada na Zona de Contato de Unidades Retangulares de Flotação por Ar Dissolvido Aplicada no Tratamento de Águas para Abastecimento", a qual analisa a influência do gradiente na entrada da zona de contato na eficiência da flotação (Projeto de Pesquisa a ser concluído).

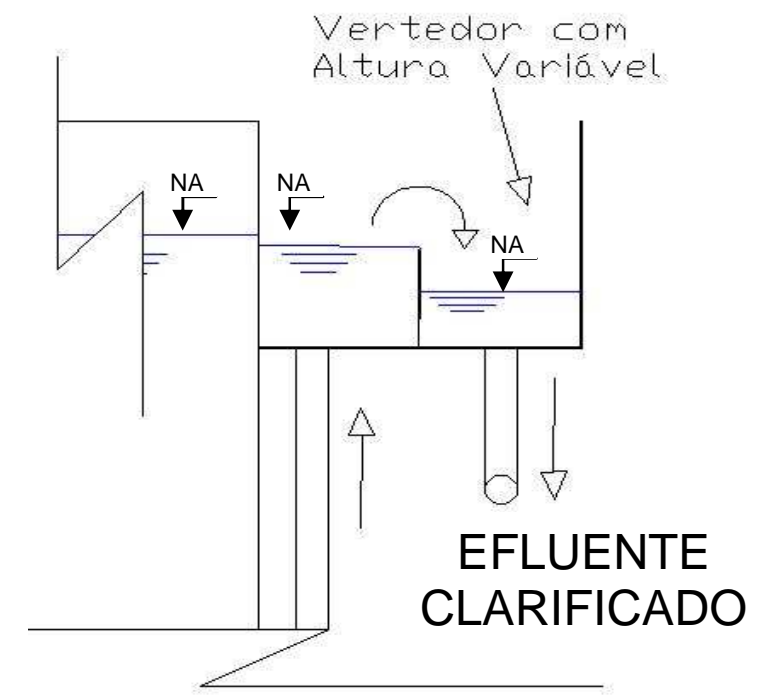

Figura 4.11: Esquema do Vertedor com Altura Variável 


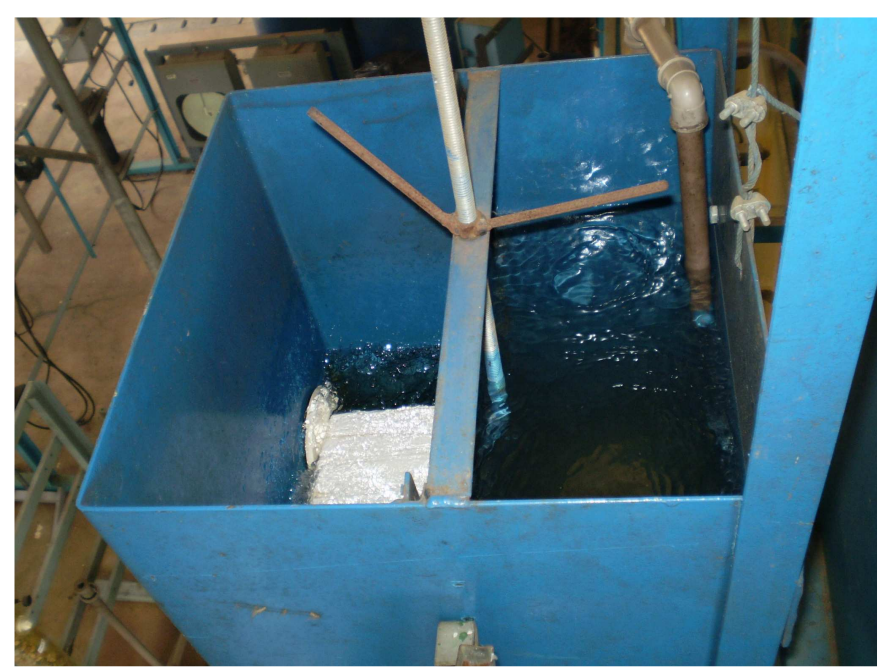

Figura 4.12: Vertedor com Altura Variável

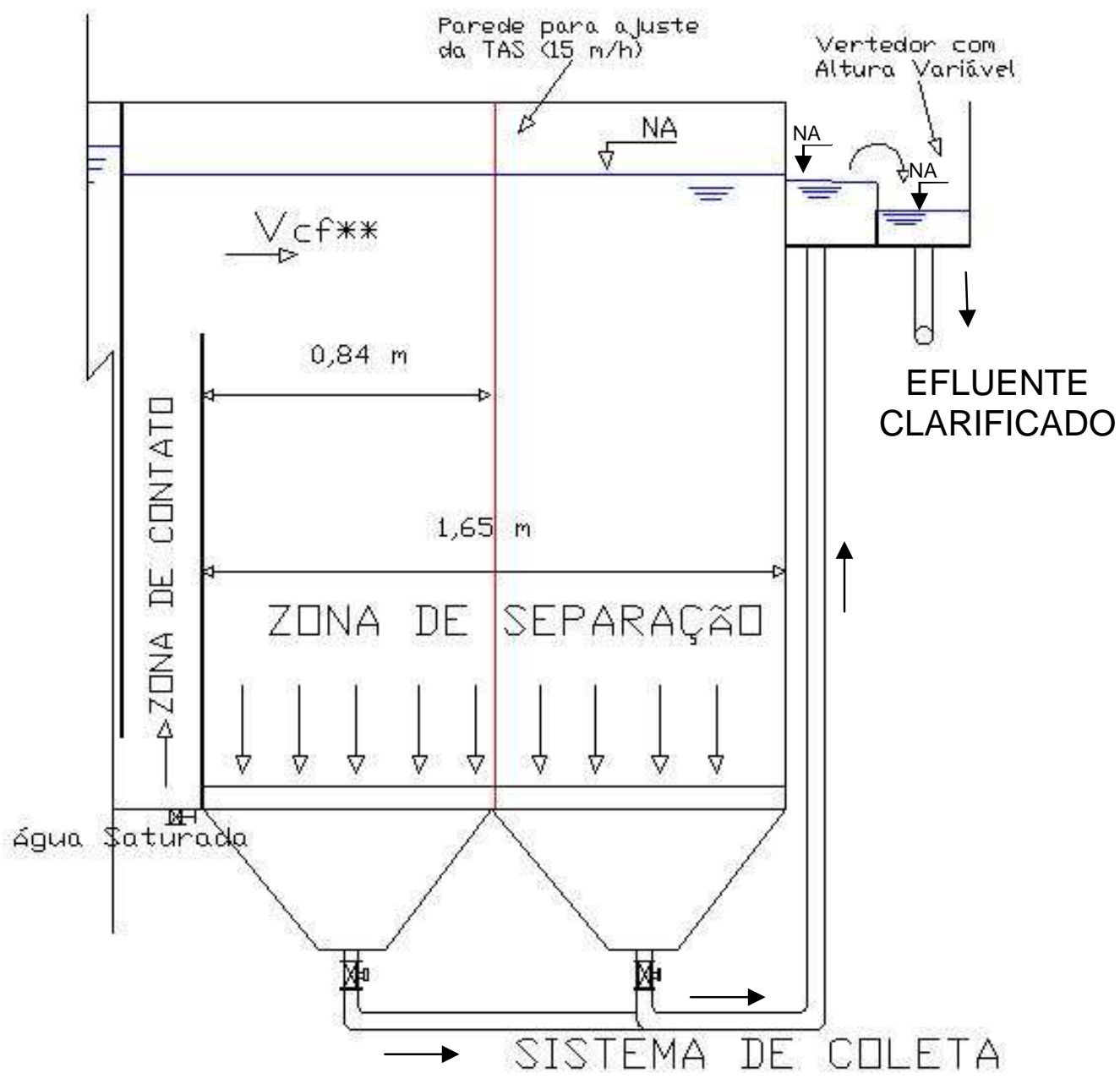

Figura 4.13: Esquema da parede ajustável para variação de $L_{z s}$. 
Para realização dos ensaios da ETAPA 2 a Velocidade Cross-Flow foi variada nos seguintes valores: 45, 70, 100, 150, 350 e 630 m/h. Está variação foi conseguida através de ajustes no nível d'água dentro do tanque de flotação através do vertedor de altura variável.

Foram avaliadas duas taxas de aplicação superficial na Zona de Separação: 7,7 $\mathrm{m} / \mathrm{h}$ e $15 \mathrm{~m} / \mathrm{h}$, que foram conseguidas através da adaptação de uma parede situada a 84 cm anteparo, que sem a parede a TAS na Zona de Separação foi de 7,7 m/h, e com a parede a TAS na Zona de Separação foi de $15 \mathrm{~m} / \mathrm{h}$ (Figura 4.9), para uma vazão constante. Para cada taxa de aplicação superficial foram variadas as Velocidades CrossFlow nos valores mencionados anteriormente. Também foram analisados dois valores de Potencial Zeta para a Água de estudo, em que foram variadas as Velocidades CrossFlow. Nesta ETAPA 2 foi feito monitoramento da eficiência da Instalação Piloto na clarificação da água estudada.

\subsection{Preparo das soluções para uso no experimento}

Na ETAPA 1 foi utilizado o sulfato de alumínio PA, da marca VETEC, onde se pesou $10 \mathrm{~g}$ deste produto em um béquer, e deste transferidos para um balão volumétrico de 1 litro, obtendo-se uma solução de $10 \mathrm{~g} / \mathrm{L}$ de sulfato de alumínio. Assim temos:

$$
\begin{aligned}
& \mathrm{C}_{1}=10 \mathrm{~g} / \mathrm{l} ; \\
& \mathrm{C}_{2}=10 \mathrm{mg} / \mathrm{l}\left(10 \times 10^{-3} \mathrm{~g} / \mathrm{l}\right) ; \\
& \mathrm{V}_{1}=? ; \\
& \mathrm{V}_{2}=21 \text { (Jarro do Jarteste). }
\end{aligned}
$$

$$
\begin{gathered}
\mathrm{C}_{1} \times \mathrm{V}_{1}=\mathrm{C}_{2} \times \mathrm{V}_{2} ; \\
\mathrm{V}_{1}=2 \mathrm{ml} .
\end{gathered}
$$


Com isto para a dosagem de $10 \mathrm{mg} / \mathrm{l}$ de solução de sulfato de alumínio temos que adicionar ao jarro do Jarteste um volume de $2 \mathrm{ml}$ da solução de cal preparada, para a dosagem de $15 \mathrm{mg} / \mathrm{l}$ serão adicionados um volume de $3 \mathrm{ml}$ e assim por diante.

O mesmo ocorreu na preparação da solução de barrilha para variação do $\mathrm{pH}$. Pesou-se em um béquer $10 \mathrm{~g}$ de barrilha e deste foi transferido para um balão volumétrico de $1 \mathrm{~L}$, obtendo uma solução de $10 \mathrm{~g} / \mathrm{L}$. Da mesma forma que o sulfato de alumínio, para cada $1 \mathrm{~mL}$ dosado da solução de barrilha no jarro do Jarteste, tem-se uma concentração de $5 \mathrm{mg} / \mathrm{L}$ adicionados ao jarro de $2 \mathrm{~L}$.

Na ETAPA II foi preparada solução em bombona de 225 L, com concentração de 11,1 g/L de sulfato de alumínio. Para a Barrilha foi preparada solução em bombona de 200 L com concentração de $10 \mathrm{~g} / \mathrm{L}$.

\subsection{Monitoramento}

Para monitoramento da ETAPA 1 foi analisada somente a eficiência de remoção de turbidez e cor, além do pH de coagulação.

Para monitoramento dos ensaios da ETAPA 2 foram realizadas as análises e leituras apresentadas na Tabela 4.1.

Foram coletadas amostras da água bruta, floculada e flotada. Amostras de água flotada foram coletadas de 10 em 10 minutos desde o inicio do funcionamento da FAD e realizadas leituras de cor aparente e turbidez, para verificar o ponto de estabilização da água de saída. A partir daí foram coletadas amostras de 10 em 10 minutos. 
A partir dos resultados obtidos nas amostras pontuais, foram preparadas amostras compostas para caracterização final do ensaio em função das 2 amostras coletadas que obtiveram melhores valores de turbidez e cor.

A água floculada foi coletada no mesmo intervalo de tempo que a água flotada, de 10 em 10 minutos, foi feita uma amostra composta para cada $V_{C F}$ analisada e realizado ensaio de sólidos suspensos totais em triplicata.

O monitoramento seguiu a mesma linha proposta pelo trabalho do aluno Kisner Anderson Maia, com o tema: "Influência da Velocidade de Entrada na Zona de Contato de Unidades Retangulares de Flotação por Ar Dissolvido Aplicada no Tratamento de Águas para Abastecimento", e orientador Marco Antônio Penalva Reali, já que o trabalho proposto por Araújo (2009) foi uma continuação do projeto de pesquisa proposto por Maia (2009), só que este presente projeto de pesquisa visou avaliar a influência da Velocidade Cross-Flow, juntamente com a TAS na Zona de Separação e o Potencial Zeta na eficiência da clarificação de água no processo de FAD.

Tabela 4.1: Análise e Leituras para monitoramento da ETAPA 2.

\begin{tabular}{|c|c|c|c|}
\hline Parâmetros & Água Bruta & Água Floculada & Água Flotada \\
\hline Temperatura & $\mathbf{X}$ & & \\
\hline pH & $\mathbf{X}$ & & \\
\hline Cor & $\mathbf{X}$ & & $\mathbf{X}$ \\
\hline Turbidez & $\mathbf{X}$ & & $\mathbf{X}$ \\
\hline $\begin{array}{c}\text { Sólidos Suspensos } \\
\text { Totais }\end{array}$ & $\mathbf{X}$ & $\mathbf{X}$ & $\mathbf{X}$ \\
\hline Alcalinidade & $\mathbf{X}$ & & \\
\hline Condutividade & $\mathbf{X}$ & & \\
\hline $\begin{array}{c}\text { Absorbância } \\
\text { 254nm }\end{array}$ & $\mathbf{X}$ & & $\mathbf{X}$ \\
\hline $\begin{array}{l}\text { Carbono Orgânico } \\
\text { Dissolvido (COD) }\end{array}$ & $\mathbf{X}$ & & $\mathbf{X}$ \\
\hline
\end{tabular}


Todas as análises e leituras respeitaram os procedimentos descritos pelo Standard Methods for the Examination of Water and Wastewater 2005 e foram desenvolvidas no Laboratório de Tratamento Avançado e Reuso de Águas - LATAR, e no Laboratório de Saneamento - LS , do Departamento de Hidráulica e Saneamento SHS/EESC/USP. 


\section{Resultados e Discussão}

\subsection{ETAPA 1:}

\subsubsection{Determinação do par Dosagem de Coagulante e pH de coagulação}

Nesta Fase da Etapa 1 foram realizados ensaios em aparelho de bancada de batelada (flotateste) para determinação do par dosagem de coagulante e $\mathrm{pH}$ de coagulação adequados para flotação. Para monitoramento dos resultados levou-se em consideração a remoção de turbidez e cor da água analisada, e o pH de coagulação.

Os parâmetros mantidos fixos foram os seguintes:

$\checkmark$ Gradiente Médio de Mistura Rápida $\left(\mathrm{G}_{\mathrm{MR}}\right)=800 \mathrm{~s}^{-1}$;

$\checkmark$ Tempo Médio de Mistura Rápida $\left(\mathrm{T}_{\mathrm{MR}}\right)=20 \mathrm{~s}$;

$\checkmark$ Gradiente Médio de Floculação $\left(\mathrm{G}_{\mathrm{F}}\right)=90 \mathrm{~s}^{-1}$;

$\checkmark$ Tempo Médio de Floculação $\left(\mathrm{T}_{\mathrm{F}}\right)=12$ minutos;

$\checkmark$ Taxa de Recirculação $\left(\mathrm{T}_{\mathrm{R}}\right)=10 \%$;

$\checkmark$ Pressão da Câmara de Saturação $\left(\mathrm{P}_{\mathrm{SAT}}\right)=4,5$ bar;

$\checkmark$ Velocidades de Flotação $=7,7 \mathrm{~m} / \mathrm{h}$ e $15 \mathrm{~m} / \mathrm{h}$;

$\checkmark$ Tempo de Saturação da água recirculada $=10$ minutos.

Os parâmetros que foram variados foram os seguintes:

$\checkmark$ Dosagem de Coagulante (Sulfato de Alumínio) de 7,5 mg/L até 47,5 mg/L de $2,5 \mathrm{em} 2,5 \mathrm{mg} / \mathrm{L}$.

$\checkmark$ pH de coagulação, onde foi variado entre 5,8 e 7,2, com ajuda de ácido sulfúrico e barrilha, em casos de redução ou aumento do $\mathrm{pH}$ respectivamente. 
Caracterização da água bruta mostrado na Tabela 5.1:

Tabela 5.1: Caracterização da Água Bruta para ensaios em laboratório (flotateste).

\begin{tabular}{cc}
\hline Parâmetros & Água Bruta \\
\hline pH & $6,56 \pm 0,12$ \\
\hline Temperatura $\left({ }^{\circ} \mathbf{C}\right)$ & $22,5 \pm 1,8$ \\
\hline Turbidez $(\mathbf{N T U})$ & $7,94 \pm 0,26$ \\
\hline Cor $($ uH) & $68 \pm 3$ \\
\hline Cor verdadeira $(\mathbf{u H})$ & $13,67 \pm 2,08$ \\
\hline Alcalinidade $(\mathbf{m g ~ C a C O} / \mathbf{L})$ & $25,34 \pm 0,3$ \\
\hline Condutividade $(\boldsymbol{\mu S} / \mathbf{c m})$ & $60,87 \pm 1,2$ \\
\hline
\end{tabular}

Após a realização dos ensaios no flotateste com a Água de estudo foram obtidos os seguintes resultados na Tabela 5.2:

Tabela 5.2: Resultados dos ensaios realizados no flotateste em relação a remoção de turbidez e cor da Água de estudo - $\left(\mathrm{G}_{\mathrm{MR}}\right)=800 \mathrm{~s}^{-1} ;\left(\mathrm{T}_{\mathrm{MR}}\right)=20 \mathrm{~s} ;\left(\mathrm{G}_{\mathrm{F}}\right)=90 \mathrm{~s}^{-1} ;\left(\mathrm{T}_{\mathrm{F}}\right)=$ 12 minutos; $\left(\mathrm{T}_{\mathrm{R}}\right)=10 \% ;\left(\mathrm{P}_{\mathrm{SAT}}\right)=4,5$ bar; $\mathrm{V}_{\mathrm{FLOT}}=12,8 \mathrm{~cm} / \mathrm{min}(7,7 \mathrm{~m} / \mathrm{h})$ e 25,1 $\mathrm{cm} / \mathrm{min}(15 \mathrm{~m} / \mathrm{h})$; Tempo de Saturação da água recirculada $=10$ minutos.

\begin{tabular}{|c|c|c|c|c|c|c|}
\hline \multirow[b]{2}{*}{ Coagulante } & \multirow[b]{2}{*}{ Barr.(*) ou ácido } & \multirow[b]{2}{*}{$\mathrm{pH}$} & \multicolumn{2}{|c|}{ Turbidez Residual (NTU) } & \multicolumn{2}{|c|}{ Cor Residual (uH) } \\
\hline & & & $\mathbf{V}_{\text {FLOT }}$ & $\mathrm{V}_{\mathrm{FLOT}}$ & $\mathrm{V}_{\text {FLOT }}$ & $\mathrm{V}_{\text {FLOT }}$ \\
\hline$(\mathrm{mg} / \mathrm{L})$ & $(\mathrm{mg} / \mathrm{L})$ & coagulação & $7,67 \mathrm{~m} / \mathrm{h}$ & $15 \mathrm{~m} / \mathrm{h}$ & $7,67 \mathrm{~m} / \mathrm{h}$ & $15 \mathrm{~m} / \mathrm{h}$ \\
\hline 7,5 & 6,3 (ácido) & 6,12 & 1,7 & 3,48 & 13 & 21 \\
\hline 7,5 & 3,15 (ácido) & 6,26 & 1,23 & 1,33 & 8 & 9 \\
\hline 7,5 & - & 6,41 & 1,69 & 2,38 & 12 & 15 \\
\hline 7,5 & *5 & 6,64 & 3,63 & 4,98 & 28 & 35 \\
\hline 10 & 6,3 (ácido) & 5,96 & 5,81 & 4,02 & 38 & 32 \\
\hline 10 & - & 6,33 & 0,66 & 0,98 & 8 & 10 \\
\hline 10 & $\star 5,0$ & 6,45 & 0,87 & 1,13 & 9 & 15 \\
\hline 10 & ${ }^{*} 10,0$ & 6,61 & 1,10 & 2,00 & 13 & 17 \\
\hline 12,5 & 6,3 (ácido) & 5,91 & 5,16 & 5,66 & 38 & 40 \\
\hline 12,5 & - & 6,26 & 0,66 & 0,69 & 7 & 8 \\
\hline 12,5 & $\star 7,5$ & 6,46 & 0,75 & 0,77 & 7 & 8 \\
\hline 12,5 & ${ }^{*} 15,0$ & 6,68 & 1,08 & 1,63 & 9 & 17 \\
\hline 15 & 6,3 (ácido) & 5,84 & 5,86 & 5,80 & 38 & 39 \\
\hline 15 & - & 6,16 & 0,66 & 0,65 & 6 & 8 \\
\hline 15 & ${ }^{*} 10,0$ & 6,44 & 0,59 & 0,56 & 4 & 6 \\
\hline 15 & $* 20,0$ & 6,75 & 0,73 & 1,21 & 8 & 12 \\
\hline 17,5 & 6,3 (ácido) & 5,80 & 5,92 & 6,33 & 38 & 41 \\
\hline 17,5 & - & 6,13 & 0,56 & 0,62 & 4 & 2 \\
\hline 17,5 & ${ }^{*} 10,0$ & 6,41 & 0,40 & 0,60 & 2 & 2 \\
\hline 17,5 & $* 25,0$ & 6,77 & 0,79 & 1,40 & 12 & 9 \\
\hline
\end{tabular}

Continua... 
Continuação

\begin{tabular}{|c|c|c|c|c|c|c|}
\hline 20 & 6,3 (ácido) & 5,75 & 7,88 & 8,07 & 40 & 43 \\
\hline 20 & - & 6,13 & 0,46 & 0,47 & 2 & 2 \\
\hline 20 & ${ }^{*} 15,0$ & 6,50 & 0,40 & 0,42 & 1 & 1 \\
\hline 20 & *30,0 & 6,84 & 0,77 & 1,38 & 4 & 8 \\
\hline 22,5 & - & 6,07 & 3,34 & 4,02 & 32 & 36 \\
\hline 22,5 & ${ }^{*} 10,0$ & 6,35 & 0,36 & 0,39 & 1 & 1 \\
\hline 22,5 & $\star 20,0$ & 6,58 & 0,34 & 0,40 & 1 & 1 \\
\hline 22,5 & ${ }^{*} 35,0$ & 6,89 & 0,69 & 1,61 & 4 & 13 \\
\hline 25 & - & 6,16 & 10,70 & 9,52 & 67 & 66 \\
\hline 25 & $* 5,0$ & 6,28 & 9,20 & 9,74 & 67 & 68 \\
\hline 25 & $* 7,5$ & 6,37 & 0,75 & 1,55 & 6 & 9 \\
\hline 25 & ${ }^{*} 12,5$ & 6,55 & 0,64 & 0,91 & 5 & 7 \\
\hline 25 & ${ }^{*} 15,0$ & 6,58 & 0,84 & 0,91 & 6 & 6 \\
\hline 25 & $* 20,0$ & 6,73 & 0,91 & 0,88 & 5 & 6 \\
\hline 25 & ${ }^{*} 30,0$ & 6,93 & 0,98 & 2,32 & 7 & 16 \\
\hline 25 & ${ }^{*} 35,0$ & 7,19 & 2,46 & 6,75 & 20 & 62 \\
\hline 27,5 & - & 6,11 & 12,20 & 10,80 & 72 & 71 \\
\hline 27,5 & $\star 5,0$ & 6,22 & 10,40 & 9,15 & 75 & 71 \\
\hline 27,5 & $\star 7,5$ & 6,33 & 0,83 & 1,07 & 7 & 13 \\
\hline 27,5 & ${ }^{*} 12,5$ & 6,56 & 0,62 & 0,80 & 4 & 7 \\
\hline 27,5 & ${ }^{\star} 27,5$ & 6,79 & 0,71 & 1,56 & 6 & 12 \\
\hline 27,5 & ${ }^{*} 30,0$ & 6,97 & 0,89 & 1,48 & 6 & 12 \\
\hline 27,5 & ${ }^{*} 40,0$ & 7,13 & 1,01 & 2,91 & 9 & 24 \\
\hline 30 & $\star 5,0$ & 6,30 & 2,75 & 4,62 & 24 & 37 \\
\hline 30 & ${ }^{*} 7,5$ & 6,38 & 0,69 & 0,82 & 6 & 8 \\
\hline 30 & ${ }^{*} 10,0$ & 6,43 & 0,66 & 0,71 & 6 & 5 \\
\hline 30 & ${ }^{*} 12,5$ & 6,55 & 0,66 & 0,77 & 3 & 6 \\
\hline 30 & ${ }^{*} 27,5$ & 6,87 & 0,65 & 1,12 & 6 & 9 \\
\hline 30 & ${ }^{*} 30,0$ & 6,97 & 0,80 & 1,68 & 7 & 14 \\
\hline 30 & ${ }^{*} 40,0$ & 7,07 & 1,00 & 2,30 & 8 & 17 \\
\hline 32,5 & ${ }^{\star} 5,0$ & 6,23 & 7,44 & 8,66 & 53 & 65 \\
\hline 32,5 & ${ }^{\star} 7,5$ & 6,36 & 0,87 & 1,08 & 6 & 8 \\
\hline 32,5 & ${ }^{*} 10,0$ & 6,39 & 0,61 & 0,66 & 3 & 4 \\
\hline 32,5 & ${ }^{*} 12,5$ & 6,44 & 0,65 & 0,71 & 3 & 4 \\
\hline 32,5 & *27,5 & 6,88 & 0,67 & 0,95 & 5 & 7 \\
\hline 32,5 & ${ }^{*} 35,0$ & 7,11 & 0,76 & 3,30 & 10 & 28 \\
\hline 35 & ${ }^{*} 6,5$ & 6,20 & 9,79 & 9,25 & 71 & 70 \\
\hline 35 & ${ }^{*} 9,0$ & 6,32 & 0,88 & 1,14 & 5 & 10 \\
\hline 35 & ${ }^{*} 12,0$ & 6,42 & 0,71 & 0,75 & 4 & 4 \\
\hline 35 & ${ }^{*} 14,0$ & 6,49 & 0,62 & 0,74 & 3 & 4 \\
\hline 35 & ${ }^{*} 27,5$ & 6,74 & 0,60 & 0,68 & 6 & 7 \\
\hline 35 & ${ }^{*} 35,0$ & 6,88 & 0,82 & 0,92 & 9 & 10 \\
\hline 35 & ${ }^{*} 45,0$ & 7,26 & 1,12 & 3,15 & 13 & 28 \\
\hline
\end{tabular}

Continua... 


\section{Continuação}

\begin{tabular}{|c|c|c|c|c|c|c|}
\hline 37,5 & ${ }^{*} 6,5$ & 6,15 & 8,81 & 9,27 & 69 & 69 \\
\hline 37,5 & ${ }^{*} 9,0$ & 6,25 & 0,77 & 1,10 & 7 & 10 \\
\hline 37,5 & ${ }^{*} 12,0$ & 6,39 & 0,54 & 0,73 & 3 & 5 \\
\hline 37,5 & ${ }^{*} 14,0$ & 6,50 & 0,56 & 0,81 & 3 & 6 \\
\hline 37,5 & ${ }^{*} 27,5$ & 6,70 & 0,59 & 0,63 & 3 & 4 \\
\hline 37,5 & ${ }^{*} 35,0$ & 6,93 & 0,68 & 1,17 & 4 & 8 \\
\hline 37,5 & ${ }^{*} 45,0$ & 7,08 & 1,22 & 2,33 & 8 & 15 \\
\hline 40 & ${ }^{*} 9,0$ & 6,26 & 0,93 & 1,14 & 8 & 10 \\
\hline 40 & ${ }^{*} 11,0$ & 6,38 & 0,71 & 0,85 & 5 & 6 \\
\hline 40 & ${ }^{*} 13,0$ & 6,47 & 0,56 & 0,69 & 4 & 3 \\
\hline 40 & ${ }^{*} 16,0$ & 6,59 & 0,61 & 0,66 & 3 & 3 \\
\hline 40 & ${ }^{*} 30,0$ & 6,78 & 0,60 & 0,61 & 4 & 5 \\
\hline 40 & ${ }^{*} 40,0$ & 6,97 & 0,67 & 1,16 & 6 & 10 \\
\hline 42,5 & ${ }^{*} 10,0$ & 6,21 & 9,57 & 9,56 & 72 & 70 \\
\hline 42,5 & ${ }^{*} 15,0$ & 6,42 & 0,53 & 0,50 & 4 & 4 \\
\hline 42,5 & ${ }^{*} 25,0$ & 6,63 & 0,55 & 0,48 & 2 & 3 \\
\hline 42,5 & ${ }^{*} 40,0$ & 7,01 & 0,56 & 1,02 & 3 & 8 \\
\hline 42,5 & ${ }^{*} 50,0$ & 7,24 & 1,77 & 9,21 & 16 & 73 \\
\hline 45 & ${ }^{*} 10,0$ & 6,17 & 10,30 & 9,33 & 4 & 70 \\
\hline 45 & ${ }^{*} 20,0$ & 6,51 & 0,54 & 0,67 & 4 & 4 \\
\hline 45 & ${ }^{*} 35,0$ & 6,88 & 0,75 & 0,75 & 13 & 3 \\
\hline 45 & ${ }^{*} 50,0$ & 7,27 & 1,31 & 6,75 & 71 & 78 \\
\hline 47,5 & ${ }^{*} 10,0$ & 6,17 & 10,60 & 8,92 & 71 & 69 \\
\hline 47,5 & ${ }^{*} 20,0$ & 6,51 & 0,57 & 0,66 & 3 & 4 \\
\hline 47,5 & ${ }^{*} 35,0$ & 6,91 & 0,81 & 0,81 & 4 & 4 \\
\hline 47,5 & ${ }^{*} 50,0$ & 7,26 & 1,61 & 10,10 & 12 & 54 \\
\hline
\end{tabular}

*: Adição de barrilha como alcalinizante.

A seguir são apresentados os diagramas de coagulação em relação à remoção de turbidez (Figura 5.1 e Figura 5.2) para as TAS na zona de separação estudadas $(7,7 \mathrm{~m} / \mathrm{h}$ e $15 \mathrm{~m} / \mathrm{h})$ : 
Diagrama de coagulação visando a flotação para Água I: Remoção de Turbidez de $90 \%$ e $95 \%$ Coagulante: Sulfato de Alumínio

$V_{\text {flot: }}: 12,8 \mathrm{~cm} / \mathrm{min}$.



Figura 5.1: Diagrama de coagulação (dosagem de coagulante versus pH) visando a flotação para eficiências de 90 e $95 \%$ de remoção na $\mathrm{V}_{\mathrm{FLOT}}$ de $12,8 \mathrm{~cm} / \mathrm{min}$ (TAS de 7,7 m/h) na zona de separação. 
Diagrama de coagulação visando a flotação para Água I: Remoção de Turbidez de $90 \%$ e $95 \%$ Coagulante: Sulfato de Alumínio

Vflot: $25,1 \mathrm{~cm} / \mathrm{min}$.

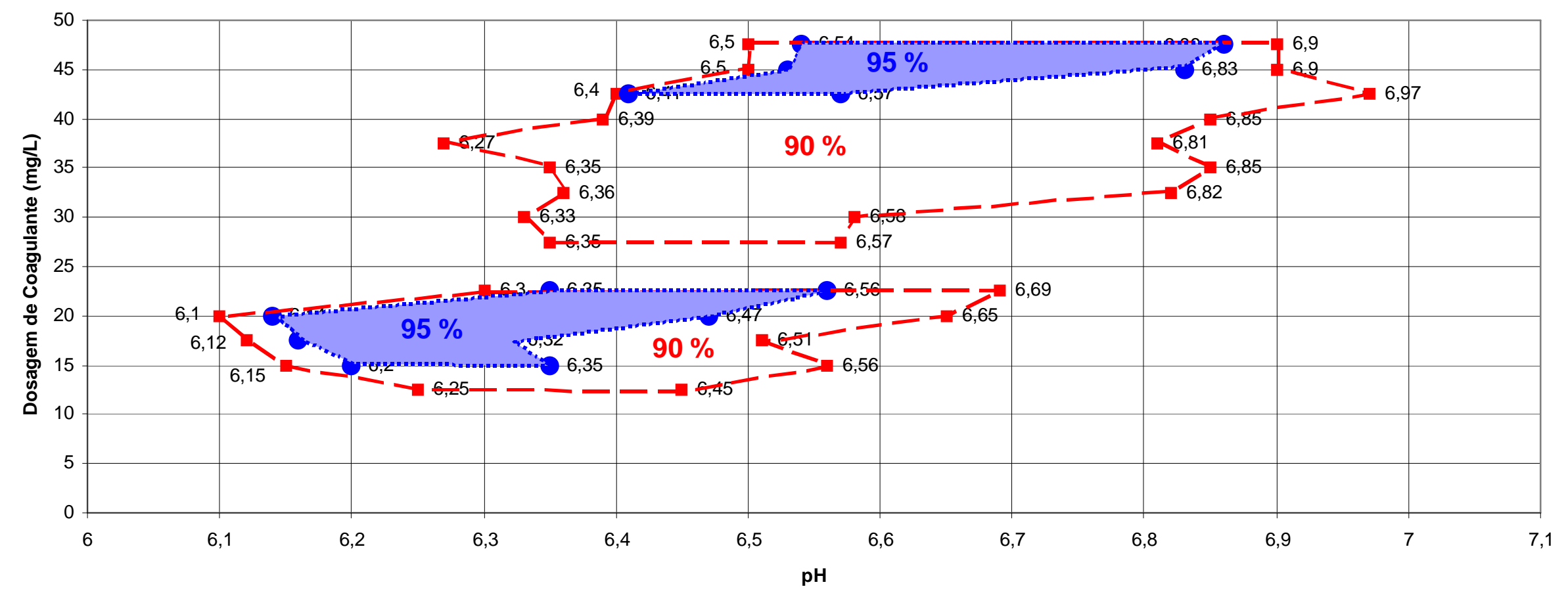

Figura 5.2: Diagrama de coagulação (dosagem de coagulante versus pH) visando a flotação para eficiências de 90 e $95 \%$ de remoção na $\mathrm{V}_{\mathrm{FLOT}}$ de $25,1 \mathrm{~cm} / \mathrm{min}$ (TAS de $15 \mathrm{~m} / \mathrm{h}$ ) na zona de separação. 




Figura 5.3: Potencial Zeta $\mathrm{x} \mathrm{pH}$, para dosagem de 22,5 $\mathrm{mg} / \mathrm{L}$ de sulfato de alumínio. $\left(\mathrm{G}_{\mathrm{MR}}\right)=800 \mathrm{~s}^{-1} ;\left(\mathrm{T}_{\mathrm{MR}}\right)=20 \mathrm{~s} ;\left(\mathrm{G}_{\mathrm{F}}\right)=90 \mathrm{~s}^{-1} ;\left(\mathrm{T}_{\mathrm{F}}\right)=12$ minutos; $\left(\mathrm{T}_{\mathrm{R}}\right)=10 \% ;\left(\mathrm{P}_{\mathrm{SAT}}\right)=$ 4,5 bar; $(\mathrm{DAS})=22,5 \mathrm{mg} / \mathrm{L}$; Tempo de Saturação da água recirculada $=10$ minutos.



Figura 5.4: Potencial Zeta $\times \mathrm{pH}$, para dosagem de $42,5 \mathrm{mg} / \mathrm{L}$ de sulfato de alumínio. $\left(\mathrm{G}_{\mathrm{MR}}\right)=800 \mathrm{~s}^{-1} ;\left(\mathrm{T}_{\mathrm{MR}}\right)=20 \mathrm{~s} ;\left(\mathrm{G}_{\mathrm{F}}\right)=90 \mathrm{~s}^{-1} ;\left(\mathrm{T}_{\mathrm{F}}\right)=12$ minutos; $\left(\mathrm{T}_{\mathrm{R}}\right)=10 \% ;\left(\mathrm{P}_{\mathrm{SAT}}\right)=$ 4,5 bar; DAS $=42,5 \mathrm{mg} / \mathrm{L}$; Tempo de Saturação da água recirculada $=10$ minutos.

Após determinado diagramas de coagulação para a Água analisada para os dois valores de $\mathrm{V}_{\text {Flot, }}$, determinou-se quais seriam as dosagens utilizadas e assim foi verificado o comportamento da variação do $\mathrm{pH}$ e dosagem de coagulante em relação ao valor do potencial zeta. Desta forma foram obtidos os dois Gráficos (Figuras 5.3 e 5.4) 
apresentados acima, os quais indicam os valores de potencial zeta para as dosagens de 22,5 mg/L e 42,5 mg/L em relação a variação do pH.

Analisando os resultados, verifica-se que para valores próximos a neutralidade a dosagem de sulfato de alumínio de $22,5 \mathrm{mg} / \mathrm{L}$ foi a mais eficiente em relação à remoção de turbidez e cor da água de estudo, enquanto que para valores de potencial zeta positivos, a dosagem de sulfato de alumínio de $42,5 \mathrm{mg} / \mathrm{L}$ obteve melhores resultados em relação à remoção de turbidez e cor. Verifica-se ainda que o pH de coagulação de ambas dosagens nos potenciais zeta escolhidos ficaram em torno de 6,3 e 6,4, típico para o coagulante Sulfato de Alumínio.

\subsubsection{Determinação do Gradiente Médio de Floculação e o Tempo Médio de Floculação}

Após a determinação do par adequado dosagem de coagulante e $\mathrm{pH}$ de coagulação foram realizados ensaios para determinação do Gradiente Médio de Floculação e do Tempo Médio de Floculação para a água em questão. Desta forma, para realização dos ensaios no aparelho de bancada foram mantidos fixos os seguintes parâmetros:

$\checkmark$ Gradiente Médio de Mistura Rápida $\left(\mathrm{G}_{\mathrm{MR}}\right)=800 \mathrm{~s}^{-1}$;

$\checkmark$ Tempo Médio de Mistura Rápida $\left(\mathrm{T}_{\mathrm{MR}}\right)=20 \mathrm{~s}$;

$\checkmark$ Taxa de Recirculação $\left(T_{R}\right)=10 \%$;

$\checkmark$ Pressão da Câmara de Saturação $\left(\mathrm{P}_{\mathrm{SAT}}\right)=4,5$ bar;

$\checkmark$ Velocidades de Flotação $=7,7 \mathrm{~m} / \mathrm{h}$ e $15 \mathrm{~m} / \mathrm{h}$;

$\checkmark$ Tempo de Saturação da água recirculada $=10$ minutos;

$\checkmark$ Dosagem de Coagulante (Sulfato de Alumínio) de 42,5 mg/L e 22,5 mg/L; 
$\checkmark$ pH de coagulação $(6,50 \pm 0,5)$ e $(6,40 \pm 0,5)$, para as DSA de 42,5 e $22,5 \mathrm{mg} / \mathrm{L}$ respectivamente.

Foram variados os seguintes parâmetros:

$\checkmark$ Gradiente Médio de Floculação $\left(\mathrm{G}_{\mathrm{F}}\right)$ foi variado de $70 \mathrm{~s}^{-1}$ até $110 \mathrm{~s}^{-1}$ de $10 \mathrm{em}$ $10 \mathrm{~s}^{-1}$

$\checkmark$ Tempo Médio de Floculação ( $\mathrm{T}_{\mathrm{F}}$ ) foi variado nos tempos de 12, 16 e 20 minutos, para a dosagem de $42,5 \mathrm{mg} / \mathrm{L}$ e 12,18 e 24 minutos para a dosagem de 22,5 $\mathrm{mg} / \mathrm{L}$.

Com a realização dos ensaios de flotateste foram obtidos os seguintes resultados apresentados nas Tabelas 5.3 e 5.4:

Tabela 5.3: Resultados do gradiente médio e tempo de floculação para a água tipo I estudada e dosagem de Sulfato de Alumínio de 22,5 mg/L.

\begin{tabular}{|c|c|c|c|c|c|c|c|c|}
\hline \multirow[b]{2}{*}{ Dosagem } & \multirow[b]{2}{*}{ Dosagem } & \multirow[b]{2}{*}{ Gradiente } & \multirow[b]{2}{*}{ Tempo } & \multirow[b]{2}{*}{$\mathrm{pH}$} & \multicolumn{2}{|c|}{$\begin{array}{c}\text { Turbidez remanesc. } \\
\text { (NTU) }\end{array}$} & \multicolumn{2}{|c|}{$\begin{array}{c}\text { Cor remanesc. } \\
(\mathrm{uH})\end{array}$} \\
\hline & & & & & V FLOT $_{\text {FLT }}$ & V $_{\text {FLOT }}$ & $\mathrm{V}_{\text {FLOT }}$ & V $_{\text {FLOT }}$ \\
\hline Coag. (mg/L) & Alcali. (mg/L) & floculação $\left(\mathrm{s}^{-1}\right)$ & floculação (min) & coagulação & $7,67 \mathrm{~m} / \mathrm{h}$ & $15 \mathrm{~m} / \mathrm{h}$ & $7,67 \mathrm{~m} / \mathrm{h}$ & $15 \mathrm{~m} / \mathrm{h}$ \\
\hline 22,5 & 10 & 70 & 12 & 6,35 & 0,60 & 0,67 & 3 & 5 \\
\hline 22,5 & 10 & 80 & 12 & 6,37 & 0,61 & 0,65 & 4 & 4 \\
\hline 22,5 & 10 & 90 & 12 & 6,36 & 0,56 & 0,69 & 3 & 4 \\
\hline 22,5 & 10 & 100 & 12 & 6,38 & 0,57 & 0,61 & 3 & 4 \\
\hline 22,5 & 10 & 110 & 12 & 6,41 & 0,55 & 0,61 & 3 & 5 \\
\hline 22,5 & 10 & 70 & 18 & 6,40 & 0,64 & 0,69 & 4 & 5 \\
\hline 22,5 & 10 & 80 & 18 & 6,38 & 0,67 & 0,63 & 4 & 4 \\
\hline 22,5 & 10 & 90 & 18 & 6,39 & 0,56 & 0,56 & 3 & 4 \\
\hline 22,5 & 10 & 100 & 18 & 6,36 & 0,58 & 0,66 & 3 & 5 \\
\hline 22,5 & 10 & 110 & 18 & 6,33 & 0,58 & 0,65 & 3 & 4 \\
\hline 22,5 & 10 & 70 & 24 & 6,42 & 0,62 & 0,73 & 4 & 5 \\
\hline 22,5 & 10 & 80 & 24 & 6,36 & 0,66 & 0,67 & 4 & 5 \\
\hline 22,5 & 10 & 90 & 24 & 6,39 & 0,54 & 0,60 & 3 & 4 \\
\hline 22,5 & 10 & 100 & 24 & 6,34 & 0,55 & 0,61 & 3 & 4 \\
\hline 22,5 & 10 & 110 & 24 & 6,35 & 0,56 & 0,65 & 3 & 5 \\
\hline
\end{tabular}


Tabela 5.4: Resultados do gradiente médio e tempo de floculação para a água tipo I estudada e dosagem de Sulfato de Alumínio de 42,5 mg/L.

\begin{tabular}{|c|c|c|c|c|c|c|c|c|}
\hline \multirow[b]{2}{*}{ Dosagem } & \multirow[b]{2}{*}{ Dosagem } & \multirow[b]{2}{*}{ Gradiente } & \multirow[b]{2}{*}{ Tempo } & \multirow[b]{2}{*}{$\mathrm{pH}$} & \multicolumn{2}{|c|}{$\begin{array}{c}\text { Turbidez remanesc. } \\
\text { (NTU) }\end{array}$} & \multicolumn{2}{|c|}{$\begin{array}{c}\text { Cor remanesc. } \\
(\mathrm{uH})\end{array}$} \\
\hline & & & & & $\mathrm{V}_{\text {FLOT }}$ & $\mathrm{V}_{\text {FLOT }}$ & $\mathrm{V}_{\text {FLOT }}$ & $\mathrm{V}_{\text {FLOT }}$ \\
\hline Coag. (mg/L) & Alcali. (mg/L) & floculação $\left(\mathrm{s}^{-1}\right)$ & floculação (min) & coagulação & $7,67 \mathrm{~m} / \mathrm{h}$ & $15 \mathrm{~m} / \mathrm{h}$ & $7,67 \mathrm{~m} / \mathrm{h}$ & $15 \mathrm{~m} / \mathrm{h}$ \\
\hline 42,5 & 20 & 70 & 12 & 6,51 & 0,45 & 0,52 & 2 & 3 \\
\hline 42,5 & 20 & 80 & 12 & 6,50 & 0,46 & 0,50 & 3 & 3 \\
\hline 42,5 & 20 & 90 & 12 & 6,51 & 0,41 & 0,54 & 2 & 3 \\
\hline 42,5 & 20 & 100 & 12 & 6,52 & 0,42 & 0,46 & 2 & 2 \\
\hline 42,5 & 20 & 110 & 12 & 6,49 & 0,40 & 0,46 & 2 & 2 \\
\hline 42,5 & 20 & 70 & 16 & 6,49 & 0,49 & 0,54 & 3 & 3 \\
\hline 42,5 & 20 & 80 & 16 & 6,50 & 0,52 & 0,48 & 3 & 3 \\
\hline 42,5 & 20 & 90 & 16 & 6,51 & 0,41 & 0,41 & 2 & 2 \\
\hline 42,5 & 20 & 100 & 16 & 6,51 & 0,43 & 0,51 & 2 & 3 \\
\hline 42,5 & 20 & 110 & 16 & 6,52 & 0,43 & 0,50 & 2 & 3 \\
\hline 42,5 & 20 & 70 & 20 & 6,52 & 0,47 & 0,58 & 3 & 3 \\
\hline 42,5 & 20 & 80 & 20 & 6,54 & 0,51 & 0,52 & 3 & 3 \\
\hline 42,5 & 20 & 90 & 20 & 6,48 & 0,39 & 0,45 & 2 & 2 \\
\hline 42,5 & 20 & 100 & 20 & 6,50 & 0,40 & 0,46 & 2 & 2 \\
\hline 42,5 & 20 & 110 & 20 & 6,48 & 0,41 & 0,50 & 2 & 3 \\
\hline
\end{tabular}

Analisando as Tabelas 5.3 e 5.4, observa-se que a eficiência em relação à remoção de turbidez e cor foi praticamente a mesma em todas as condições estudadas na floculação. Portanto, para o uso na ETAPA 2 foi escolhido o Gradiente Médio de Floculação de $90 \mathrm{~s}^{-1}$ e o Tempo Médio de Floculação de 12 minutos.

Assim, para continuidade do projeto de pesquisa, na ETAPA 1 foram escolhidas as dosagens de 22,5 mg/L e 42,5 mg/L de Sulfato de Alumínio, com pH de coagulação por volta de 6,4 para a dosagem de $22,5 \mathrm{mg} / \mathrm{L}$ de Sulfato de Alumínio e de 6,5 para a dosagem de 42,5 mg/L de Sulfato de Alumínio. Tais dosagens proporcionaram potenciais zeta em torno de zero (neutralidade) e positivo (por volta de $+10 \mathrm{mV}$ ), para as dosagens de 22,5 e 42,5 mg/L respectivamente. Para a Floculação foram escolhidos o Gradiente Médio de Floculação de $90 \mathrm{~s}^{-1}$ e o Tempo Médio de Floculação de 12 minutos. Tais parâmetros foram aplicados à Instalação Piloto de Flotação por Ar 
Dissolvido para verificar a eficiência da flotação quando variado a Velocidade CrossFlow e a Taxa de Aplicação Superficial na Zona de Separação e o Potencial Zeta. 


\subsection{ETAPA 2:}

Escolhidos o par dosagem de coagulante e pH de coagulação, tempo e gradiente de floculação, determinados na ETAPA 1 do projeto de pesquisa, partiu-se para a ETAPA 2 que consistiu na verificação da influência da Velocidade Cross-flow na eficiência da instalação piloto de Flotação por Ar Dissolvido, em que foram variados dois valores de Taxa de Aplicação Superficial na Zona de Separação e de dois valores de Potencial Zeta.

A seguir, são mostrados os resultados em relação aos ensaios realizados durante a ETAPA 2 do projeto de pesquisa.

\subsubsection{Ensaio 1: Potencial Zeta Positivo e TAS na Zona de Separação igual a $7,67 \mathrm{~m} / \mathrm{h}$ :}

Foram mantidos fixos os seguintes parâmetros para realização do Ensaio 1 da ETAPA 2 (Tabela 5.5):

Tabela 5.5: Parâmetros para realização do Ensaio 1 na Instalação Piloto de Flotação por Ar Dissolvido da ETAPA 2:

\begin{tabular}{cc}
\hline Parâmetros & Valores \\
\hline Velocidade na Zona de contato $(\mathbf{m} / \mathbf{h})$ & 180 \\
\hline Tempo de contato $(\mathbf{s})$ & 34 \\
\hline TAS zona de separação $(\mathbf{m} / \mathbf{h})$ & 7,67 \\
\hline Recirculação $(\%)$ & 10 \\
\hline Dosagem de coagulante $(\mathbf{m g} / \mathbf{L})$ & 42,5 \\
\hline Gradiente de floculação $\left(\mathbf{s}^{-1}\right)$ & 90 \\
\hline Tempo de floculação $\left(\mathbf{m i n}^{\mathbf{1}}\right)$ & 12 \\
\hline Vazão de entrada $\left(\mathbf{m}^{\mathbf{3}} / \mathbf{h}\right)$ & 4,6 \\
\hline
\end{tabular}


Caracterização da água bruta para o Ensaio 1 da ETAPA 2 é apresentada na

Tabela5.6:

Tabela 5.6: Caracterização da Água I do Ensaio 1 da ETAPA 2

\begin{tabular}{ccccccc}
\hline Amostras & $\mathrm{pH}$ & $\begin{array}{c}\text { Alcalinidade }(\mathbf{m g} / \mathbf{L} \\
\text { CaCO3) }\end{array}$ & $\begin{array}{c}\text { Condutividade } \\
(\boldsymbol{\mu S} / \mathbf{c m})\end{array}$ & $\begin{array}{c}\text { Turbidez } \\
(\text { NTU) }\end{array}$ & $\begin{array}{c}\text { Cor } \\
(\mathrm{UH})\end{array}$ & $\begin{array}{c}\text { SST } \\
(\mathbf{m g} / \mathbf{L})\end{array}$ \\
\hline Bruta & 6,58 & 28,2 & 52,9 & 7,72 & 46 & 7,6 \\
\hline Poço & 6,22 & 27,7 & 49,5 & 0,35 & 1 & - \\
\hline
\end{tabular}

Caracterização da água coagulada do Ensaio 1 da ETAPA 2 é apresentada na Tabela5.7:

Tabela 5.7: Caracterização da água coagulada do ensaio 1 da ETAPA 2, para dosagem de Sulfato de Alumínio de 42,5 mg/L.

\begin{tabular}{cc}
\hline \multicolumn{2}{c}{ Água Coagulada } \\
\hline Parâmetros & Valores \\
\hline Potencial Zeta $(\mathrm{mV})$ & $13,3 \pm 0,3$ \\
\hline Temperatura $\left({ }^{\circ} \mathrm{C}\right)$ & 28 \\
\hline $\mathrm{pH}$ da água coagulada & 6,28 \\
\hline Condutividade $(\mu \mathrm{S} / \mathrm{cm})$ & 125,9 \\
\hline
\end{tabular}

As coletas foram realizadas respeitando intervalo de 20 minutos para cada mudança da Velocidade Cross-flow para estabilização do sistema de flotação. Cada coleta de amostra pontual foi feita de 10 em 10 minutos. Após análise das amostras pontuais foram feitas amostras compostas, assim como descrito em Material e Métodos. Os resultados foram os seguintes:

As velocidades Cross-flow analisadas são apresentadas na Tabela 5.8: 
Tabela 5.8: Velocidades Cross-flow analisadas no Ensaio 1 da ETAPA 2

\begin{tabular}{c|c}
\hline \multicolumn{2}{c}{ Velocidade Cross-flow $(\boldsymbol{m} / \boldsymbol{h})$} \\
\hline $\mathrm{V}_{\mathrm{CF} 1}$ & 40 \\
\hline $\mathrm{V}_{\mathrm{CF} 2}$ & 70 \\
\hline $\mathrm{V}_{\mathrm{CF} 3}$ & 100 \\
\hline $\mathrm{V}_{\mathrm{CF} 4}$ & 150 \\
\hline $\mathrm{V}_{\mathrm{CF} 5}$ & 200 \\
\hline $\mathrm{V}_{\mathrm{CF} 6}$ & $\mathbf{2 5 0}$ \\
\hline $\mathrm{V}_{\mathrm{CF} 7}$ & 350 \\
\hline $\mathrm{V}_{\mathrm{CF} 8}$ & 630 \\
\hline
\end{tabular}

Os valores de Turbidez, Cor, ABS 254 nm e COT das amostras compostas do

Ensaio 1 são apresentadas na Tabela 5.9:

Tabela 5.9: Resultados das análises das amostras compostas do Ensaio 1 da ETAPA 2.

\begin{tabular}{|c|c|c|c|c|c|c|}
\hline Amostras & Turbidez (NTU) & $\begin{array}{l}\text { Cor } \\
\text { (UH) }\end{array}$ & $\begin{array}{c}\text { ABS } 254 \\
\mathrm{~nm}\end{array}$ & $\begin{array}{c}\text { COT } \\
(\mathrm{mg} / \mathrm{L})\end{array}$ & S.D. & C.V. (\%) \\
\hline$V_{C F 1}=40 \mathrm{~m} / \mathrm{h}$ & 0,81 & 2 & 0,008 & 5,425 & 0,058 & $1,07 \%$ \\
\hline$V_{C F 2}=70 \mathrm{~m} / \mathrm{h}$ & 0,83 & 2 & 0,009 & 5,468 & 0,09 & $1,65 \%$ \\
\hline$V_{C F 3}=100 \mathrm{~m} / \mathrm{h}$ & 0,76 & 2 & 0,005 & 6,454 & 0,211 & $3,27 \%$ \\
\hline$V_{C F 4}=150 \mathrm{~m} / \mathrm{h}$ & 0,67 & 1 & 0,008 & 5,654 & 0,028 & $0,50 \%$ \\
\hline$V_{\text {CF5 }}=200 \mathrm{~m} / \mathrm{h}$ & 0,70 & 1 & 0,007 & 5,637 & 0,109 & $1,94 \%$ \\
\hline$V_{\text {CF6 }}=250 \mathrm{~m} / \mathrm{h}$ & 0,65 & 1 & 0,005 & 4,834 & 0,041 & $0,86 \%$ \\
\hline$V_{C F 7}=350 \mathrm{~m} / \mathrm{h}$ & 0,69 & 1 & 0,003 & 4,951 & 0,088 & $1,78 \%$ \\
\hline$V_{\text {CF8 }}=630 \mathrm{~m} / \mathrm{h}$ & 0,74 & 1 & 0,008 & 4,203 & 0,076 & $1,82 \%$ \\
\hline Bruta & 7,72 & 45 & 0,045 & 4,128 & 0,078 & $1,89 \%$ \\
\hline
\end{tabular}




\section{Turbidez da Água Bruta e Residual (NTU)}

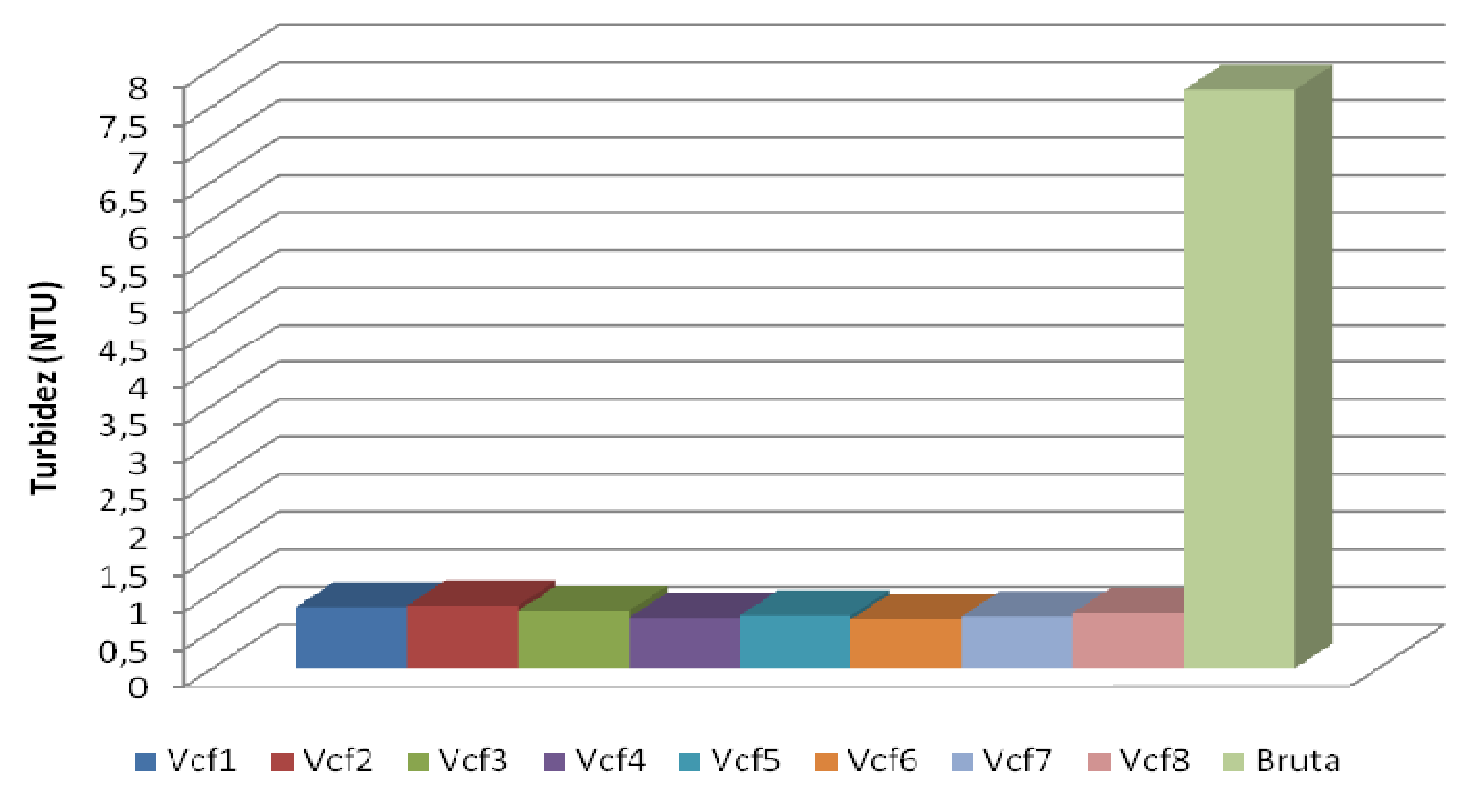

Figura 5.5: Turbidez Residual (NTU) - Ensaio 1 - ETAPA 2. DSA = 42,5 mg/L; PZ = $+13,3 \pm 0,3 ; \mathrm{G}_{\mathrm{F}}=90 \mathrm{~s}^{-1} ; \mathrm{T}_{\mathrm{F}}=12$ minutos; $\mathrm{T}_{\mathrm{R}}=10 \% ; \mathrm{P}_{\mathrm{SAT}}=4,5$ bar; Variação de $\mathrm{V}_{\mathrm{CF}}$ : $40 ; 70 ; 100 ; 150 ; 200 ; 250 ; 350$ e $630 \mathrm{~m} / \mathrm{h}$; TAS $_{\mathrm{ZS}}=7,67 \mathrm{~m} / \mathrm{h} ; \mathrm{Q}_{\text {ent }}=4,6 \mathrm{~m} 3 / \mathrm{h} ; \mathrm{TAS}_{\mathrm{ZC}}$ $=180 \mathrm{~m} / \mathrm{h} ; \mathrm{T}_{\mathrm{ZC}}=34 \mathrm{~s}$.

Analisando a Figura 5.5, tem-se que a remoção de turbidez foi constante, situando em uma faixa de remoção da ordem de $90 \%$. A remoção de turbidez de forma satisfatória ocorreu mesmo em condições em que a Velocidade Cross-Flow apresentou altos valores, devido ao potencial zeta ter-se apresentado em condições positivas (+13 $\mathrm{mV}$ ). O potencial zeta positivo deve, muito provavelmente, ter acarretado em maior afinidade entre o contato floco+bolha, permitindo, que em condições de Velocidade Cross-flow com valores bastante elevados $\left(\mathrm{V}_{\mathrm{CF}}=630 \mathrm{~m} / \mathrm{h}\right)$, a maior parte das ligações bolhas/flocos não foi rompidas, mantendo-se ainda condições adequadas de flotação, permanecendo a camada de flocos no topo do flotador para posterior remoção. 


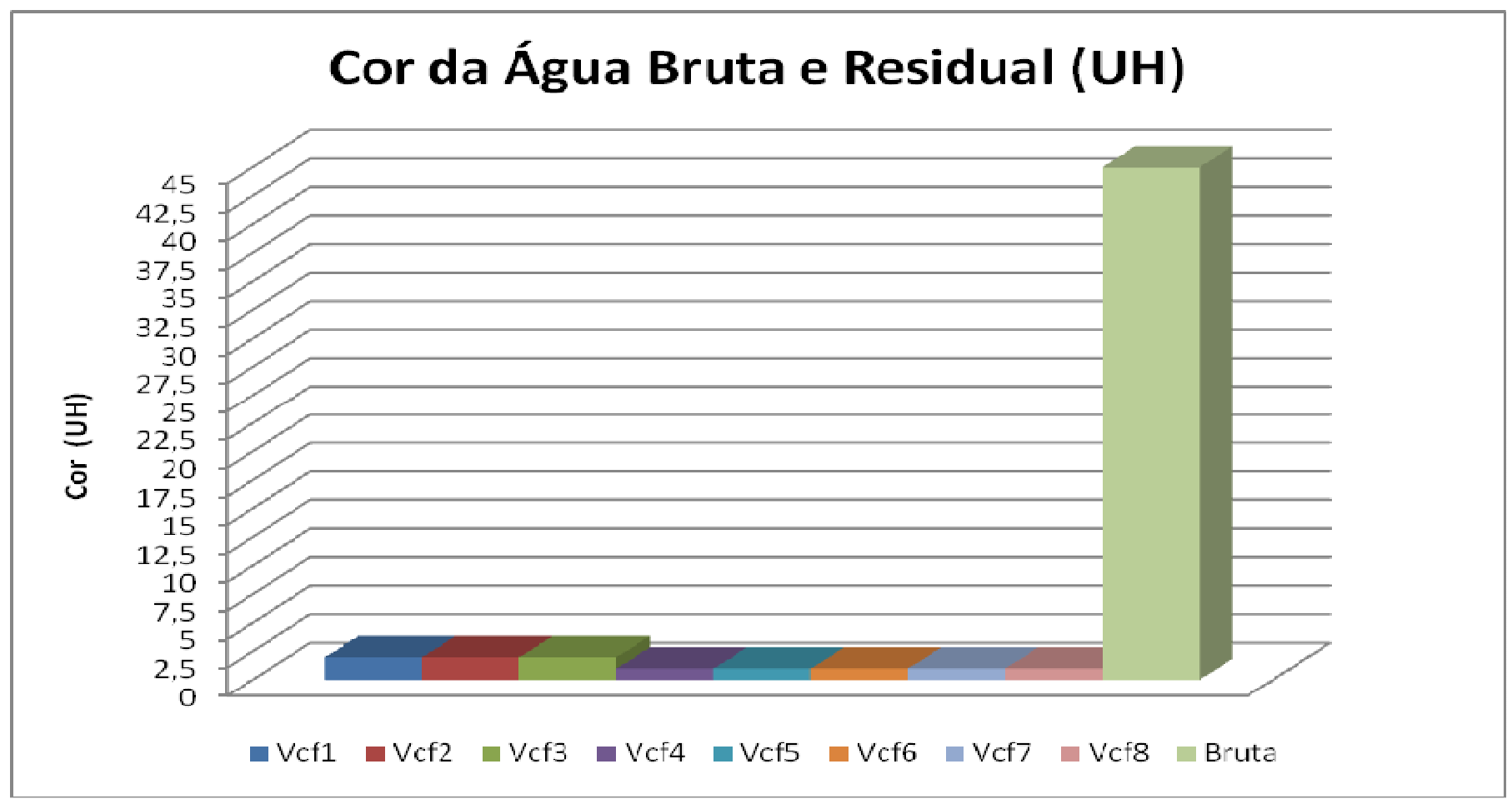

Figura 5.6: Cor Residual (UH) - Ensaio 1 - ETAPA 2. DSA $=42,5 \mathrm{mg} / \mathrm{L} ; \mathrm{PZ}=+13,3 \pm$ 0,$3 ; \mathrm{G}_{\mathrm{F}}=90 \mathrm{~s}^{-1} ; \mathrm{T}_{\mathrm{F}}=12$ minutos; $\mathrm{T}_{\mathrm{R}}=10 \% ; \mathrm{P}_{\mathrm{SAT}}=4,5$ bar; Variação de $\mathrm{V}_{\mathrm{CF}}: 40 ; 70$; $100 ; 150 ; 200 ; 250 ; 350$ e $630 \mathrm{~m} / \mathrm{h}$; $\mathrm{TAS}_{\mathrm{ZS}}=7,67 \mathrm{~m} / \mathrm{h} ; \mathrm{Q}_{\mathrm{ent}}=4,6 \mathrm{~m}^{3} / \mathrm{h} ; \mathrm{TAS}_{\mathrm{ZC}}=180$ $\mathrm{m} / \mathrm{h} ; \mathrm{T}_{\mathrm{ZC}}=34 \mathrm{~s}$.

Assim como na remoção de turbidez, a remoção de cor permaneceu constante nas Velocidades Cross-flow analisadas, situando em torno de 97 \% de remoção. Mesmo em condições de alta turbulência, com altos valores de $\mathrm{V}_{\mathrm{CF}}$, a remoção se deu satisfatória. Tal fato deve-se ao alto valor de potencial zeta, gerando uma ligação entre floco+bolha mais forte e estável, que mesmo em condições hidrodinâmicas, consideradas até então adversas, pôde obter eficiências muito altas em relação à remoção de cor (cor residual entre 1 e 2 UH). 


\section{ABS 254 nm da Água Bruta e Residual}

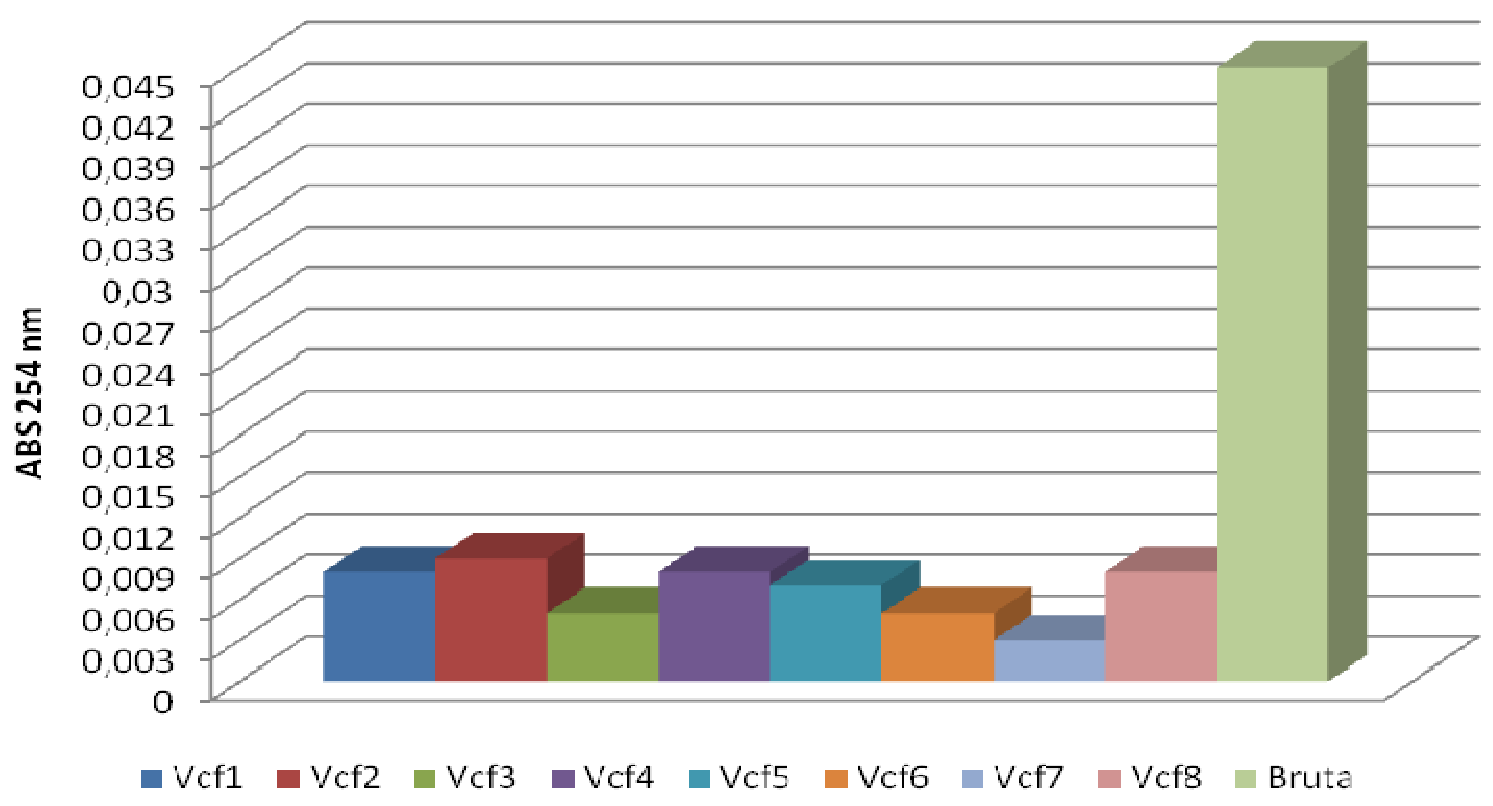

Figura 5.7: ABS $254 \mathrm{~nm}$ - Ensaio 1 - ETAPA 2. DSA = 42,5 mg/L; PZ $=+13,3 \pm 0,3$; $\mathrm{G}_{\mathrm{F}}=90 \mathrm{~s}^{-1} ; \mathrm{T}_{\mathrm{F}}=12$ minutos; $\mathrm{T}_{\mathrm{R}}=10 \% ; \mathrm{P}_{\mathrm{SAT}}=4,5$ bar; Variação de $\mathrm{V}_{\mathrm{CF}}: 40 ; 70 ; 100 ;$ $150 ; 200 ; 250 ; 350$ e $630 \mathrm{~m} / \mathrm{h}$; TAS $_{\mathrm{ZS}}=7,67 \mathrm{~m} / \mathrm{h} ; \mathrm{Q}_{\mathrm{ent}}=4,6 \mathrm{~m}^{3} / \mathrm{h} ; \mathrm{TAS}_{\mathrm{ZC}}=180 \mathrm{~m} / \mathrm{h}$; $\mathrm{T}_{\mathrm{ZC}}=34 \mathrm{~s}$.

No que concerne à redução dos valores de $\mathrm{ABS} 254 \mathrm{~nm}$, os melhores resultados foram nas velocidades de 100, 250 e $350 \mathrm{~m} / \mathrm{h}$, obtendo redução de $89 \%$, $89 \%$ e $93 \%$ respectivamente. As demais velocidades obtiveram remoção entre 80 e $84 \%$ de ABS $254 \mathrm{~nm}$.

A determinação de Sólidos Suspensos Totais das amostras compostas foi realizada em triplicata, sendo que na Tabela 5.10 são apresentados os valores da média e do desvio padrão das referidas determinações. 
Tabela 5.10: Resultados de SST da amostra flotada e floculada do Ensaio 1 da ETAPA2.

\begin{tabular}{|c|c|c|c|c|c|c|}
\hline Amostras & $\begin{array}{l}\text { SST Flotada } \\
(\mathrm{mg} / \mathrm{L})\end{array}$ & $\begin{array}{l}\text { Desvio } \\
\text { padrão }\end{array}$ & $\begin{array}{l}\text { SST Floculada } \\
\text { (mg/L) }\end{array}$ & $\begin{array}{l}\text { Desvio } \\
\text { padrão }\end{array}$ & $\begin{array}{l}\text { Lodo Produzido } \\
\text { (mg/L) }\end{array}$ & $\begin{array}{l}\text { Desvio } \\
\text { padrão }\end{array}$ \\
\hline $\mathrm{V}_{\mathrm{CF} 1}=40 \mathrm{~m} / \mathrm{h}$ & 4,7 & 0,71 & 28,5 & 0,14 & 23,8 & 0,85 \\
\hline$V_{C F 2}=70 \mathrm{~m} / \mathrm{h}$ & 4,7 & 0,71 & 27,9 & 0,14 & 23,2 & 0,00 \\
\hline$V_{C F 3}=100 \mathrm{~m} / \mathrm{h}$ & 4,1 & 1,56 & 27,2 & 0,57 & 23,1 & 0,99 \\
\hline$V_{\text {CF4 }}=150 \mathrm{~m} / \mathrm{h}$ & 4 & 1,13 & 27,7 & 1,84 & 23,7 & 2,97 \\
\hline$V_{C F 5}=200 \mathrm{~m} / \mathrm{h}$ & 3,2 & 0,57 & 27,2 & 0,28 & 24 & 0,85 \\
\hline$V_{C F 6}=250 \mathrm{~m} / \mathrm{h}$ & 2,2 & 2,26 & 28,6 & 0,28 & 26,4 & 1,98 \\
\hline $\mathrm{V}_{\mathrm{CF7}}=350 \mathrm{~m} / \mathrm{h}$ & 3,3 & 0,14 & 26,2 & 0,28 & 22,9 & 0,42 \\
\hline$V_{C F 8}=630 \mathrm{~m} / \mathrm{h}$ & 2,5 & 0,14 & 27,1 & 0,99 & 24,6 & 1,13 \\
\hline
\end{tabular}

Analisando a Tabela 5.10, observa-se que a produção de lodo situou-se em torno de $24 \mathrm{~g} / \mathrm{m}^{3}$ de água tratada para todas as Velocidades Cross-flow analisadas.

Analisando o Ensaio 1 da Etapa 2, em todas as Velocidades Cross-Flow analisadas foram obtidos resultados satisfatórios, mostrando sempre uma remoção constante dos parâmetros analisados durante o monitoramento dos mesmos. $\mathrm{O}$ valor positivo relativamente alto de potencial zeta apresentado na água coagulada, resultou em uma ligação entre floco+bolha estável, que mesmo em condições de alta turbulência $\left(\mathrm{V}_{\mathrm{CF}}\right.$ muito alto) a remoção foi satisfatória. 


\subsubsection{Ensaio 2: Potencial Zeta próximo de zero e TAS na Zona de Separação igual a $7,67 \mathrm{~m} / \mathrm{h}$ :}

Foram mantidos fixos os seguintes parâmetros para realização do Ensaio 2 da ETAPA 2 (Tabela 5.11):

Tabela 5.11: Parâmetros para realização do Ensaio 2 na Instalação Piloto de Flotação por Ar Dissolvido da ETAPA 2:

\begin{tabular}{cc}
\hline Parâmetros & Valores \\
\hline Velocidade na Zona de contato $(\mathbf{m} / \mathbf{h})$ & 180 \\
\hline Tempo de contato $(\mathbf{s})$ & 34 \\
\hline TAS zona de separação $(\mathbf{m} / \mathbf{h})$ & 7,67 \\
\hline Recirculação $(\boldsymbol{\%})$ & 10 \\
\hline Dosagem de coagulante $(\mathbf{m g} / \mathbf{L})$ & 22,5 \\
\hline Gradiente de floculação $\left(\mathbf{s}^{-1}\right)$ & 90 \\
\hline Tempo de floculação $\left(\mathbf{m i n}^{\mathbf{1}}\right)$ & 12 \\
\hline Vazão de entrada $\left(\mathbf{m}^{\mathbf{3}} / \mathbf{h}\right)$ & 4,6 \\
\hline
\end{tabular}

A caracterização da água bruta é mostrada na Tabela 5.12:

Tabela 5.12: Caracterização da Água I do Ensaio 2 da ETAPA 2

\begin{tabular}{ccccccc}
\hline Amostras & $\mathbf{p H}$ & $\begin{array}{c}\text { Alcalinidade }(\mathbf{m g} / \mathbf{L} \\
\left.\mathbf{C a C O}_{3}\right)\end{array}$ & $\begin{array}{c}\text { Condutividade } \\
(\mu \mathbf{s} / \mathbf{c m})\end{array}$ & $\begin{array}{c}\text { Turbidez } \\
(\mathbf{N T U})\end{array}$ & $\begin{array}{c}\text { Cor } \\
(\mathrm{UH})\end{array}$ & $\begin{array}{c}\text { SST } \\
(\mathbf{m g} / \mathbf{L})\end{array}$ \\
\hline Bruta & 6,52 & 37,0 & 70,2 & 7,27 & 45 & 11,5 \\
\hline Poço & 6,38 & 37,0 & 54,3 & 0,51 & 1 & - \\
\hline
\end{tabular}

Caracterização da água coagulada é apresentada na Tabela 5.13:

Tabela 5.13: Caracterização da água coagulada do ensaio 2 da ETAPA 2, para dosagem de Sulfato de Alumínio de 22,5 mg/L.

\begin{tabular}{cc}
\hline \multicolumn{2}{c}{ Água Coagulada } \\
\hline Parâmetros & Valores \\
\hline Potencial Zeta $(\mathrm{mV})$ & $0,2 \pm 2$ \\
\hline Temperatura $\left({ }^{\circ} \mathrm{C}\right)$ & 25,5 \\
\hline pH da água coagulada & 6,39 \\
\hline Condutividade $(\mu \mathrm{S} / \mathrm{cm})$ & 113,4 \\
\hline
\end{tabular}


As coletas foram realizadas respeitando um intervalo de 20 minutos para cada mudança da Velocidade Cross-flow para estabilização do sistema de flotação. Cada coleta de amostra pontual foi feita de 10 em 10 minutos. Após análise das amostras pontuais foram feitas amostras compostas, assim como descrito em Material e Métodos. Os resultados foram os seguintes:

As velocidades Cross-flow analisadas são apresentadas na Tabela 5.14:

Tabela 5.14: Velocidades Cross-flow analisadas no Ensaio 2 da ETAPA 2

\begin{tabular}{c|c}
\hline \multicolumn{2}{c}{ Velocidade Cross-flow $(\mathrm{m} / \mathrm{h})$} \\
\hline $\mathrm{V}_{\mathrm{CF} 1}$ & 40 \\
\hline $\mathrm{V}_{\mathrm{CF} 2}$ & 70 \\
\hline $\mathrm{V}_{\mathrm{CF} 3}$ & 100 \\
\hline $\mathrm{V}_{\mathrm{CF} 4}$ & 150 \\
\hline $\mathrm{V}_{\mathrm{CF5}}$ & 350 \\
\hline $\mathrm{V}_{\mathrm{CF} 6}$ & 630 \\
\hline
\end{tabular}

Os valores de Turbidez, Cor, ABS $254 \mathrm{~nm}$ e COT das amostras compostas do Ensaio 2 são apresentadas na Tabela 5.15:

Tabela 5.15: Resultados das análises das amostras compostas do Ensaio 2 da ETAPA 2

\begin{tabular}{|c|c|c|c|c|c|c|}
\hline Amostras & Turbidez (NTU) & $\begin{array}{l}\text { Cor } \\
\text { (UH) }\end{array}$ & $\begin{array}{c}\text { ABS } 254 \\
n m\end{array}$ & $\begin{array}{c}\text { COT } \\
(\mathrm{mg} / \mathrm{L}) \\
\end{array}$ & S.D.* & $\begin{array}{c}C^{C . V_{.}^{* \star}} \\
(\%)\end{array}$ \\
\hline$V_{C F 1}=40 \mathrm{~m} / \mathrm{h}$ & 0,84 & 2 & 0,003 & 3,969 & 0,031 & $0,78 \%$ \\
\hline $\mathrm{V}_{\mathrm{CF} 2}=70 \mathrm{~m} / \mathrm{h}$ & 0,90 & 2 & 0,001 & 3,798 & 0,098 & $2,59 \%$ \\
\hline$V_{C F 3}=100 \mathrm{~m} / \mathrm{h}$ & 0,98 & 2 & 0,004 & 3,891 & 0,077 & $1,99 \%$ \\
\hline$V_{C F 4}=150 \mathrm{~m} / \mathrm{h}$ & 1,24 & 3 & 0,005 & 3,946 & 0,054 & $1,37 \%$ \\
\hline$V_{\text {CF5 }}=350 \mathrm{~m} / \mathrm{h}$ & 1,21 & 3 & 0,004 & 3,971 & 0,017 & $0,43 \%$ \\
\hline$V_{\text {CF6 }}=630 \mathrm{~m} / \mathrm{h}$ & 1,24 & 3 & 0,003 & 3,955 & 0,030 & $0,78 \%$ \\
\hline Bruta & 7,27 & 45 & 0,045 & 4,423 & 0,065 & $1,47 \%$ \\
\hline
\end{tabular}

S.D.* - Desvio Padrão.

C.V.** - Coeficiente de variância. 


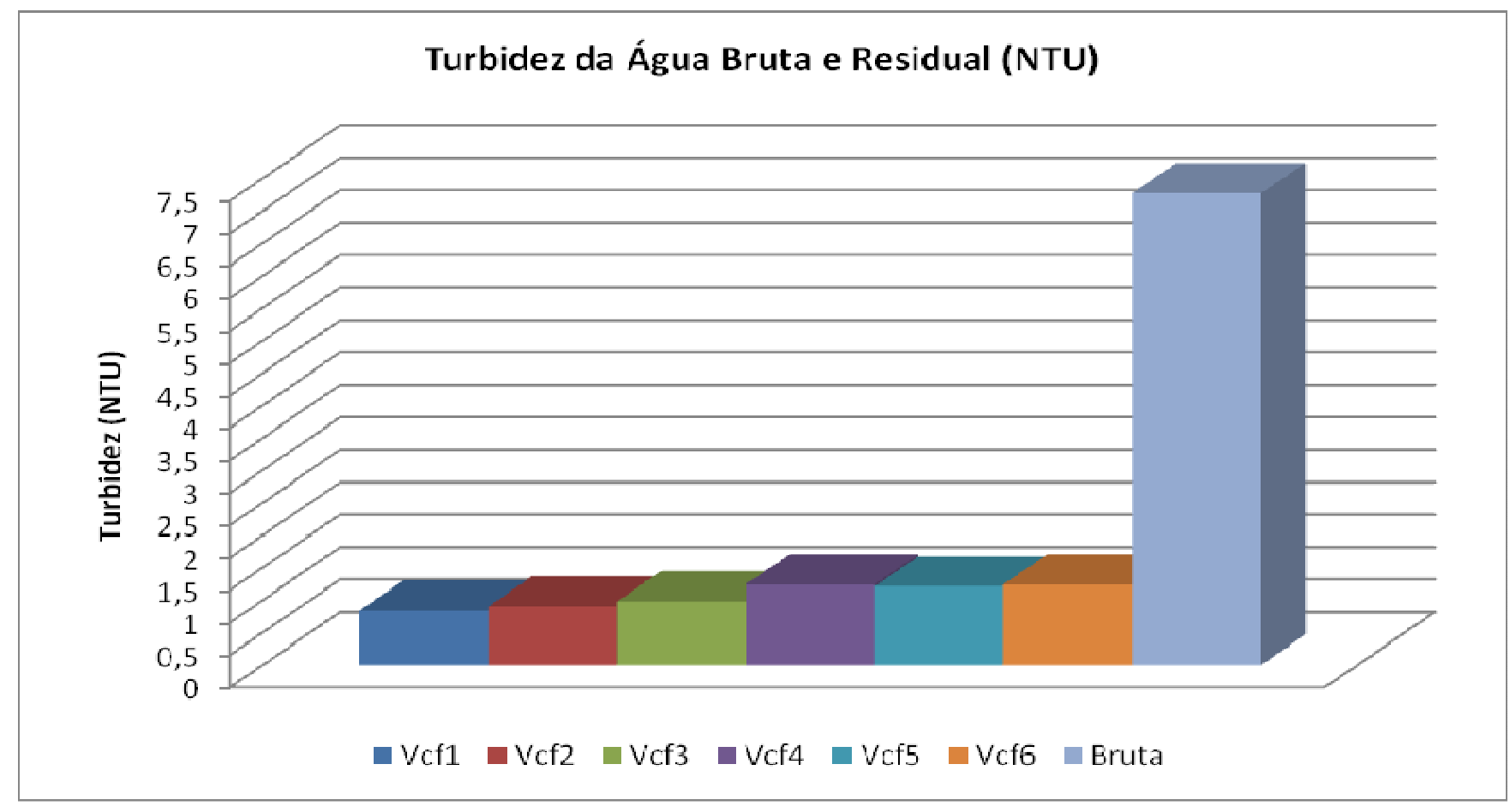

Figura 5.8: Turbidez Residual (NTU) - Ensaio 2 - ETAPA 2. DSA = 22,5 mg/L; PZ = $+0,2 \pm 0,2 ; \mathrm{G}_{\mathrm{F}}=90 \mathrm{~s}^{-1} ; \mathrm{T}_{\mathrm{F}}=12$ minutos; $\mathrm{T}_{\mathrm{R}}=10 \% ; \mathrm{P}_{\mathrm{SAT}}=4,5$ bar; Variação de $\mathrm{V}_{\mathrm{CF}}$ : $40 ; 70 ; 100 ; 150 ; 350$ e $630 \mathrm{~m} / \mathrm{h}$; TAS $_{\mathrm{ZS}}=7,67 \mathrm{~m} / \mathrm{h} ; \mathrm{Q}_{\mathrm{ent}}=4,6 \mathrm{~m}^{3} / \mathrm{h} ; \mathrm{TAS}_{\mathrm{ZC}}=180 \mathrm{~m} / \mathrm{h}$; $\mathrm{T}_{\mathrm{ZC}}=34 \mathrm{~s}$.

Analisando a Figura 5.8, observa-se maior remoção da turbidez nas velocidades Cross-flow entre 40 e $100 \mathrm{~m} / \mathrm{h}$, com remoção em torno de 88 e $87 \%$, permanecendo com turbidez residual em torno de 0,9 NTU. Nas velocidades Cross-flow maiores, entre 150 e $630 \mathrm{~m} / \mathrm{h}$, percebe-se um acréscimo na turbidez residual, ficando em torno de 1,2 NTU, com remoção por volta de 83 \%. Assim, como relatado por Haarhoff et al (1995), Lundh et al (2002) e Edzwald (2007), a flotação obteve melhor eficiência nas velocidades Cross-flow analisadas entre 40 e $100 \mathrm{~m} / \mathrm{h}$, sendo que, acima destes valores de $V_{C F}$, verificou-se queda de eficiência. Isto se deveu, muito provavelmente, a um excesso de turbulência na região que interliga a zona de contato com a zona de separação (onde se é definida a velocidade Cross-flow) e conseqüente prejuízo na formação do desejado fluxo padrão estratificado na zona de separação, conforme 
preconizado por Lund et al (2000 e 2002), Reali e Patrizzi (2007) e Edswald (2007), prejudicando assim a eficiência da flotação.

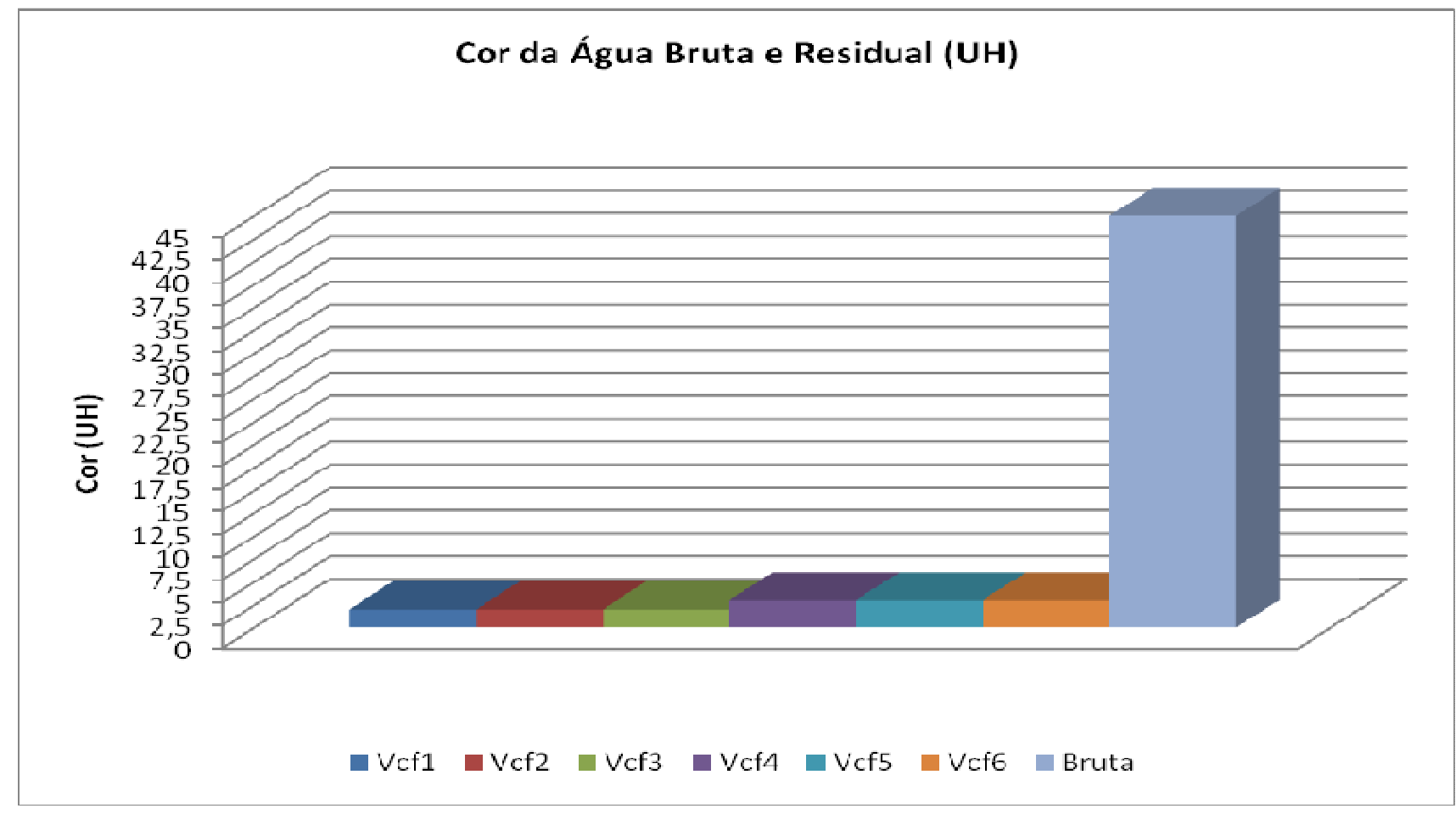

Figura 5.9: Cor Residual (UH) - Ensaio 2 - ETAPA 2. DSA $=22,5 \mathrm{mg} / \mathrm{L} ; \mathrm{PZ}=+0,2 \pm$ 0,$2 ; \mathrm{G}_{\mathrm{F}}=90 \mathrm{~s}^{-1} ; \mathrm{T}_{\mathrm{F}}=12$ minutos; $\mathrm{T}_{\mathrm{R}}=10 \% ; \mathrm{P}_{\mathrm{SAT}}=4,5$ bar; Variação de $\mathrm{V}_{\mathrm{CF}}: 40 ; 70$; $100 ; 150 ; 350$ e $630 \mathrm{~m} / \mathrm{h}$; TAS $_{\mathrm{ZS}}=7,67 \mathrm{~m} / \mathrm{h} ; \mathrm{Q}_{\mathrm{ent}}=4,6 \mathrm{~m}^{3} / \mathrm{h} ; \mathrm{TAS}_{\mathrm{ZC}}=180 \mathrm{~m} / \mathrm{h} ; \mathrm{T}_{\mathrm{ZC}}=$ $34 \mathrm{~s}$.

Na remoção de cor, foi observada melhor remoção nas velocidades Cross-Flow entre 40 e $100 \mathrm{~m} / \mathrm{h}$, ficando com remoção de $96 \%$, permanecendo com cor residual de 2 UH. Nas demais velocidades Cross-Flow houve pequeno acréscimo na cor residual, resultando em efluente final flotado com 3 UH (remoção de $93 \%$ ). Isto se deve, muito provavelmente, a não formação do fluxo padrão estratificado na zona de separação, como relatado por Lundh et al (2002), Haarhoff et al (1995), Edzwald (2007) e Reali e Patrizzi (2007), em que a eficiência da flotação fica prejudicada, devido ao maior carreamento de flocos ao efluente final flotado. 


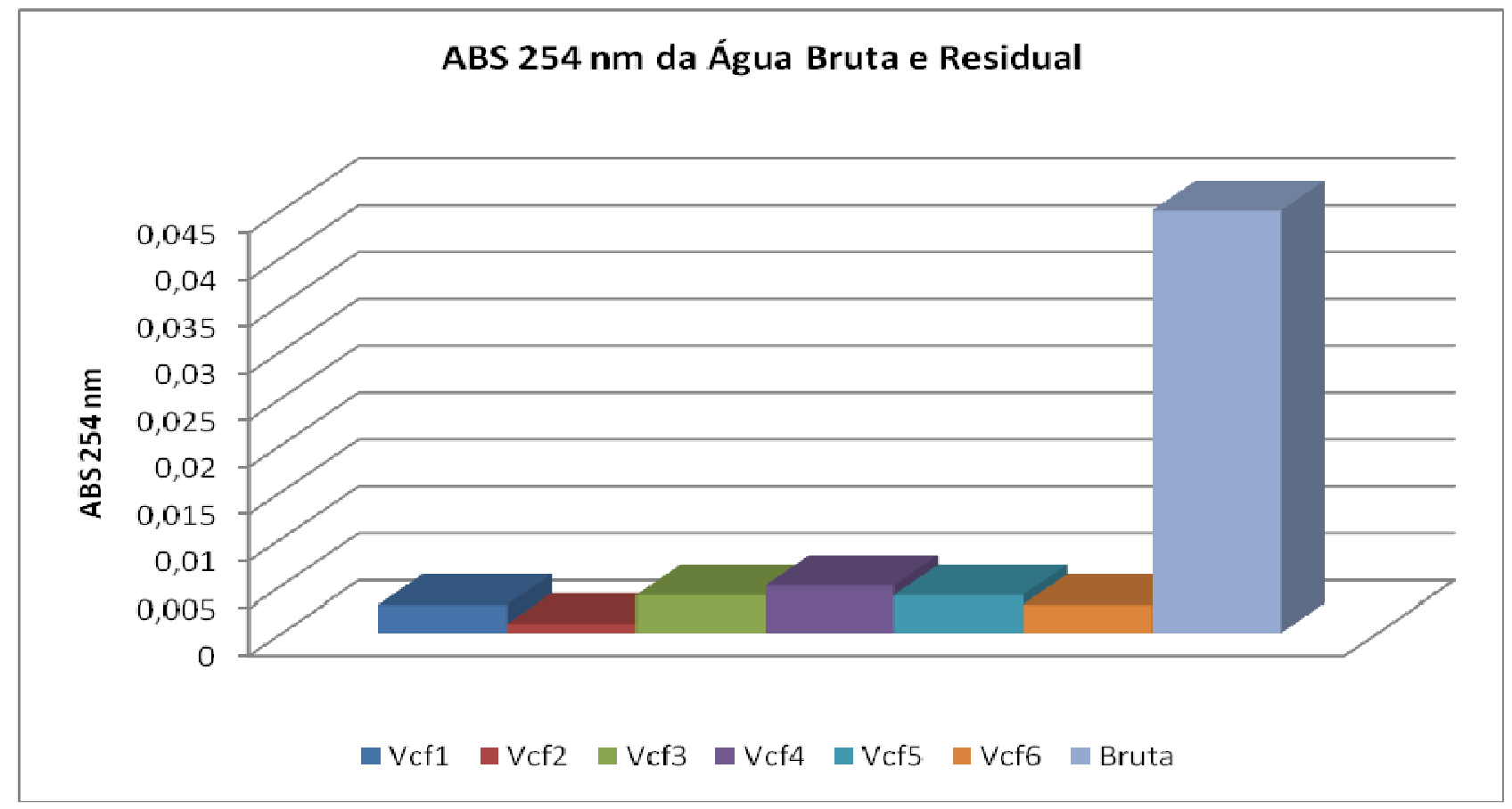

Figura 5.10: ABS $254 \mathrm{~nm}$ residual - Ensaio 2 - ETAPA 2. DSA = 22,5 mg/L; PZ = $+0,2 \pm 0,2 ; \mathrm{G}_{\mathrm{F}}=90 \mathrm{~s}^{-1} ; \mathrm{T}_{\mathrm{F}}=12$ minutos; $\mathrm{T}_{\mathrm{R}}=10 \% ; \mathrm{P}_{\mathrm{SAT}}=4,5$ bar; Variação de $\mathrm{V}_{\mathrm{CF}}$ : $40 ; 70 ; 100 ; 150 ; 350$ e $630 \mathrm{~m} / \mathrm{h}$; TAS $_{\mathrm{ZS}}=7,67 \mathrm{~m} / \mathrm{h} ; \mathrm{Q}_{\mathrm{ent}}=4,6 \mathrm{~m}^{3} / \mathrm{h} ; \mathrm{TAS}_{\mathrm{ZC}}=180 \mathrm{~m} / \mathrm{h}$; $\mathrm{T}_{\mathrm{ZC}}=34 \mathrm{~s}$.

Na ABS $254 \mathrm{~nm}$ verificou-se uma remoção que variou entre 90 e $98 \%$ nas velocidades analisadas.

A determinação de Sólidos Suspensos Totais das amostras compostas foi realizada em triplicata, sendo que na Tabela 5.16 são apresentados os valores da média e do desvio padrão das referidas determinações.

Tabela 5.16: Resultados de SST da amostra flotada e floculada do Ensaio 2 da ETAPA 2.

\begin{tabular}{|c|c|c|c|c|c|c|}
\hline $\begin{array}{c}\text { Amostras } \\
\mathrm{V}_{\mathrm{CF} 1}=40 \mathrm{~m} / \mathrm{h}\end{array}$ & $\begin{array}{c}\text { SST Floculada } \\
\text { (mg/L) } \\
19,1\end{array}$ & $\begin{array}{c}\text { Desvio } \\
\text { padrão } \\
0,42\end{array}$ & $\begin{array}{c}\text { SST Flotada } \\
\text { (mg/L) } \\
3,2\end{array}$ & $\begin{array}{c}\text { Desvio } \\
\text { padrão } \\
0,40\end{array}$ & $\begin{array}{c}\text { Lodo Produzido } \\
\text { (mg/L) } \\
15,9\end{array}$ & $\begin{array}{c}\text { Desvio } \\
\text { padrão } \\
0,12\end{array}$ \\
\hline $\mathrm{V}_{\mathrm{CF} 2}=70 \mathrm{~m} / \mathrm{h}$ & 19,2 & 1,40 & 3,3 & 0,81 & 15,9 & 1,62 \\
\hline$V_{C F 3}=100 \mathrm{~m} / \mathrm{h}$ & 19,9 & 2,05 & 4,2 & 0,87 & 15,7 & 2,80 \\
\hline$V_{C F 4}=150 \mathrm{~m} / \mathrm{h}$ & 19,1 & 0,50 & 3,5 & 0,70 & 15,5 & 1,10 \\
\hline $\mathrm{V}_{\mathrm{CF} 5}=350 \mathrm{~m} / \mathrm{h}$ & 20,1 & 0,76 & 3,7 & 0,46 & 16,4 & 0,60 \\
\hline $\mathrm{V}_{\mathrm{CF} 6}=630 \mathrm{~m} / \mathrm{h}$ & 18,4 & 0,60 & 4,2 & 0,50 & 14,1 & 1,10 \\
\hline
\end{tabular}

Produção de lodo em torno de $16 \mathrm{~g} / \mathrm{m}^{3}$ nas velocidades Cross-flow analisadas. 
Analisando o ensaio 2 percebe-se que para potencial zeta neutro e uma TAS na zona de separação de $7,67 \mathrm{~m} / \mathrm{h}$ foi obtido eficiência satisfatória de remoção dos parâmetros monitorados nas velocidades Cross-flow de 40, 70 e $100 \mathrm{~m} / \mathrm{h}$, onde foram obtidos os melhores resultados referentes a remoção de turbidez e cor. Nas demais velocidades Cross-flow analisadas, 150,350 e $630 \mathrm{~m} / \mathrm{h}$, houve perda da eficiência na flotação, devido a principalmente a não formação do fluxo padrão estratificado, como relatado por Lundh et al (2002), Haarhoff et al (1995) e Edzwald (2007). A não ocorrência do fluxo padrão estratificado faz com que haja maior turbulência na zona de separação e, consequentemente, o possível rompimento da ligação floco+bolha, fazendo com que parte considerável dos flocos não seja removida, prejudicando a eficiência da flotação.

No ensaio 1 não ocorreu tal fato, devido ao alto valor do potencial zeta (em torno de $+13 \mathrm{mV}$ ). Tal potencial zeta positivo acarretou maior afinidade entre floco e bolha, pois a bolha, assim como relatado por Bratby (2006), possui potencial elétrico negativo, e o floco com potencial zeta positivo proporcionaram uma ligação mais forte e estável, onde mesmo com elevados valores de $\mathrm{V}_{\mathrm{CF}}$ houve a remoção eficiente dos agregados microbolhas/flocos formados na zona de contato que antecede à região onde se estabelece a $\mathrm{V}_{\mathrm{CF}}$. 


\subsubsection{Ensaio 3: Potencial Zeta positivo e TAS na Zona de Separação igual a $15 \mathrm{~m} / \mathrm{h}$ :}

Foram mantidos fixos os seguintes parâmetros para realização do Ensaio 3 da ETAPA 2 (Tabela 5.17):

Tabela 5.17: Parâmetros para realização do Ensaio 3 na Instalação Piloto de Flotação por Ar Dissolvido da ETAPA 2:

\begin{tabular}{cc}
\hline Parâmetros & Valores \\
\hline Velocidade na Zona de contato $(\mathbf{m} / \mathbf{h})$ & 180 \\
\hline Tempo de contato $(\mathbf{s})$ & 34 \\
\hline TAS zona de separação $(\mathbf{m} / \mathbf{h})$ & 15 \\
\hline Recirculação $(\boldsymbol{\%})$ & 10 \\
\hline Dosagem de coagulante $(\mathbf{m g} / \mathbf{L})$ & 42,5 \\
\hline Gradiente de floculação $\left(\mathbf{s}^{-1}\right)$ & 90 \\
\hline Tempo de floculação $\left(\mathbf{m i n}^{\mathbf{1}}\right)$ & 12 \\
\hline Vazão de entrada $\left(\mathbf{m}^{\mathbf{3}} / \mathbf{h}\right)$ & 4,6 \\
\hline
\end{tabular}

A caracterização da água bruta é apresentada na Tabela 5.18:

Tabela 5.18: Caracterização da Água I do Ensaio 3 da ETAPA 2

\begin{tabular}{|c|c|c|c|c|c|c|}
\hline Amostras & $\mathrm{pH}$ & $\begin{array}{c}\text { Alcalinidade }(\mathrm{mg} / \mathrm{L} \\
\mathrm{CaCO} 3)\end{array}$ & $\begin{array}{c}\text { Condutividade } \\
(\mu \mathrm{S} / \mathrm{cm})\end{array}$ & $\begin{array}{l}\text { Turbidez } \\
\text { (NTU) }\end{array}$ & $\begin{array}{l}\text { Cor } \\
\text { (UH) }\end{array}$ & $\begin{array}{c}\mathrm{SST} \\
(\mathrm{mg} / \mathrm{L})\end{array}$ \\
\hline Bruta & 6,61 & 27,2 & 86,2 & 7,15 & 41 & 8,3 \\
\hline Poço & 6,42 & 26,2 & 61,1 & 0,46 & 1 & - \\
\hline
\end{tabular}

Caracterização da água coagulada é apresentada na Tabela 5.19:

Tabela 5.19: Caracterização da água coagulada do ensaio 3 da ETAPA 2, para dosagem de Sulfato de Alumínio de 42,5 mg/L.

\begin{tabular}{cc}
\hline \multicolumn{2}{c}{ Água Coagulada } \\
\hline Parâmetros & Valores \\
\hline Potencial Zeta $(\mathrm{mV})$ & $10,3 \pm 0,5$ \\
\hline Temperatura $\left({ }^{\circ} \mathrm{C}\right)$ & 26 \\
\hline $\mathrm{pH}$ da água coagulada & 6,25 \\
\hline Condutividade $(\mu \mathrm{S} / \mathrm{cm})$ & 134,9 \\
\hline
\end{tabular}


As coletas foram realizadas respeitando um intervalo de 20 minutos para cada mudança da Velocidade Cross-flow para estabilização do sistema de flotação. Cada coleta de amostra pontual foi feita de 10 em 10 minutos. Após análise das amostras pontuais foram feitas amostras compostas, assim como descrito em Material e Métodos. Os resultados foram os seguintes:

As velocidades Cross-flow analisadas são apresentadas na Tabela 5.20:

Tabela 5.20: Velocidades Cross-flow analisadas no Ensaio 3 da ETAPA 2

\begin{tabular}{c|c}
\hline \multicolumn{2}{c}{ Velocidade Cross-flow $(\mathrm{m} / \mathrm{h})$} \\
\hline $\mathrm{V}_{\mathrm{CF} 1}$ & 40 \\
\hline $\mathrm{V}_{\mathrm{CF} 2}$ & 70 \\
\hline $\mathrm{V}_{\mathrm{CF} 3}$ & 100 \\
\hline $\mathrm{V}_{\mathrm{CF} 4}$ & 150 \\
\hline $\mathrm{V}_{\mathrm{CF5}}$ & 350 \\
\hline $\mathrm{V}_{\mathrm{CF} 6}$ & 630 \\
\hline
\end{tabular}

Os valores de Turbidez, Cor, ABS 254 nm e COT das amostras compostas do Ensaio 3 são apresentadas na Tabela 5.21:

Tabela 5.21: Resultados das análises das amostras compostas do Ensaio 3 da ETAPA 2.

\begin{tabular}{|c|c|c|c|c|c|c|}
\hline Amostras & Turbidez (NTU) & $\begin{array}{l}\text { Cor } \\
\text { (UH) }\end{array}$ & $\begin{array}{c}\text { ABS } 254 \\
n m\end{array}$ & $\begin{array}{c}\text { COT } \\
\text { (mg/L) }\end{array}$ & S.D. & C.V. (\%) \\
\hline $\mathrm{V}_{\mathrm{CF} 1}=40 \mathrm{~m} / \mathrm{h}$ & 1,40 & 3 & 0,011 & 3,465 & 0,074 & $2,13 \%$ \\
\hline $\mathrm{V}_{\mathrm{CF} 2}=70 \mathrm{~m} / \mathrm{h}$ & 1,14 & 3 & 0,01 & 3,406 & 0,049 & $1,43 \%$ \\
\hline$V_{C F 3}=100 \mathrm{~m} / \mathrm{h}$ & 1,31 & 3 & 0,01 & 4,233 & 0,078 & $1,85 \%$ \\
\hline$V_{C F 4}=150 \mathrm{~m} / \mathrm{h}$ & 1,17 & 5 & 0,009 & 4,145 & 0,058 & $1,41 \%$ \\
\hline$V_{\text {CF5 }}=350 \mathrm{~m} / \mathrm{h}$ & 1,05 & 3 & 0,009 & 3,888 & 0,024 & $0,61 \%$ \\
\hline$V_{\mathrm{CF} 6}=630 \mathrm{~m} / \mathrm{h}$ & 1,24 & 5 & 0,013 & 4,255 & 0,090 & $2,13 \%$ \\
\hline Bruta & 7,15 & 41 & 0,053 & 3,82 & 0,039 & $1,03 \%$ \\
\hline
\end{tabular}




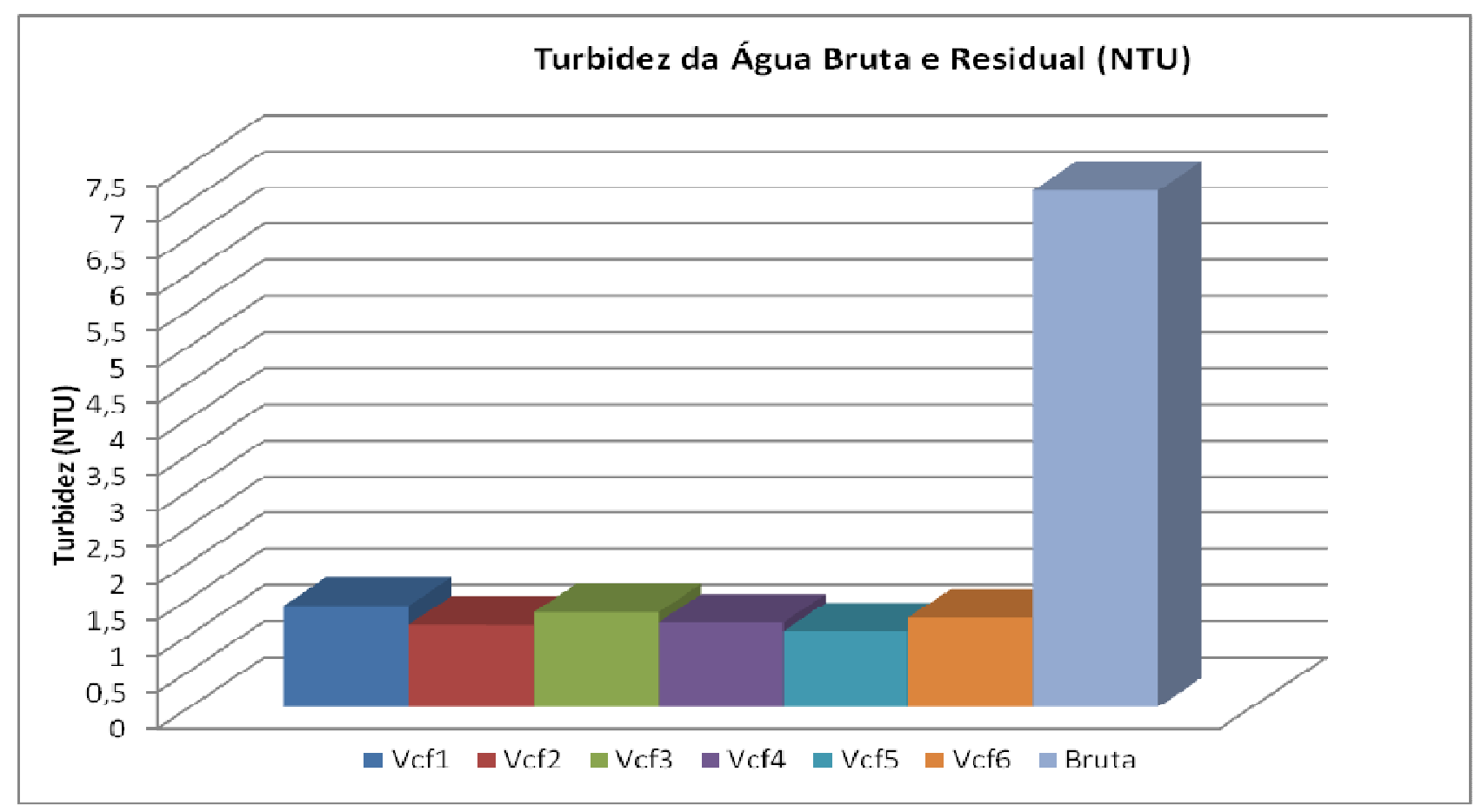

Figura 5.11: Turbidez Residual (NTU) - Ensaio 3 - ETAPA 2. DSA = 42,5 mg/L; PZ = $+10,3 \pm 0,5 ; \mathrm{G}_{\mathrm{F}}=90 \mathrm{~s}^{-1} ; \mathrm{T}_{\mathrm{F}}=12$ minutos; $\mathrm{T}_{\mathrm{R}}=10 \% ; \mathrm{P}_{\mathrm{SAT}}=4,5$ bar; Variação de $\mathrm{V}_{\mathrm{CF}}$ : $40 ; 70 ; 100 ; 150 ; 350$ e $630 \mathrm{~m} / \mathrm{h}$.; TAS $\mathrm{ZS}=15 \mathrm{~m} / \mathrm{h} ; \mathrm{Q}_{\mathrm{ent}}=4,6 \mathrm{~m} / \mathrm{h} ; \mathrm{TAS}_{\mathrm{ZC}}=180 \mathrm{~m} / \mathrm{h}$; $\mathrm{T}_{\mathrm{ZC}}=34 \mathrm{~s}$.

Analisando a Figura 5.11, observa-se que a remoção de turbidez nas velocidades Cross-Flow analisadas foram praticamente as mesmas, variando a remoção entre 80 e $85 \%$, permanecendo com turbidez residual entre 1,05 NTU $\left(\mathrm{V}_{\mathrm{CF} 5}\right)$ e $1,4 \mathrm{NTU}\left(\mathrm{V}_{\mathrm{CF} 1}\right)$. Assim, mesmo em condições adversas de escoamento, ou seja, imposição de valores bastante elevados de $\mathrm{V}_{\mathrm{CF}}$ na saída da zona de contato, a remoção de turbidez foi satisfatória. Esta remoção, muito provavelmente, foi devida ao alto valor do potencial zeta (por volta de $+10 \mathrm{mV}$ ), que fez com que a ligação entre floco+bolha se tornasse mais forte e estável e assim a eficiência de remoção não fosse afetada. 




Figura 5.12: Cor Residual (UH) - Ensaio 3 - ETAPA 2. DSA = 42,5 mg/L; PZ = $+10,3 \pm 0,5 ; \mathrm{G}_{\mathrm{F}}=90 \mathrm{~s}^{-1} ; \mathrm{T}_{\mathrm{F}}=12$ minutos; $\mathrm{T}_{\mathrm{R}}=10 \% ; \mathrm{P}_{\mathrm{SAT}}=4,5$ bar; Variação de $\mathrm{V}_{\mathrm{CF}}$ : $40 ; 70 ; 100 ; 150 ; 350$ e $630 \mathrm{~m} / \mathrm{h} . ; \mathrm{TAS}_{\mathrm{ZS}}=15 \mathrm{~m} / \mathrm{h} ; \mathrm{Q}_{\mathrm{ent}}=4,6 \mathrm{~m} / \mathrm{h} ; \mathrm{TAS}_{\mathrm{ZC}}=180 \mathrm{~m} / \mathrm{h}$; $\mathrm{T}_{\mathrm{ZC}}=34 \mathrm{~s}$.

O mesmo ocorreu na remoção de cor, situando em uma faixa de remoção entre 88 e $93 \%$, com cor residual entre 3 UH e 5 UH (Figura 5.12). Esta alta eficiência de remoção vem associada ao potencial zeta positivo, que mesmo em condições de $V_{\mathrm{CF}}$ altos, a remoção foi satisfatória. 




Figura 5.13: ABS $254 \mathrm{~nm}$ residual - Ensaio 3 -ETAPA 2. DSA = 42,5 mg/L; PZ = $+10,3 \pm 0,5 ; \mathrm{G}_{\mathrm{F}}=90 \mathrm{~s}^{-1} ; \mathrm{T}_{\mathrm{F}}=12$ minutos; $\mathrm{T}_{\mathrm{R}}=10 \% ; \mathrm{P}_{\mathrm{SAT}}=4,5$ bar; Variação de $\mathrm{V}_{\mathrm{CF}}$ : $40 ; 70 ; 100 ; 150 ; 350$ e $630 \mathrm{~m} / \mathrm{h} . ; \mathrm{TAS}_{\mathrm{ZS}}=15 \mathrm{~m} / \mathrm{h} ; \mathrm{Q}_{\mathrm{ent}}=4,6 \mathrm{~m} / \mathrm{h} ; \mathrm{TAS}_{\mathrm{ZC}}=180 \mathrm{~m} / \mathrm{h}$; $\mathrm{T}_{\mathrm{ZC}}=34 \mathrm{~s}$.

Com a ABS 254 nm não foi diferente. Houve remoção de ABS 254 nm com valores muito próximos uns dos outros para as velocidades Cross-flow analisadas (entre 75 e $83 \%$ de remoção), tudo isso devido ao alto valor do potencial zeta, ocasionando uma ligação entre floco+bolha mais forte e estável.

A determinação de Sólidos Suspensos Totais das amostras compostas foi realizada em triplicata, sendo que na Tabela 5.22 são apresentados os valores da média e do desvio padrão das referidas determinações. 
Tabela 5.22: Resultados de SST da amostra flotada e floculada do Ensaio 3 da ETAPA2.

\begin{tabular}{|c|c|c|c|c|c|c|}
\hline Amostras & $\begin{array}{l}\text { SST Floculada } \\
\text { (mg/L) }\end{array}$ & $\begin{array}{l}\text { Desvio } \\
\text { Padrão }\end{array}$ & $\begin{array}{l}\text { SST Flotada } \\
\text { (mg/L) }\end{array}$ & $\begin{array}{l}\text { Desvio } \\
\text { Padrão }\end{array}$ & $\begin{array}{l}\text { Lodo Produzido } \\
\text { (mg/L) }\end{array}$ & $\begin{array}{l}\text { Desvio } \\
\text { Padrão }\end{array}$ \\
\hline $\mathrm{V}_{\mathrm{CF} 1}=40 \mathrm{~m} / \mathrm{h}$ & 27,9 & 0,42 & 4,1 & 0,58 & 23,8 & 0,80 \\
\hline $\mathrm{V}_{\mathrm{CF} 2}=70 \mathrm{~m} / \mathrm{h}$ & 28,7 & 0,46 & 4,6 & 0,40 & 24,1 & 0,83 \\
\hline$V_{C F 3}=100 \mathrm{~m} / \mathrm{h}$ & 27,4 & 2,69 & 4,5 & 0,42 & 22,9 & 2,27 \\
\hline$V_{C F 4}=150 \mathrm{~m} / \mathrm{h}$ & 28,8 & 1,44 & 4,7 & 0,42 & 24,1 & 1,50 \\
\hline$V_{\text {CF5 }}=350 \mathrm{~m} / \mathrm{h}$ & 28,7 & 0,46 & 4,5 & 0,64 & 24,1 & 0,64 \\
\hline$V_{C F 6}=630 \mathrm{~m} / \mathrm{h}$ & 27,6 & 0,60 & 4,6 & 0,72 & 23,0 & 1,22 \\
\hline
\end{tabular}

A produção de lodo no Ensaio 3 situou-se na ordem de $24 \mathrm{~kg} / \mathrm{m}^{3}$ da água tratada.

Assim como ocorrido no ensaio 1, o ensaio 3, (mesmo com TAS na zona de separação de $15 \mathrm{~m} / \mathrm{h}$, o dobro da TAS na zona de separação analisada no ensaio 1), permaneceu com remoções altas de turbidez, cor e ABS $254 \mathrm{~nm}$ em todas as velocidades. Este fato é devido ao valor do potencial zeta positivo (em torno de +10 $\mathrm{mV}$ ) fazendo com que a ligação entre floco+bolha ficasse mais forte e estável, devido ao fato das bolhas possuírem carga elétrica negativa. Esta ligação mais forte e estável entre floco+bolha fez que mesmo em condições de $\mathrm{V}_{\mathrm{CF}}$ altos, a remoção de turbidez, cor e ABS 254 nm fosse satisfatória. Já em relação à TAS aplicada na zona de separação no ensaio 3, ocorreu uma diminuição da eficiência da flotação pelo fato da TAS aplicada ser o dobro em relação aos ensaios 1 e 2. Isso fez com que ocorresse maior carreamento de flocos ao efluente final e assim ligeira piora na qualidade do efluente clarificado. 


\subsubsection{Ensaio 4: Potencial Zeta próximo de zero e TAS na Zona de Separação igual a $15 \mathrm{~m} / \mathrm{h}$ :}

Foram mantidos fixos os seguintes parâmetros para realização do Ensaio 4 da ETAPA 2 (Tabela 5.23):

Tabela 5.23: Parâmetros para realização do Ensaio 4 na Instalação Piloto de Flotação por Ar Dissolvido da ETAPA 2:

\begin{tabular}{cc}
\hline Parâmetros & Valores \\
\hline Velocidade na Zona de contato $(\mathbf{m} / \mathbf{h})$ & 180 \\
\hline Tempo de contato $(\mathbf{s})$ & 34 \\
\hline TAS zona de separação $(\mathbf{m} / \mathbf{h})$ & 15 \\
\hline Recirculação $(\%)$ & 10 \\
\hline Dosagem de coagulante $(\mathbf{m g} / \mathbf{L})$ & 22,5 \\
\hline Gradiente de floculação $\left(\mathbf{s}^{-1}\right)$ & 90 \\
\hline Tempo de floculação $\left(\mathbf{m i n}^{\mathbf{1}}\right)$ & 12 \\
\hline Vazão de entrada $\left(\mathbf{m}^{\mathbf{3}} / \mathbf{h}\right)$ & 4,6 \\
\hline
\end{tabular}

A caracterização da água bruta é apresentada na Tabela 5.24:

Tabela 5.24: Caracterização da Água I do Ensaio 4 da ETAPA 2

\begin{tabular}{ccccccc}
\hline Amostras & pH & $\begin{array}{c}\text { Alcalinidade }(\mathbf{m g} / \mathbf{L} \\
\text { CaCO3) }\end{array}$ & $\begin{array}{c}\text { Condutividade } \\
(\mu \mathrm{S} / \mathbf{c m})\end{array}$ & $\begin{array}{c}\text { Turbidez } \\
(\text { NTU) }\end{array}$ & $\begin{array}{c}\text { Cor } \\
(\mathrm{UH})\end{array}$ & $\begin{array}{c}\text { SST } \\
(\mathbf{m g} / \mathbf{L})\end{array}$ \\
\hline Bruta & 6,72 & 26,7 & 82 & 7,2 & 43 & 8,7 \\
\hline Poço & 6,51 & 25,7 & 58 & 0,5 & 1 & - \\
\hline
\end{tabular}

Caracterização da água coagulada é apresentada na Tabela 5.25:

Tabela 5.25: Caracterização da água coagulada do ensaio 3 da ETAPA 2, para dosagem de Sulfato de Alumínio de 22,5 mg/L.

\begin{tabular}{cc}
\hline \multicolumn{2}{c}{ Água Coagulada } \\
\hline Parâmetros & Valores \\
\hline Potencial Zeta $(\mathrm{mV})$ & $0,3 \pm 02$ \\
\hline Temperatura $\left({ }^{\circ} \mathrm{C}\right)$ & 27 \\
\hline $\mathrm{pH}$ da água coagulada & 6,35 \\
\hline Condutividade $(\mu \mathrm{S} / \mathrm{cm})$ & 103 \\
\hline
\end{tabular}


Para estabilização do sistema, a coleta do efluente flotado e floculado, para cada variação de $\mathrm{V}_{\mathrm{CF}}$ aplicada na saída da zona de contato da unidade piloto de flotação, respeitou-se um intervalo de 20 minutos para que procedesse a coleta da primeira amostra. Cada coleta de amostra pontual foi feita de 10 em 10 minutos, após a espera de 20 minutos para estabilização do sistema de FAD. Cada ensaio durou em média 1h e 30min. Após análise das amostras pontuais foram feitas amostras compostas, assim como descrito em Material e Métodos. Os resultados foram os seguintes:

As velocidades Cross-flow analisadas são apresentadas na Tabela 5.26:

Tabela 5.26: Velocidades Cross-flow analisadas no Ensaio 4 da ETAPA 2

\begin{tabular}{c|c}
\hline \multicolumn{2}{c}{ Velocidade Cross-flow $(\boldsymbol{m} / \mathbf{h})$} \\
\hline $\mathrm{V}_{\mathrm{CF} 1}$ & 40 \\
\hline $\mathrm{V}_{\mathrm{CF} 2}$ & 70 \\
\hline $\mathrm{V}_{\mathrm{CF} 3}$ & 100 \\
\hline $\mathrm{V}_{\mathrm{CF} 4}$ & 150 \\
\hline $\mathrm{V}_{\mathrm{CF5}}$ & 350 \\
\hline $\mathrm{V}_{\mathrm{CF} 6}$ & 630 \\
\hline
\end{tabular}

Os valores de Turbidez, Cor, ABS 254 nm e COT das amostras compostas do Ensaio 4 são apresentadas na Tabela 5.27:

Tabela 5.27: Resultados das análises das amostras compostas do Ensaio 4 da ETAPA 2.

\begin{tabular}{cccc}
\hline Amostras & Turbidez (NTU) & $\begin{array}{c}\text { Cor } \\
(\mathbf{U H})\end{array}$ & $\begin{array}{c}\text { ABS 254 } \\
\mathbf{n m}\end{array}$ \\
\hline $\mathbf{V}_{\mathrm{CF} 1}=\mathbf{4 0 ~} \mathbf{~} / \mathbf{h}$ & 1,45 & 6 & 0,01 \\
\hline $\mathbf{V}_{\mathrm{CF} 2}=\mathbf{7 0} \mathbf{~} / \mathbf{h}$ & 1,36 & 6 & 0,01 \\
\hline $\mathbf{V}_{\mathrm{CF} 3}=\mathbf{1 0 0} \mathbf{~} / \mathbf{h}$ & 1,52 & 6 & 0,013 \\
\hline $\mathbf{V}_{\mathrm{CF} 4}=\mathbf{1 5 0} \mathbf{~} / \mathbf{h}$ & 1,48 & 6 & 0,012 \\
\hline $\mathbf{V}_{\mathrm{CF5}}=\mathbf{3 5 0} \mathbf{~} / \mathbf{h}$ & 1,43 & 6 & 0,01 \\
\hline $\mathbf{V}_{\mathrm{CF} 6}=\mathbf{6 3 0} \mathbf{~} / \mathbf{h}$ & 4,20 & 22 & 0,033 \\
\hline Bruta & 7,20 & 43 & 0,048 \\
\hline
\end{tabular}






Figura 5.14: Turbidez Residual (NTU) - Ensaio 4 - ETAPA 2. DSA = 22,5 mg/L; PZ = $+0,3 \pm 0,2 ; \mathrm{G}_{\mathrm{F}}=90 \mathrm{~s}^{-1} ; \mathrm{T}_{\mathrm{F}}=12$ minutos; $\mathrm{T}_{\mathrm{R}}=10 \% ; \mathrm{P}_{\mathrm{SAT}}=4,5$ bar; Variação de $\mathrm{V}_{\mathrm{CF}}$ : $40 ; 70 ; 100 ; 150 ; 350$ e $630 \mathrm{~m} / \mathrm{h}$; TAS $_{\mathrm{ZS}}=15 \mathrm{~m} / \mathrm{h} ; \mathrm{Q}_{\mathrm{ent}}=4,6 \mathrm{~m}^{3} / \mathrm{h} ; \mathrm{TAS}_{\mathrm{ZC}}=180 \mathrm{~m} / \mathrm{h}$; $\mathrm{T}_{\mathrm{ZC}}=34 \mathrm{~s}$.

Analisando a Figura 5.14 do ensaio 4 da etapa 2 é notada que a remoção de turbidez se deu satisfatória entre as velocidades Cross-flow analisadas de 40 e $350 \mathrm{~m} / \mathrm{h}$, ficando com remoção entre 79 e $81 \%$ de turbidez (turbidez residual entre 1,35 NTU e 1,5 NTU) . Na $\mathrm{V}_{\mathrm{CF} 6}$ de $630 \mathrm{~m} / \mathrm{h}$ houve uma piora significativa na remoção, havendo remoção de apenas $42 \%$ da turbidez (turbidez residual de 4,2 NTU). Esta alta na turbidez residual observada na velocidade Cross-Flow de $630 \mathrm{~m} / \mathrm{h}$ é devido a não formação do fluxo estratificado padrão, fazendo com que a remoção de turbidez fosse prejudicada, sendo carreado muitos flocos em suspensão ao efluente flotado. 




Figura 5.15: Cor Residual (UH) - Ensaio 4 - ETAPA 2. DSA = 22,5 mg/L; PZ = +0,3 \pm 0,$2 ; \mathrm{G}_{\mathrm{F}}=90 \mathrm{~s}^{-1} ; \mathrm{T}_{\mathrm{F}}=12$ minutos; $\mathrm{T}_{\mathrm{R}}=10 \% ; \mathrm{P}_{\mathrm{SAT}}=4,5$ bar; Variação de $\mathrm{V}_{\mathrm{CF}}: 40 ; 70$; $100 ; 150 ; 350$ e $630 \mathrm{~m} / \mathrm{h}$.; $\mathrm{TAS}_{\mathrm{ZS}}=15 \mathrm{~m} / \mathrm{h} ; \mathrm{Q}_{\mathrm{ent}}=4,6 \mathrm{~m} / \mathrm{h} ; \mathrm{TAS}_{\mathrm{ZC}}=180 \mathrm{~m} / \mathrm{h} ; \mathrm{T}_{\mathrm{ZC}}=34$ s.

Analisando a Figura 5.15, a remoção de cor foi satisfatória entre as velocidades Cross-Flow analisadas de 40 e $350 \mathrm{~m} / \mathrm{h}$, ficando com remoção $86 \%$ de cor (cor residual de $6 \mathrm{UH})$. Na $\mathrm{V}_{\mathrm{CF} 6}$ de $630 \mathrm{~m} / \mathrm{h}$ houve uma piora na remoção muito significativa, havendo remoção de somente $49 \%$ da cor (cor residual de 22 UH). Assim a remoção de cor na velocidade Cross-flow de 630 não foi satisfatória devido a não formação do fluxo estratificado padrão na zona de separação, fazendo com que a eficiência da flotação em relação à remoção de cor ficasse prejudicada. 


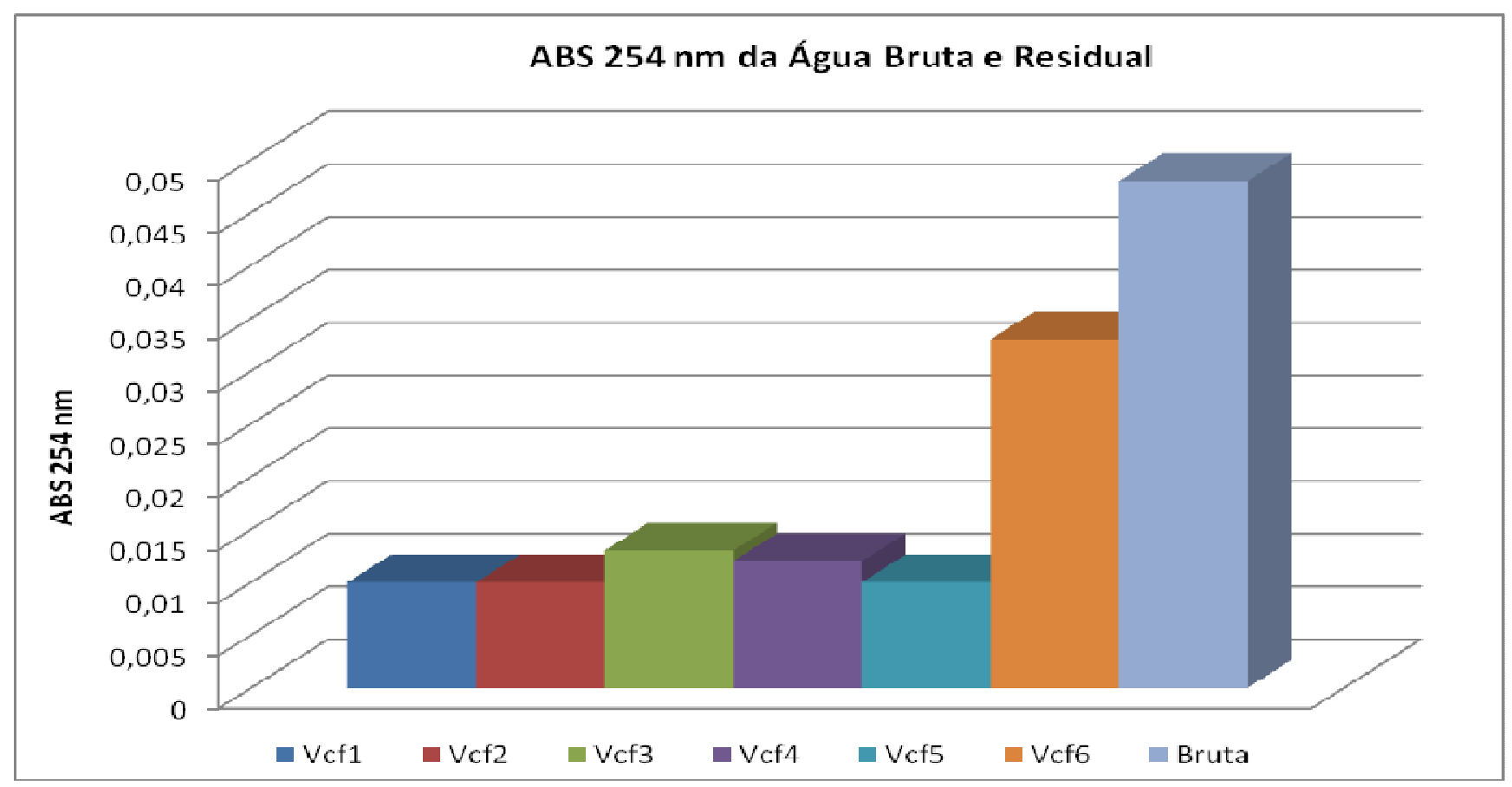

Figura 5.16: ABS $254 \mathrm{~nm}$ Residual - Ensaio 4 - ETAPA 2. DSA = 22,5 mg/L; PZ = $+0,3 \pm 0,2 ; \mathrm{G}_{\mathrm{F}}=90 \mathrm{~s}^{-1} ; \mathrm{T}_{\mathrm{F}}=12$ minutos; $\mathrm{T}_{\mathrm{R}}=10 \% ; \mathrm{P}_{\mathrm{SAT}}=4,5$ bar; Variação de $\mathrm{V}_{\mathrm{CF}}$ : $40 ; 70 ; 100 ; 150 ; 350$ e $630 \mathrm{~m} / \mathrm{h}$; $\operatorname{TAS}_{\mathrm{ZS}}=15 \mathrm{~m} / \mathrm{h} ; \mathrm{Q}_{\mathrm{ent}}=4,6 \mathrm{~m}^{3} / \mathrm{h} ; \mathrm{TAS}_{\mathrm{ZC}}=180 \mathrm{~m} / \mathrm{h}$; $\mathrm{T}_{\mathrm{ZC}}=34 \mathrm{~s}$.

$\mathrm{Na}$ redução do valor de ABS $254 \mathrm{~nm}$ também foi percebido a piora na velocidade Cross- flow de $630 \mathrm{~m} / \mathrm{h}$, havendo uma redução somente de $31 \%$ de ABS 254 nm. Nas demais velocidades Cross-Flow analisadas a redução se deu entre 73 e 79 $\%$ (ABS $254 \mathrm{~nm}$ residual entre 0,01 e 0,013 ).

A determinação de Sólidos Suspensos Totais das amostras compostas foi realizada em triplicata, sendo que na Tabela 5.28 são apresentados os valores da média e do desvio padrão das referidas determinações. 
Tabela 5.28: Resultados de SST da amostra flotada e floculada do Ensaio 4 da ETAPA 2.

\begin{tabular}{|c|c|c|c|c|c|c|}
\hline Amostras & $\begin{array}{l}\text { SST Floculada } \\
\text { (mg/L) }\end{array}$ & $\begin{array}{l}\text { Desvio } \\
\text { Padrão }\end{array}$ & $\begin{array}{l}\text { SST Flotada } \\
\text { (mg/L) }\end{array}$ & $\begin{array}{l}\text { Desvio } \\
\text { Padrão }\end{array}$ & $\begin{array}{l}\text { Lodo Produzido } \\
\text { (mg/L) }\end{array}$ & $\begin{array}{l}\text { Desvio } \\
\text { Padrão }\end{array}$ \\
\hline $\mathrm{V}_{\mathrm{CF} 1}=40 \mathrm{~m} / \mathrm{h}$ & 19,3 & 1,21 & 4,5 & 0,23 & 14,8 & 1,00 \\
\hline $\mathrm{V}_{\mathrm{CF} 2}=70 \mathrm{~m} / \mathrm{h}$ & 20,3 & 0,90 & 4,3 & 0,31 & 16,0 & 1,11 \\
\hline$V_{C F 3}=100 \mathrm{~m} / \mathrm{h}$ & 19,7 & 0,70 & 4,5 & 0,23 & 15,1 & 0,76 \\
\hline$V_{C F 4}=150 \mathrm{~m} / \mathrm{h}$ & 19,6 & 1,97 & 4,3 & 0,50 & 15,3 & 2,10 \\
\hline$V_{C F 5}=350 \mathrm{~m} / \mathrm{h}$ & 19,9 & 1,14 & 4,6 & 0,35 & 15,3 & 1,10 \\
\hline$V_{C_{F 6}}=630 \mathrm{~m} / \mathrm{h}$ & 20,3 & 0,83 & 10,2 & 0,92 & 10,1 & 1,55 \\
\hline
\end{tabular}

Produção de lodo no Ensaio 4 da ETAPA 2 permaneceu na ordem de 15 g de lodo $/ \mathrm{m}^{3}$ de água tratada.

Esta alta nos valores de turbidez, de cor e de ABS $254 \mathrm{~nm}$ residual observada na velocidade Cross-Flow de $630 \mathrm{~m} / \mathrm{h}$ demonstra claramente que esse valor resultou em estrutura de fluxo prejudicial ao processo de separação por flotação. Tal fato foi agravado pela TAS na zona de separação ser maior que nos ensaios 1 e 2 . Nos ensaio 1 e 2 foi analisada TAS com valor de $7,67 \mathrm{~m} / \mathrm{h}$ na zona de separação, enquanto que nos ensaios 3 e 4, a TAS na zona de separação foi de $15 \mathrm{~m} / \mathrm{h}$. Isto fez com que o carreamento de flocos para o efluente flotado fosse muito maior devido a uma velocidade maior na zona de separação em comparação a analisada anteriormente nos ensaios 1 e 2 . 


\section{Turbidez remanescente (NTU)}

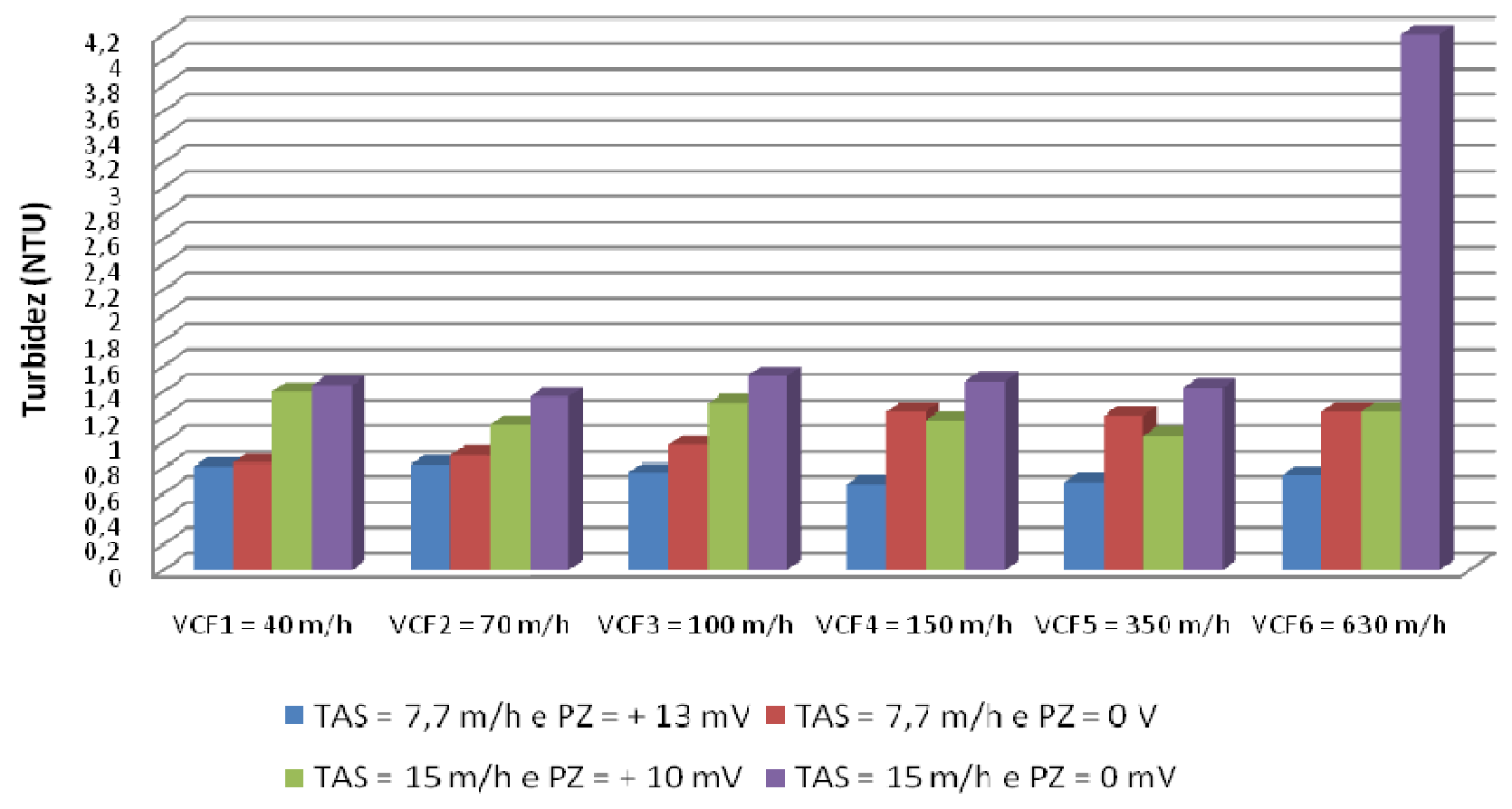

Figura 5.17: Comparativo entre as Velocidades Cross-Flow analisadas, TAS na zona de separação e os valores de Potencial Zeta em relação a Turbidez remanescente (NTU).

Analisando a Figura 5.17, percebe-se que para TAS de 7,7 m/h a remoção de turbidez se deu mais satisfatória em velocidades Cross-Flow entre 40 e $100 \mathrm{~m} / \mathrm{h}$, havendo pequena piora em relação, mas significativa, em relação a remoção de turbidez nas Velocidades analisadas maiores que $100 \mathrm{~m} / \mathrm{h}$, para valores de Potencial Zeta próximo da neutralidade. Para valores positivos de Potencial Zeta, com a TAS de 7,7 m/h na zona de separação, esta piora não foi constatada, devido a ligação entre floco + bolha tornar-se mais estável, ocasionando menores taxas de rompimento entre o agregado floco + bolha.

Para TAS de $15 \mathrm{~m} / \mathrm{h}$ na zona de separação e valor de potencial zeta próximo da neutralidade foi averiguado piora em relação a remoção de turbidez na velocidade Cross-flow de $630 \mathrm{~m} / \mathrm{h}$, devido a turbulência na passagem entre a zona de contato e a zona de separação, e assim, provável não formação do fluxo padrão estratificado na 
zona de separação, o que ocasionou o maior rompimento dos agregados flocos + bolhas.

Para valor de potencial zeta positivo esta piora na eficiencia da flotação não foi percebida devido à maior estabilidade entre os agregados de flocos + bolhas, para a TAS de $15 \mathrm{~m} / \mathrm{h}$ na zna de sepração analisada.

Comparando as TAS na zona de separação analisadas ocorreu uma pequena piora em relação à remoção de turbidez para a TAS de $15 \mathrm{~m} / \mathrm{h}$ devido à maior velocidade descendente proporcionada pela mesma na zona de separação, ocasionando maior carreamento de flocos ao efluente final flotado.

Assim analisando as variações de TAS na zona de separação, as variações de $\mathrm{V}_{\mathrm{CF}}$ e de $\mathrm{PZ}$, chega-se as seguintes discussões em relação à remoção de turbidez mostrado na Tabela 5.29:

Tabela 5.29: Discussão em relação à remoção da turbidez, analisando as variações de TAS na zona de separação, as variações de $\mathrm{V}_{\mathrm{CF}}$ e de PZ.

\begin{tabular}{|c|c|c|c|}
\hline $\begin{array}{l}\text { TAS na zona } \\
\text { de separação }\end{array}$ & $\mathbf{P Z}$ & $\begin{array}{l}\text { Faixa de } \mathrm{V}_{\mathrm{CF}} \\
\text { recomendáveis a } \\
\text { projetos }\end{array}$ & Observações \\
\hline $7,7 \mathrm{~m} / \mathrm{h}$ & neutro & Entre 40 e $100 \mathrm{~m} / \mathrm{h}$ & $\begin{array}{c}\text { Piora na remoção de turbidez a partir de } \mathrm{V}_{\mathrm{CF}} \text { de } 100 \\
\mathrm{~m} / \mathrm{h} \text { devido ao PZ neutro gerar ligações entre floco + } \\
\text { bolha menos estáveis e provável não formação do fluxo } \\
\text { padrão estratificado devido a altos valores de } \mathrm{V}_{\mathrm{CF}} \mathrm{em} \\
\text { velocidades acima de } 100 \mathrm{~m} / \mathrm{h} \text {. }\end{array}$ \\
\hline $7,7 \mathrm{~m} / \mathrm{h}$ & positivo & Entre 40 e $630 \mathrm{~m} / \mathrm{h}$ & $\begin{array}{l}\text { Remoção de turbidez satisfatória em todas as } \mathrm{V}_{\mathrm{CF}} \\
\text { analisadas - PZ proporcionou ligação entre floco }+ \\
\text { bolha mais estável. }\end{array}$ \\
\hline $15 \mathrm{~m} / \mathrm{h}$ & neutro & Entre 40 e $350 \mathrm{~m} / \mathrm{h}$ & $\begin{array}{l}\text { Piora na remoção de turbidez devido a maior TAS na } \\
\text { zona de separação, ocasionando maior carreamento de } \\
\text { flocos ao efluente final flotado. Piora na remoção de } \\
\text { turbidez a partir de } \mathrm{V}_{\mathrm{CF}} \text { de } 350 \mathrm{~m} / \mathrm{h} \text { devido ao } \mathrm{PZ} \\
\text { neutro gerar ligações entre floco + bolha menos } \\
\text { estáveis e provável não formação do fluxo padrão } \\
\text { estratificado devido a altos valores de } \mathrm{V}_{\mathrm{CF}} \text {. }\end{array}$ \\
\hline $15 \mathrm{~m} / \mathrm{h}$ & positivo & Entre 40 e $630 \mathrm{~m} / \mathrm{h}$ & $\begin{array}{l}\text { Piora na remoção de turbidez devido a maior TAS na } \\
\text { zona de separação, ocasionando maior carreamento de } \\
\text { flocos ao efluente final flotado. Remoção de turbidez } \\
\text { em todas as } \mathrm{V}_{\mathrm{CF}} \text { analisadas foi constante - PZ } \\
\text { proporcionou ligação entre floco + bolha mais estável. }\end{array}$ \\
\hline
\end{tabular}




\section{Cor Remanescente (UH)}



Figura 5.18: Comparativo entre as Velocidades Cross-Flow analisadas, TAS na zona de separação e os valores de Potencial Zeta em relação à Cor remanescente (UH).

De acordo com a Figura 5.18, para TAS de 7,7 m/h a remoção de cor foi mais satisfatória em velocidades Cross-Flow entre 40 e $100 \mathrm{~m} / \mathrm{h}$, havendo pequena piora em relação, mas significativa, em relação à remoção de cor nas Velocidades analisadas maiores que $100 \mathrm{~m} / \mathrm{h}$, para valores de Potencial Zeta próximo da neutralidade. Valor positivo de Potencial Zeta associado com a TAS de $7,7 \mathrm{~m} / \mathrm{h}$ na zona de separação, resultou em remoção satisfatória de cor em todas as velocidades Cross-flow analisadas, devido à ligação entre floco + bolha tornar-se mais estável, ocasionando menores taxas de rompimento entre o agregado floco + bolha.

Para TAS de $15 \mathrm{~m} / \mathrm{h}$ na zona de separação e valor de potencial zeta próximo da neutralidade foi averiguado piora em relação a remoção de cor na velocidade Cross-flow de $630 \mathrm{~m} / \mathrm{h}$, devido à turbulência na passagem entre a zona de contato e a zona de separação, e assim, provável não formação do fluxo padrão estratificado na zona de 
separação, o que ocasionou o maior rompimento dos agregados flocos + bolhas. Para valor de potencial zeta positivo esta piora na eficiência da flotação não foi percebida devido à maior estabilidade entre os agregados de flocos + bolhas, para a TAS de 15 m/h na zona de separação analisada.

Comparando as TAS na zona de separação analisadas ocorreu uma pequena piora em relação à remoção de cor para a TAS de $15 \mathrm{~m} / \mathrm{h}$ devido à maior velocidade descendente proporcionada pela mesma na zona de separação, ocasionando maior carreamento de flocos ao efluente final flotado.

Assim, analisando as variações de TAS na zona de separação, as variações de $\mathrm{V}_{\mathrm{CF}}$ e de $\mathrm{PZ}$, chega-se a seguinte discussão em relação à remoção de cor, mostrada na Tabela 5.30:

Tabela 5.30: Conclusão em relação à remoção de cor, analisando as variações de TAS na zona de separação, as variações de $\mathrm{V}_{\mathrm{CF}}$ e de $\mathrm{PZ}$.

\begin{tabular}{|c|c|c|c|}
\hline $\begin{array}{l}\text { TAS na zona } \\
\text { de separação }\end{array}$ & $\mathbf{P Z}$ & $\begin{array}{l}\text { Faixa de } \mathrm{V}_{\mathrm{CF}} \\
\text { recomendáveis a } \\
\text { projetos }\end{array}$ & Observações \\
\hline $7,7 \mathrm{~m} / \mathrm{h}$ & neutro & Entre 40 e $100 \mathrm{~m} / \mathrm{h}$ & $\begin{array}{l}\text { Piora na remoção de cor a partir de } \mathrm{V}_{\mathrm{CF}} \text { de } 100 \mathrm{~m} / \mathrm{h} \\
\text { devido ao } \mathrm{PZ} \text { neutro gerar ligações entre floco }+ \\
\text { bolha menos estáveis e provável não formação do } \\
\text { fluxo padrão estratificado devido a altos valores de } \\
\qquad \mathrm{V}_{\mathrm{CF}} \text {. }\end{array}$ \\
\hline $7,7 \mathrm{~m} / \mathrm{h}$ & positivo & Entre 40 e $630 \mathrm{~m} / \mathrm{h}$ & $\begin{array}{c}\text { Remoção de cor satisfatória em todas as } \mathrm{V}_{\mathrm{CF}} \\
\text { analisadas - PZ proporcionou ligação entre floco }+ \\
\text { bolha mais estável. }\end{array}$ \\
\hline $15 \mathrm{~m} / \mathrm{h}$ & neutro & Entre 40 e $350 \mathrm{~m} / \mathrm{h}$ & $\begin{array}{l}\text { Piora na remoção de cor devido a maior TAS na zona } \\
\text { de separação, ocasionando maior carreamento de } \\
\text { flocos ao efluente final flotado. Piora na remoção de } \\
\text { cor a partir de } \mathrm{V}_{\mathrm{CF}} \text { de } 350 \mathrm{~m} / \mathrm{h} \text { devido ao } \mathrm{PZ} \text { neutro } \\
\text { gerar ligações entre floco + bolha menos estáveis e } \\
\text { provável não formação do fluxo padrão estratificado } \\
\text { devido a altos valores de } \mathrm{V}_{\mathrm{CF}} \text {. }\end{array}$ \\
\hline $15 \mathrm{~m} / \mathrm{h}$ & positivo & Entre 40 e $630 \mathrm{~m} / \mathrm{h}$ & $\begin{array}{c}\text { Piora na remoção de cor devido a maior TAS na zona } \\
\text { de separação, ocasionando maior carreamento de } \\
\text { flocos ao efluente final flotado. Remoção de cor em } \\
\text { todas as } \mathrm{V}_{\mathrm{CF}} \text { analisadas foi constante - } \mathrm{PZ} \\
\text { proporcionou ligação entre floco + bolha mais } \\
\text { estável. }\end{array}$ \\
\hline
\end{tabular}




\section{Conclusões e recomendações}

A pesquisa verificou a variação da Velocidade Cross-flow (40, 70, 100, 150, 350 e $600 \mathrm{~m} / \mathrm{h}$ ) sob duas condições de Taxa de Aplicação na Zona de Separação $\left(\mathrm{TAS}_{\mathrm{ZS}}\right)$ : 7,7 e $15 \mathrm{~m} / \mathrm{h}$; e sob dois valores de potencial zeta (positivo: $+10 \mathrm{mV}$; e neutro: $0 \mathrm{mV}$ ), e conclui-se que em todas as condições analisadas houve boa eficiência na remoção de turbidez, cor e ABS $254 \mathrm{~nm}$, não havendo grandes diferenças de remoção entre as velocidades analisadas. Analisando os ensaios como um todo, é perceptível que em situações em que se tenha potencial zeta positivo, as ligações entre flocos e bolhas de ar parecem ser mais fortes e estáveis, e assim a eficiência da flotação sofre menos influência quando submetida a altos valores de $\mathrm{V}_{\mathrm{CF}}$. Quando o potencial zeta ficou próximo à neutralidade a eficiência da flotação ficou ligeiramente comprometida quando submetida a altos valores de $\mathrm{V}_{\mathrm{CF}}$. A TAS na zona de separação menor $(7,7 \mathrm{~m} / \mathrm{h})$, se obteve resultados mais satisfatórios em relação à eficiência da flotação quando comparados a TAS maior na zona de separação $(15 \mathrm{~m} / \mathrm{h})$, devido ao maior carreamento de flocos proporcionado pela maior $\mathrm{TAS}_{\mathrm{ZS}}$ ao efluente final clarificado, resultando em uma pequena piora na eficiência da flotação. Verificou-se que para a água analisada houve pequena variação na eficiência da flotação em relação a remoção de turbidez, cor e ABS $254 \mathrm{~nm}$, sob as condições impostas de variação na Velocidade Cross-flow. Assim, conclui-se que a coagulação e floculação em condições adequadas, nas condições analisadas na pesquisa, bem como as dimensões do flotador, a qualidade da água (turbidez de 7,5 NTU e cor aparente de $43 \mathrm{UH}$ ), velocidades Cross-flow (40, 70, $100,150,350$ e $600 \mathrm{~m} / \mathrm{h})$, TAS $_{\mathrm{ZS}}(7,7 \mathrm{~m} / \mathrm{h}$ e $15 \mathrm{~m} / \mathrm{h})$ e potencial zeta $(+10 \mathrm{mV}$ e $0 \mathrm{mV})$, a eficiência será praticamente constante, quando o tratamento foi submetido às condições analisadas. Desta forma, a coagulação e floculação são os principais 
parâmetros para que haja boa eficiência na flotação por ar dissolvido independentemente da Velocidade Cross-flow aplicada sob as condições analisadas nesta pesquisa.

Recomenda-se o estudo de águas com características diferentes da analisada, variando a Velocidade Cross-flow com mais de um valor de potencial zeta e valores ainda mais altos de TAS na zona de separação. Recomenda-se a realização de estudos com análise de imagens na região de saída da zona de contato com vistas a se verificar a estabilidade das ligações entre microbolhas de ar e flocos em função de diferentes valores de $V_{C F}$ e de TAS na zona de separação de instalação piloto de flotação. Também é recomendável o estudo de configurações de flotadores: comprimento/largura, em caso de flotadores retangulares, e flotadores circulares, e suas influências na eficiência da flotação tratando água para abastecimento quando variado a Velocidades Cross-flow. 


\section{Referências Bibliográficas}

BRATBY, JOHN. Coagulation and Flocculation in Water and Wastewater Treatment second edition - London: IWA 407p., 2006.

DI BERNARDO, LUIZ; DANTAS, ÂNGELA DI BERNARDO. Métodos e Técnicas de Tratamento de Água - segunda edição / volume 1 - São Carlos: RiMa, 792p., 2005.

EDZWALD, JAMES K.; WALSH, J. P.; KAMINSKI, G. S. Flocculation and Air Requirements for Dissolved Air Flotation. Journal of American Water Works Association, p. 92-100, 1992.

EDZWALD, JAMES K. Principles and Applications of Dissolved Air Flotation. Water Science and Technology, v.31, n.3-4, p.1-23, 1995.

EDZWALD, JAMES K. The Science and Engineering of Dissolved Air Flotation for Drinking Water Treatment - In: The $5^{\text {th }}$ International Conference on Flotation in Water and Wastewater Systems, Seul, Korea, 2007.

EDZWALD, JAMES K. Dissolved Air Flotation and Me. Water Research, 2009.

HAARHOFF, J; VAN VUUREN, L. R. J. Design Parameters for Dissolved Air Flotation in South África. Water Science and Technology, p. 203-212, 1995.

HAARHOFF, J. Dissolved Air Flotation: Progress and Prospects for Drinking Water Treatment. In: The $5^{\text {th }}$ International Conference on Flotation in Water and Wastewater Systems, Seul, Korea, 2007.

HAN, M.; KIM, W.; DOCKKO, S. Collision efficiency factor of bubble and particle $\left(\alpha_{\mathrm{bp}}\right)$ in DAF: theory and experimental verification. Water Science and Technology, Vol 43, Nº 8, p. 139-144, 2001. 
LEPPINEN, D. M.; DALZIEL, S. B. Bubble size distribution in Dissolved Air Flotation Tanks. Jornal of Water Supply: Reseach and Technology - AQUA, p. 531-543, 2004.

LUNDH, M.; JONSSON, L.; DAHLQUIST, J. Experimental Studies of the Fluid Dynamics in the Separation Zone in Dissolved Air Flotation. Water Research, v. 34, p. 21-30, 2000.

LUNDH, M.; JONSSON, L.; DAHLQUIST, J. The Influence of Contact Zone Configuration on the Flow Structure in a Dissolved Air Flotation Pilot Plant. Water Research, v. 36, p. 1585-1595, 2002.

MOOYOUNG HAN, TSCHUNG-IL KIM, HARYONG KIM, SUNGWON PARK Flocculation options in DAF - In: The $5^{\text {th }}$ International Conference on Flotation in Water and Wastewater Systems, Seul, Korea, 2007.

MORUZZI, R. B. Avaliação da Influência da Distribuição de Tamanho de Partículas e do Binômio Velocidade/Tempo de Detenção na Zona de Reação no Desempenho da Flotação com Utilização de Sonda Ultrasônica e Técnica de Análise por Imagem. Tese de doutorado apresentada à Escola de Engenharia de São Carlos, Universidade de São Paulo. São Carlos: EESC - USP. 240p, 2005.

MORUZZI, R. B. and REALI, M.A.P. Characterization of micro-bubbles sizes distribution in DAF contact zone by a non-intrusive image analysis system. In: The $5^{\text {th }}$ International Conference on Flotation in Water and Wastewater Systems, Seul, Korea, 2007.

PATRIZZI, L. J. Remoção de Ferro, Manganês e Substancias Húmicas de Água para Abastecimento, com Uso de Flotação por Ar Dissolvido de Alta Taxa e Oxidação Química. Tese de doutorado apresentada à Escola de Engenharia de São Carlos, Universidade de São Paulo. São Carlos: EESC - USP.232p, 2002. 
REALI, M. A. P. Concepção e Avaliação de um Sistema Compacto para Tratamento de Águas de Abastecimento Utilizando o Processo de Flotação por Ar Dissolvido e Filtração com Taxa Declinante. 1991. 373 f. Tese (Doutorado)-Escola de Engenharia de São Carlos, Universidade de São Paulo, São Carlos, 1991. 2 v.

REALI, M. A. P; MARCHETTO, M. Clarificação por Flotação de Água Bruta com Cor Moderadamente Elevada. $19^{\circ}$ Congresso Brasileiro de Engenharia Sanitária e Ambiental. p. 1411-1424, 1997

REALI, MARCO ANTÔNIO P; PENETRA, ROGÉRIO; AISSE, MIGUEL MANSUR; JÜRGENSEN, DÉCIO; FLORÊNCIO, LOURDINHA; SOBRINHO, PEDRO ALEM. Livro: Pós Tratamento de Efluentes de Reatores Anaeróbios, Capítulo 6: Pós Tratamento de Efluentes de Reatores Anaeróbios por Sistemas de Flotação. Prosab, 35p., 2001.

REALI, M. A. P.; PATRIZZI, L. J. The Influence of the Contact Zone Configuration on the Efficiency of a DAF Pilot Plant. In: The $5^{\text {th }}$ International Conference on Flotation in Water and Wastewater Systems, Seul, Korea, 2007.

SCHOFIELD, T. Dissolved air flotation in drinking water production. Water Science and Technology., v.43, n.8, p.9-18, 2001.

SHAWWA, A.R.; SMITH, D.W. Dissolved air flotation model for drinking water treatment. Can. J. Civ. Eng., v. 27, p. 373-382, 2000.

ZABEL, T. The Advantages of Dissolved Air Flotation for Water Treatment. Journal of American Water Works Association, p. 42-46, 1985. 


\section{ANEXO I}

VALORES DE TURBIDEZ PONTUAL DOS ENSAIOS REALIZADOS

\section{NA ETAPA 2 - INSTALAÇÃO PILOTO DE FLOTAÇÃo POR AR DISSOLVIDO.}

Ensaio 1 da Etapa 2:

Valores de turbidez pontual do Ensaio 1 da ETAPA 2:

\begin{tabular}{|c|c|c|c|c|c|c|c|c|}
\hline & $\begin{array}{l}\text { Vcf1 = } \\
40 \mathrm{~m} / \mathrm{h}\end{array}$ & $\begin{array}{l}\text { Vcf2 = } \\
70 \mathrm{~m} / \mathrm{h}\end{array}$ & $\begin{array}{c}\text { Vcf3 = } \\
100 \mathrm{~m} / \mathrm{h}\end{array}$ & $\begin{array}{c}\text { Vcf4 = } \\
150 \mathrm{~m} / \mathrm{h}\end{array}$ & $\begin{array}{c}\text { Vcf5 = } \\
200 \mathrm{~m} / \mathrm{h}\end{array}$ & $\begin{array}{c}\text { Vcf6 = } \\
250 \mathrm{~m} / \mathrm{h}\end{array}$ & $\begin{array}{c}\text { Vcf7 = } \\
350 \mathrm{~m} / \mathrm{h}\end{array}$ & $\begin{array}{c}\text { Vcf8 = } \\
630 \mathrm{~m} / \mathrm{h}\end{array}$ \\
\hline Amostras & Turbidez & Turbidez & Turbidez & Turbidez & Turbidez & Turbidez & Turbidez & Turbidez \\
\hline 1 & 1,63 & 1,26 & 1,48 & 1,51 & 1,41 & 0,67 & 0,75 & 3,17 \\
\hline 2 & 1,07 & 0,99 & 0,97 & 0,64 & 0,81 & 0,65 & 0,64 & 1,06 \\
\hline 3 & 0,94 & 0,83 & 0,74 & 0,62 & 0,71 & 0,62 & 0,57 & 0,84 \\
\hline 4 & 0,75 & 0,78 & 0,71 & 0,73 & 0,62 & 0,66 & 0,56 & 0,70 \\
\hline 5 & 0,78 & 0,84 & 0,60 & 0,85 & 0,61 & 0,61 & 0,58 & 0,62 \\
\hline 6 & 0,88 & 0,87 & 0,93 & 0,75 & 0,65 & 0,89 & 0,64 & 0,84 \\
\hline
\end{tabular}

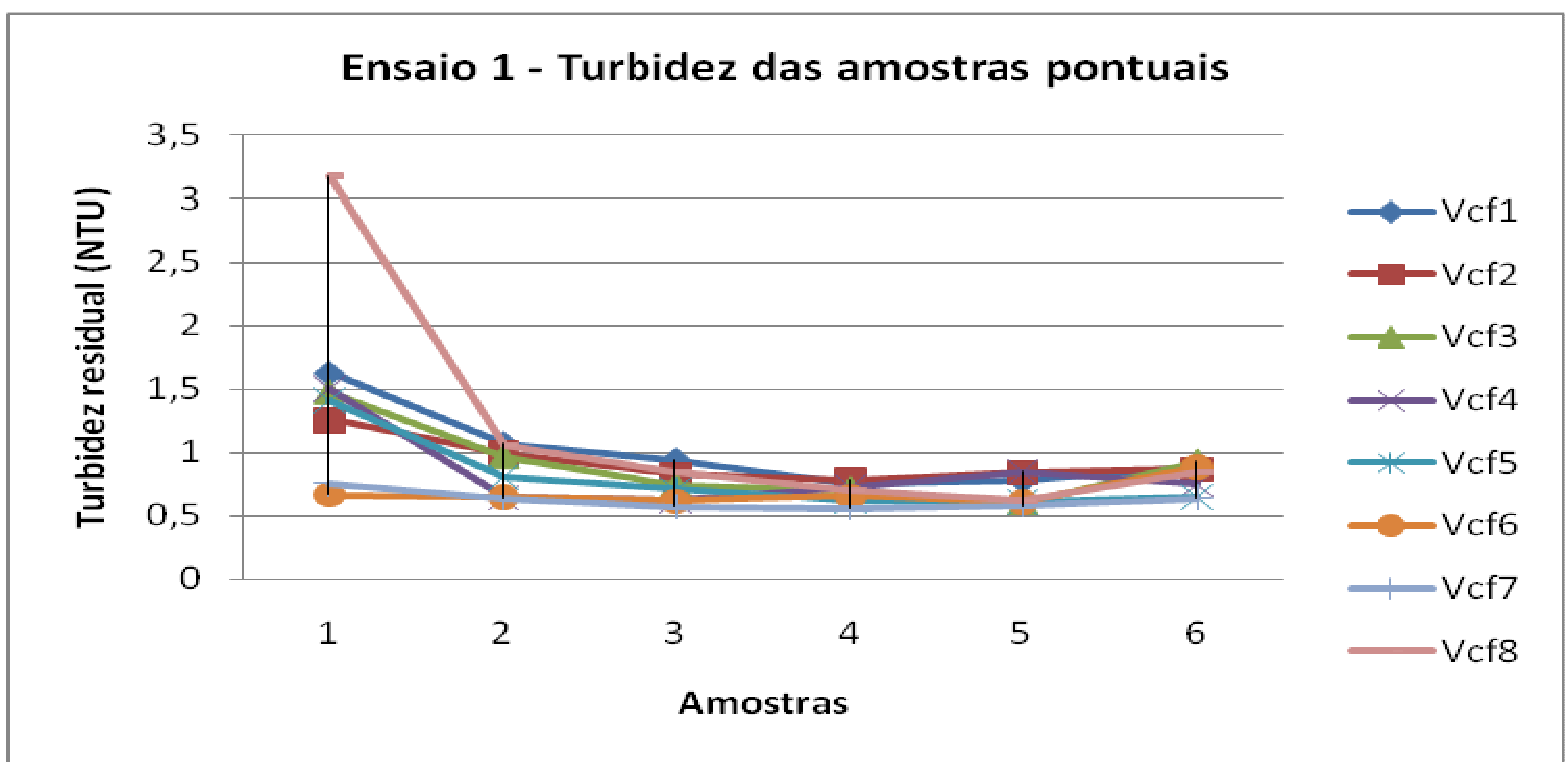

Gráfico A.1: Turbidez Residual (NTU) das amostras pontuais - Ensaio 1 - ETAPA 2. $\mathrm{DSA}=42,5 \mathrm{mg} / \mathrm{L} ; \mathrm{PZ}=+13,3 \pm 0,3 ; \mathrm{G}_{\mathrm{F}}=90 \mathrm{~s}^{-1} ; \mathrm{T}_{\mathrm{F}}=12$ minutos$; \mathrm{T}_{\mathrm{R}}=10 \% ; \mathrm{P}_{\mathrm{SAT}}=$ 4,5 bar; Variação de $\mathrm{V}_{\mathrm{CF}}: 40 ; 70 ; 100 ; 150 ; 200 ; 250 ; 350$ e $630 \mathrm{~m} / \mathrm{h}$.; TAS $_{\mathrm{ZS}}=7,67$ $\mathrm{m} / \mathrm{h} ; \mathrm{Q}_{\mathrm{ent}}=4,6 \mathrm{~m}^{3} / \mathrm{h} ; \mathrm{TAS}_{\mathrm{ZC}}=180 \mathrm{~m} / \mathrm{h} ; \mathrm{T}_{\mathrm{ZC}}=34 \mathrm{~s}$. 
Ensaio 2 da Etapa 2:

Valores de turbidez pontual do Ensaio 2 da ETAPA 2:

\begin{tabular}{|c|c|c|c|c|c|c|}
\hline & $\begin{array}{l}\text { Vcf1 = } \\
40 \mathrm{~m} / \mathrm{h}\end{array}$ & $\begin{array}{l}\text { Vcf2 = } \\
70 \mathrm{~m} / \mathrm{h}\end{array}$ & $\begin{array}{c}\text { Vcf3 = } \\
100 \mathrm{~m} / \mathrm{h}\end{array}$ & $\begin{array}{c}\text { Vcf4 = } \\
150 \mathrm{~m} / \mathrm{h}\end{array}$ & $\begin{array}{c}\text { Vcf5 = } \\
350 \mathrm{~m} / \mathrm{h}\end{array}$ & $\begin{array}{c}\text { Vcf6 }= \\
630 \mathrm{~m} / \mathrm{h}\end{array}$ \\
\hline Amostras & Turbidez & Turbidez & Turbidez & Turbidez & Turbidez & Turbidez \\
\hline 1 & 1,32 & 1,42 & 1,01 & 1,12 & 3,88 & 2,28 \\
\hline 2 & 0,99 & 1,27 & 0,92 & 1,20 & 1,30 & 1,16 \\
\hline 3 & 0,97 & 1,00 & 1,13 & 1,07 & 1,40 & 1,02 \\
\hline 4 & 0,74 & 0,88 & 0,97 & 1,10 & 1,20 & 1,11 \\
\hline 5 & 0,88 & 0,78 & 1,07 & 1,17 & 1,22 & 1,17 \\
\hline 6 & 0,94 & 0,94 & 0,97 & 1,38 & 1,20 & 1,20 \\
\hline
\end{tabular}



Gráfico A.2: Turbidez Residual (NTU) das amostras pontuais - Ensaio 2 - ETAPA 2. $\mathrm{DSA}=22,5 \mathrm{mg} / \mathrm{L} ; \mathrm{PZ}=+0,2 \pm 0,2 ; \mathrm{G}_{\mathrm{F}}=90 \mathrm{~s}^{-1} ; \mathrm{T}_{\mathrm{F}}=12$ minutos; $\mathrm{T}_{\mathrm{R}}=10 \% ; \mathrm{P}_{\mathrm{SAT}}=4,5$ bar; Variação de $\mathrm{V}_{\mathrm{CF}}: 40 ; 70 ; 100 ; 150 ; 200 ; 250 ; 350$ e $630 \mathrm{~m} / \mathrm{h}$.; TAS $_{Z S}=7,67 \mathrm{~m} / \mathrm{h}$; $\mathrm{Q}_{\mathrm{ent}}=4,6 \mathrm{~m}^{3} / \mathrm{h} ; \mathrm{TAS}_{\mathrm{ZC}}=180 \mathrm{~m} / \mathrm{h} ; \mathrm{T}_{\mathrm{ZC}}=34 \mathrm{~s}$. 
Ensaio 3 da Etapa 2:

Valores de turbidez pontual do Ensaio 3 da ETAPA 2:

\begin{tabular}{|c|c|c|c|c|c|c|}
\hline & $\begin{array}{l}\text { Vcf1 = } \\
40 \mathrm{~m} / \mathrm{h}\end{array}$ & $\begin{array}{l}\text { Vcf2 = } \\
70 \mathrm{~m} / \mathrm{h}\end{array}$ & $\begin{array}{c}\text { Vcf3 = } \\
100 \mathrm{~m} / \mathrm{h}\end{array}$ & $\begin{array}{c}\text { Vcf4 = } \\
150 \mathrm{~m} / \mathrm{h}\end{array}$ & $\begin{array}{c}\text { Vcf5 = } \\
350 \mathrm{~m} / \mathrm{h}\end{array}$ & $\begin{array}{c}\text { Vcf6 }= \\
630 \mathrm{~m} / \mathrm{h}\end{array}$ \\
\hline Amostras & Turbidez & Turbidez & Turbidez & Turbidez & Turbidez & Turbidez \\
\hline 1 & 2,45 & 1,37 & 1,76 & 1,93 & 1,19 & 1,23 \\
\hline 2 & 1,64 & 1,08 & 1,44 & 1,34 & 1,12 & 1,18 \\
\hline 3 & 1,37 & 1,07 & 1,32 & 1,33 & 1,07 & 1,19 \\
\hline 4 & 1,40 & 1,04 & 1,36 & 1,04 & 1,08 & 1,60 \\
\hline 5 & 1,42 & 1,27 & 1,19 & 1,22 & 1,10 & 1,43 \\
\hline 6 & 1,32 & 1,14 & 1,49 & 1,33 & 1,07 & 1,35 \\
\hline
\end{tabular}



Gráfico A.3: Turbidez Residual (NTU) das amostras pontuais - Ensaio 3 - ETAPA 2. $\mathrm{DSA}=42,5 \mathrm{mg} / \mathrm{L} ; \mathrm{PZ}=+10,3 \pm 0,5 ; \mathrm{G}_{\mathrm{F}}=90 \mathrm{~s}^{-1} ; \mathrm{T}_{\mathrm{F}}=12$ minutos; $\mathrm{T}_{\mathrm{R}}=10 \% ; \mathrm{P}_{\mathrm{SAT}}=$ 4,5 bar; Variação de $\mathrm{V}_{\mathrm{CF}}: 40 ; 70 ; 100 ; 150 ; 200 ; 250 ; 350$ e $630 \mathrm{~m} / \mathrm{h} . ; \mathrm{TAS}_{\mathrm{ZS}}=15 \mathrm{~m} / \mathrm{h}$; $\mathrm{Q}_{\mathrm{ent}}=4,6 \mathrm{~m}^{3} / \mathrm{h} ; \mathrm{TAS}_{\mathrm{ZC}}=180 \mathrm{~m} / \mathrm{h} ; \mathrm{T}_{\mathrm{ZC}}=34 \mathrm{~s}$. 
Ensaio 4 da Etapa 2:

Valores de turbidez pontual do Ensaio 4 da ETAPA 2:

\begin{tabular}{|c|c|c|c|c|c|c|}
\hline & $\begin{array}{l}\text { Vcf1 = } \\
40 \mathrm{~m} / \mathrm{h}\end{array}$ & $\begin{array}{l}\text { Vcf2 = } \\
70 \mathrm{~m} / \mathrm{h}\end{array}$ & $\begin{array}{c}\text { Vcf3 = } \\
100 \mathrm{~m} / \mathrm{h}\end{array}$ & $\begin{array}{c}\text { Vcf4 = } \\
150 \mathrm{~m} / \mathrm{h}\end{array}$ & $\begin{array}{c}\text { Vcf5 = } \\
350 \mathrm{~m} / \mathrm{h}\end{array}$ & $\begin{array}{c}\text { Vcf6 }= \\
630 \mathrm{~m} / \mathrm{h}\end{array}$ \\
\hline Amostras & Turbidez & Turbidez & Turbidez & Turbidez & Turbidez & Turbidez \\
\hline 1 & 2,10 & 1,32 & 1,89 & 1,53 & 1,55 & 2,13 \\
\hline 2 & 1,85 & 1,31 & 1,70 & 1,42 & 1,58 & 2,79 \\
\hline 3 & 1,54 & 1,27 & 1,62 & 1,58 & 1,45 & 4,00 \\
\hline 4 & 1,40 & 1,44 & 1,50 & 1,33 & 1,35 & 3,54 \\
\hline 5 & 1,64 & 1,40 & 1,62 & 1,45 & 1,36 & 4,13 \\
\hline 6 & 1,33 & - & 1,5 & 1,54 & 1,42 & 4,50 \\
\hline
\end{tabular}



Gráfico A.4: Turbidez Residual (NTU) das amostras pontuais - Ensaio 4 - ETAPA 2. $\mathrm{DSA}=22,5 \mathrm{mg} / \mathrm{L} ; \mathrm{PZ}=+0,3 \pm 0,2 ; \mathrm{G}_{\mathrm{F}}=90 \mathrm{~s}^{-1} ; \mathrm{T}_{\mathrm{F}}=12$ minutos; $\mathrm{T}_{\mathrm{R}}=10 \% ; \mathrm{P}_{\mathrm{SAT}}=4,5$ bar; Variação de $\mathrm{V}_{\mathrm{CF}}: 40 ; 70 ; 100 ; 150 ; 200 ; 250 ; 350$ e $630 \mathrm{~m} / \mathrm{h}$.; TAS $_{\mathrm{ZS}}=15 \mathrm{~m} / \mathrm{h}$; $\mathrm{Q}_{\mathrm{ent}}=4,6 \mathrm{~m}^{3} / \mathrm{h} ; \mathrm{TAS}_{\mathrm{ZC}}=180 \mathrm{~m} / \mathrm{h} ; \mathrm{T}_{\mathrm{ZC}}=34 \mathrm{~s}$. 


\section{ANEXO II}

CALIBRAÇÃO DOS MEDIDORES DE VAZÃO DA INSTALAÇÃO PILOTO DE FLOTAÇÃO POR AR DISSOLVIDO.

$\underline{\text { Medidor de Vazão de Entrada }\left(Q_{\text {ent }}\right)}$

\begin{tabular}{cccc}
\hline Volume (L) & Tempo $(s)$ & $Q_{\text {AFERIDA }}(\mathbf{m} 3 / h)$ & $Q_{\text {VISOR }}(\mathbf{m} 3 / h)$ \\
\hline 20 & 46,5 & 1,55 & \\
20 & 48,5 & 1,48 & \\
20 & 47,8 & 1,51 & $1,4-1,6$ \\
20 & 48,6 & 1,48 & \\
20 & 48,8 & 1,48 & \\
20 & 48,5 & 1,48 & \\
& & & \\
Média: & 48,116667 & 1,50 & \\
\hline
\end{tabular}

\begin{tabular}{cccc}
\hline Volume $(L)$ & Tempo $(s)$ & $Q_{\text {AFERIDA }}(\mathbf{m} 3 / h)$ & $Q_{\text {VISOR }}(m 3 / h)$ \\
\hline 50 & 65,2 & 2,76 & \\
50 & 65,3 & 2,76 & \\
50 & 65,1 & 2,76 & $2,5-2,9$ \\
50 & 65,6 & 2,74 & \\
50 & 66,9 & 2,69 & \\
50 & 66,8 & 2,69 & \\
& & & \\
Média: & 65,8 & 2,74 & \\
\hline
\end{tabular}

\begin{tabular}{cccc}
\hline Volume (L) & Tempo $(s)$ & $\boldsymbol{Q}_{\text {AFERIDA }}(\mathrm{m} 3 / \mathrm{h})$ & $\boldsymbol{Q}_{\text {VISOR }}(\mathrm{m} 3 / \mathrm{h})$ \\
\hline 50 & 39,5 & 4,56 & \\
50 & 39,8 & 4,52 & \\
50 & 39,8 & 4,52 & $4,2-4,6$ \\
50 & 39,7 & 4,53 & \\
50 & 39,9 & 4,51 & \\
50 & 39,3 & 4,58 & \\
& & & \\
Média: & 39,7 & 4,54 & \\
\hline
\end{tabular}




\begin{tabular}{cccc}
\hline Volume (L) & Tempo $(\boldsymbol{s})$ & $\boldsymbol{Q}_{\text {AFERIDA }}(\mathbf{m} 3 / \mathrm{h})$ & $\boldsymbol{Q}_{\text {VISOR }}(\mathrm{m} 3 / \mathrm{h})$ \\
\hline 50 & 32,1 & 5,61 & \\
50 & 32,2 & 5,59 & \\
50 & 32,2 & 5,59 & $5,2-5,7$ \\
50 & 32,2 & 5,59 & \\
50 & 32,2 & 5,59 & \\
50 & 32,3 & 5,57 & \\
& & & \\
Média: & 32,2 & 5,59 & \\
\hline
\end{tabular}

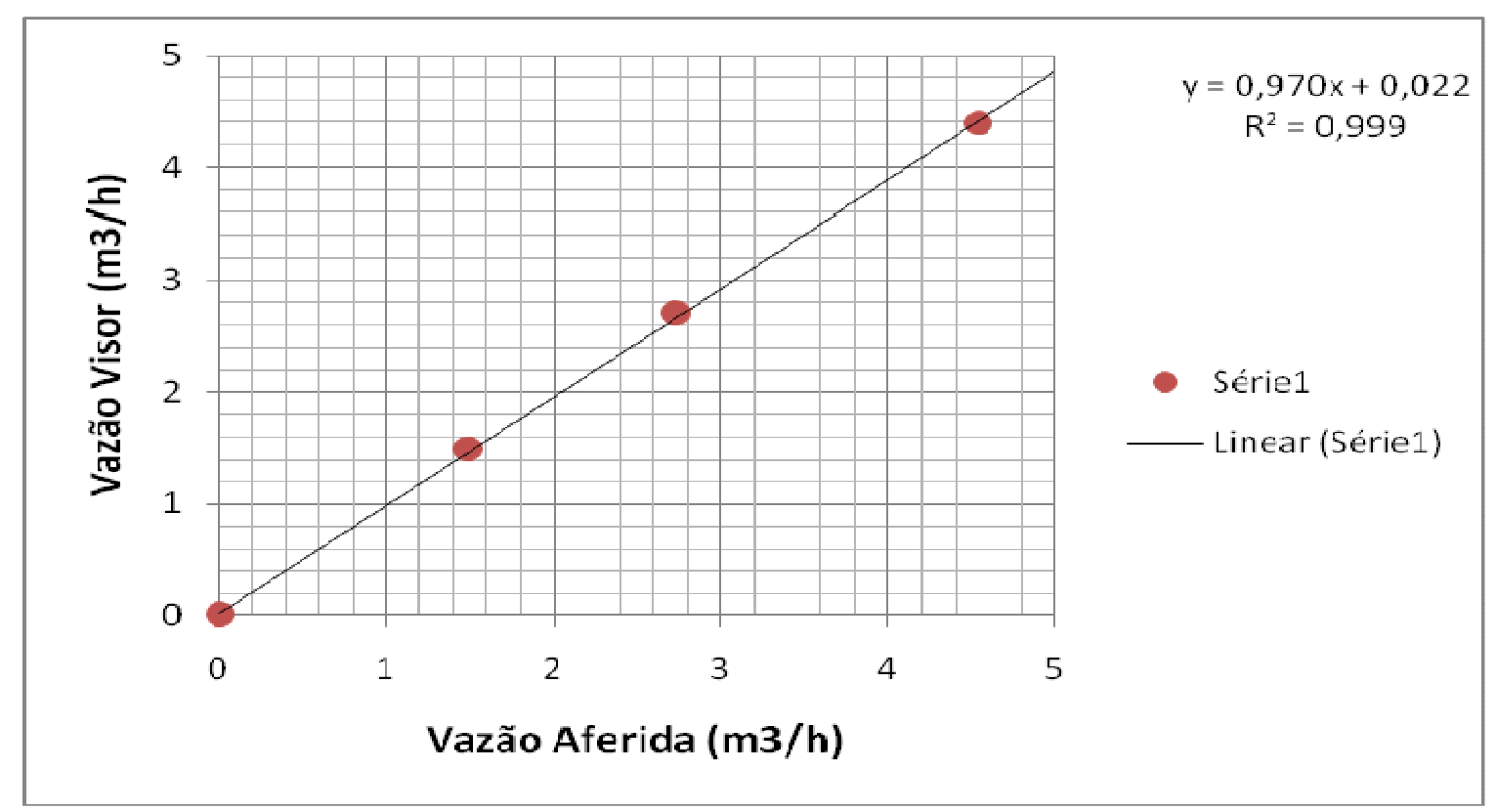

Medidor de Vazão de Recirculação da Água Saturada $\left(\mathrm{Q}_{\text {rec }}\right)$

\begin{tabular}{cccc}
\hline Volume (L) & Tempo $(\boldsymbol{s})$ & $\boldsymbol{Q}_{\text {AFERIDA }}(\mathbf{m} 3 / \mathbf{h})$ & $\boldsymbol{Q}_{\text {VISOR }}(\mathbf{m} 3 / \boldsymbol{h})$ \\
\hline 2 & 21,79 & 0,33 & 0,2 \\
1,96 & 20,76 & 0,34 & 0,2 \\
1,94 & 20,49 & 0,34 & 0,2 \\
1,95 & 19,72 & 0,36 & 0,2 \\
1,96 & 19,72 & 0,36 & 0,2 \\
1,96 & 20,22 & 0,35 & 0,2 \\
& & & \\
Média: & 20,45 & 0,35 & 0,2 \\
\hline
\end{tabular}




\begin{tabular}{|c|c|c|c|}
\hline Volume (L) & Tempo (s) & $Q_{\text {AFERIDA }}(\mathrm{m} 3 / \mathrm{h})$ & $Q_{V I S O R}(m 3 / h)$ \\
\hline 1,95 & 11,21 & 0,63 & 0,4 \\
\hline 1,95 & 11,47 & 0,61 & 0,4 \\
\hline 1,97 & 11,73 & 0,60 & 0,4 \\
\hline 1,97 & 11,73 & 0,60 & 0,4 \\
\hline 1,99 & 12,24 & 0,59 & 0,4 \\
\hline 2 & 12,51 & 0,58 & 0,4 \\
\hline Média: & 11,815 & 0,60 & 0,4 \\
\hline Volume (L) & Tempo (s) & $Q_{\text {AFERIDA }}(m 3 / h)$ & $Q_{V I S O R}(m 3 / h)$ \\
\hline 1,94 & 8,12 & 0,86 & 0,6 \\
\hline 1,98 & 8,38 & 0,85 & 0,6 \\
\hline 1,98 & 8,38 & 0,85 & 0,6 \\
\hline 1,99 & 8,38 & 0,85 & 0,6 \\
\hline 1,99 & 8,38 & 0,85 & 0,6 \\
\hline 1,98 & 8,38 & 0,85 & 0,6 \\
\hline Média: & 8,34 & 0,85 & 0,6 \\
\hline
\end{tabular}

\begin{tabular}{cccc}
\hline Volume (L) & Tempo $(s)$ & $Q_{\text {AFERIDA }}(\mathrm{m} 3 / h)$ & $Q_{\text {VISOR }}(\mathrm{m} 3 / \mathbf{h})$ \\
\hline 20 & 46,79 & 1,54 & 1 \\
20 & 47,54 & 1,51 & 1 \\
20 & 47,46 & 1,52 & 1 \\
20 & 46,79 & 1,54 & 1 \\
20 & 46,49 & 1,55 & 1 \\
20 & 47,04 & 1,53 & 1 \\
& & & \\
Média: & 47,02 & 1,53 & 1 \\
\hline
\end{tabular}

\begin{tabular}{cccc}
\hline Volume (L) & Tempo (s) & $\boldsymbol{Q}_{\text {AFERIDA }}(\mathbf{m} 3 / \boldsymbol{h})$ & $\boldsymbol{Q}_{\text {VISOR }}(\mathbf{m} 3 / \boldsymbol{h})$ \\
\hline 50 & 96,55 & 1,86 & 1,2 \\
50 & 95,02 & 1,89 & 1,2 \\
50 & 97,53 & 1,85 & 1,2 \\
50 & 96,81 & 1,86 & 1,2 \\
50 & 97,58 & 1,84 & 1,2 \\
50 & 97,42 & 1,85 & 1,2 \\
& & & \\
& & & 1,2 \\
Média: & 96,818333 & 1,86 & \\
\hline
\end{tabular}




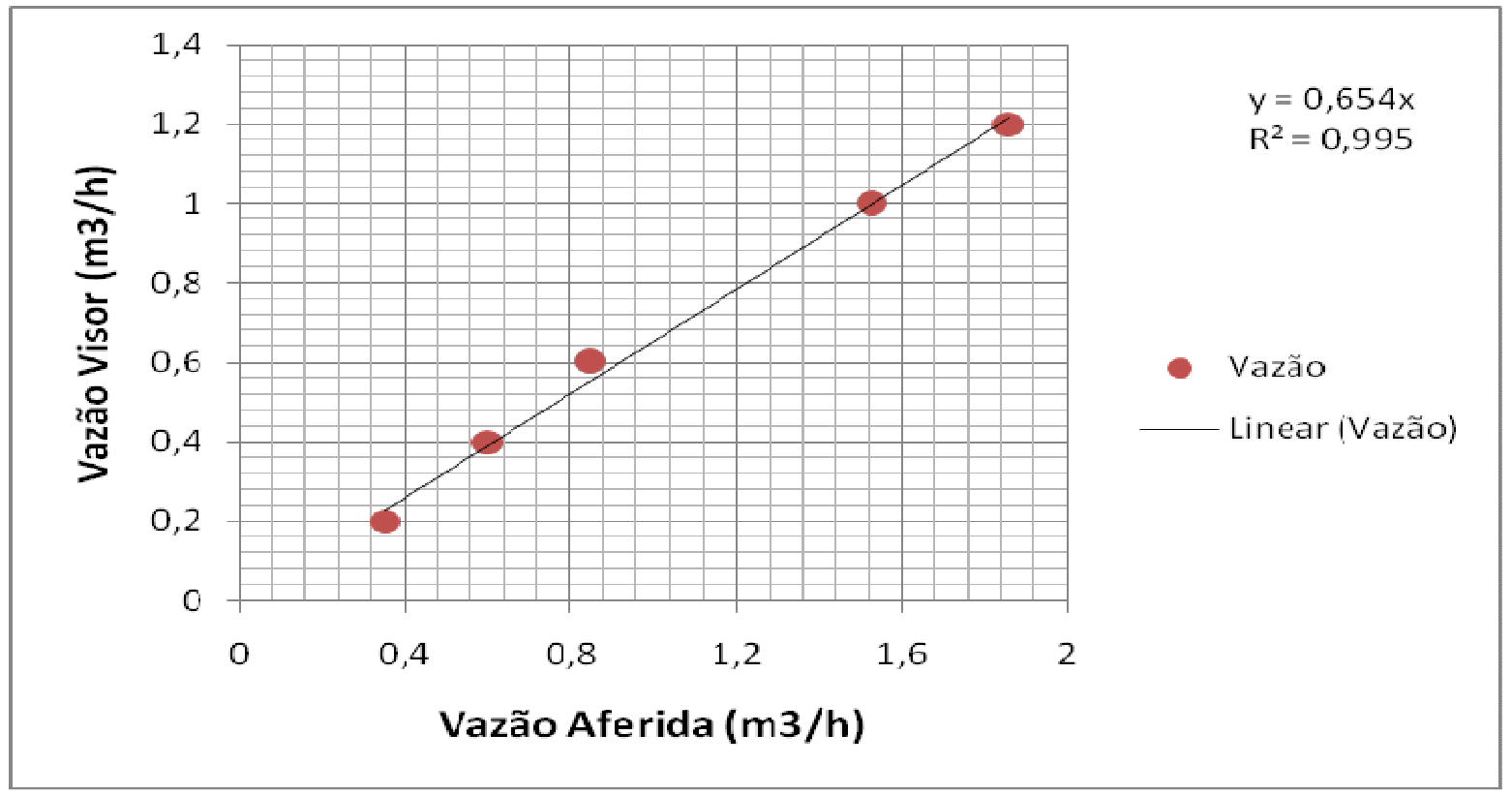




\section{ANEXO III}

FOTOS: INSTALAÇÃO PILOTO DE FLOTAÇÃO POR AR DISSOLVIDO (FAD)

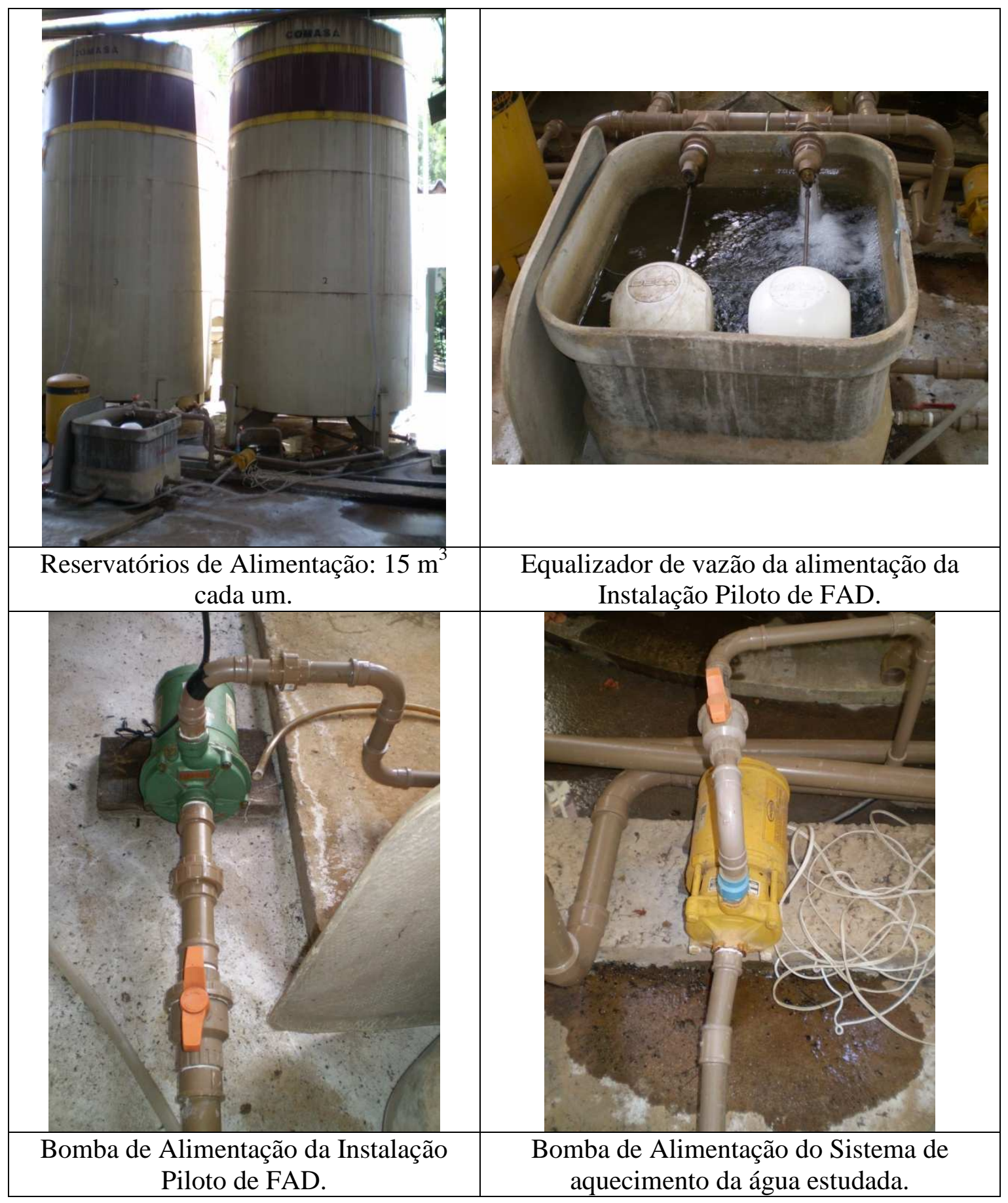









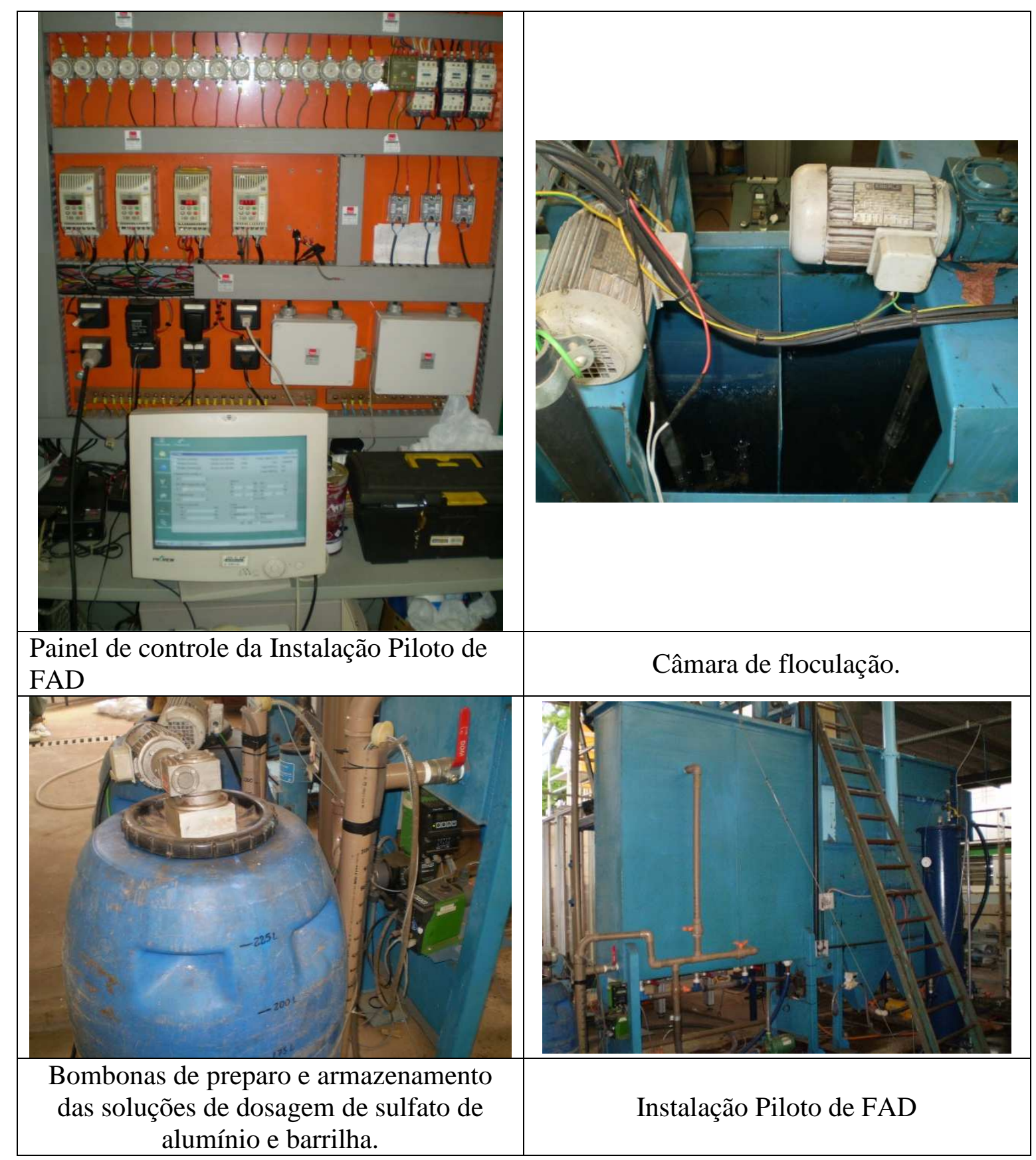




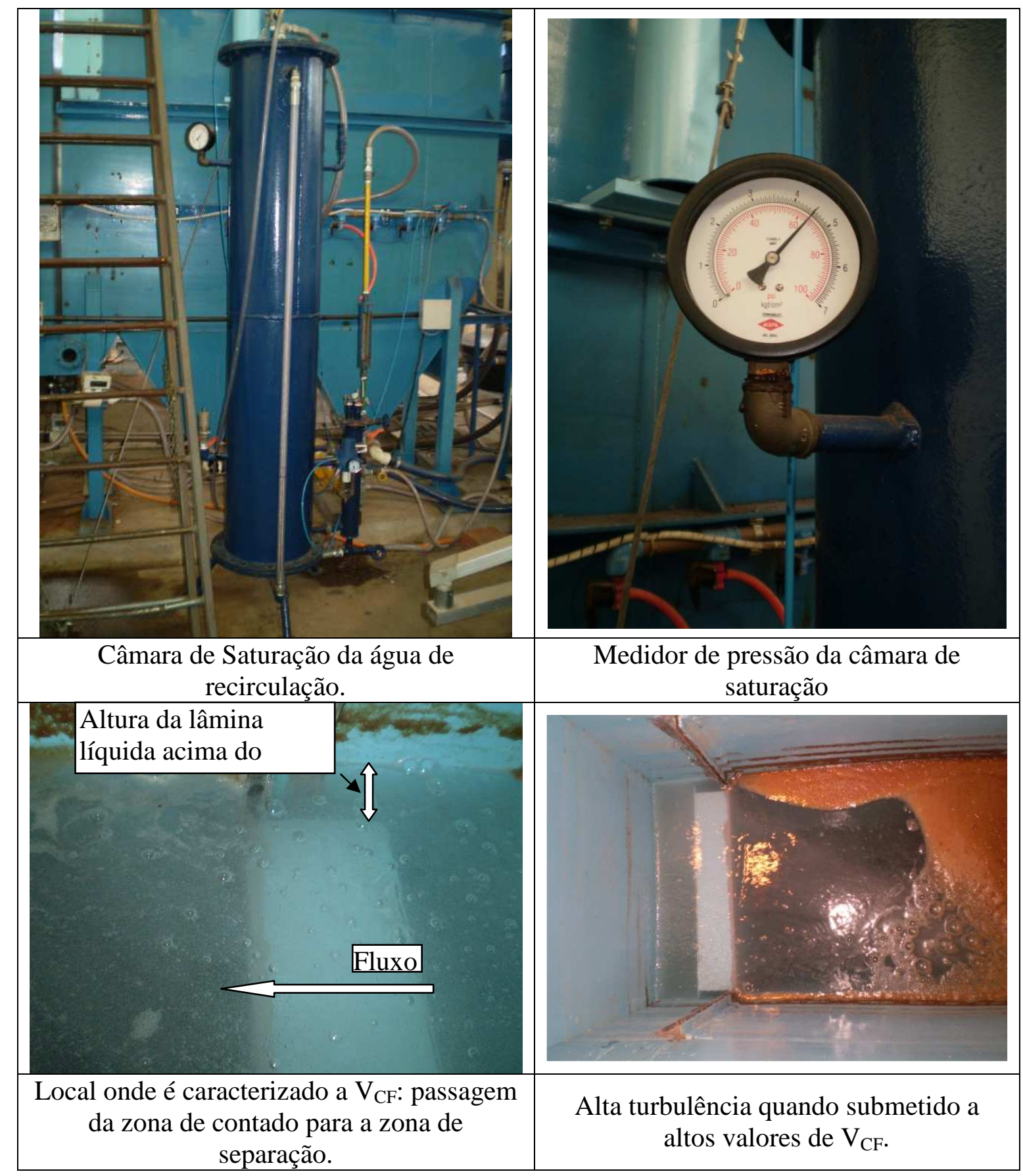




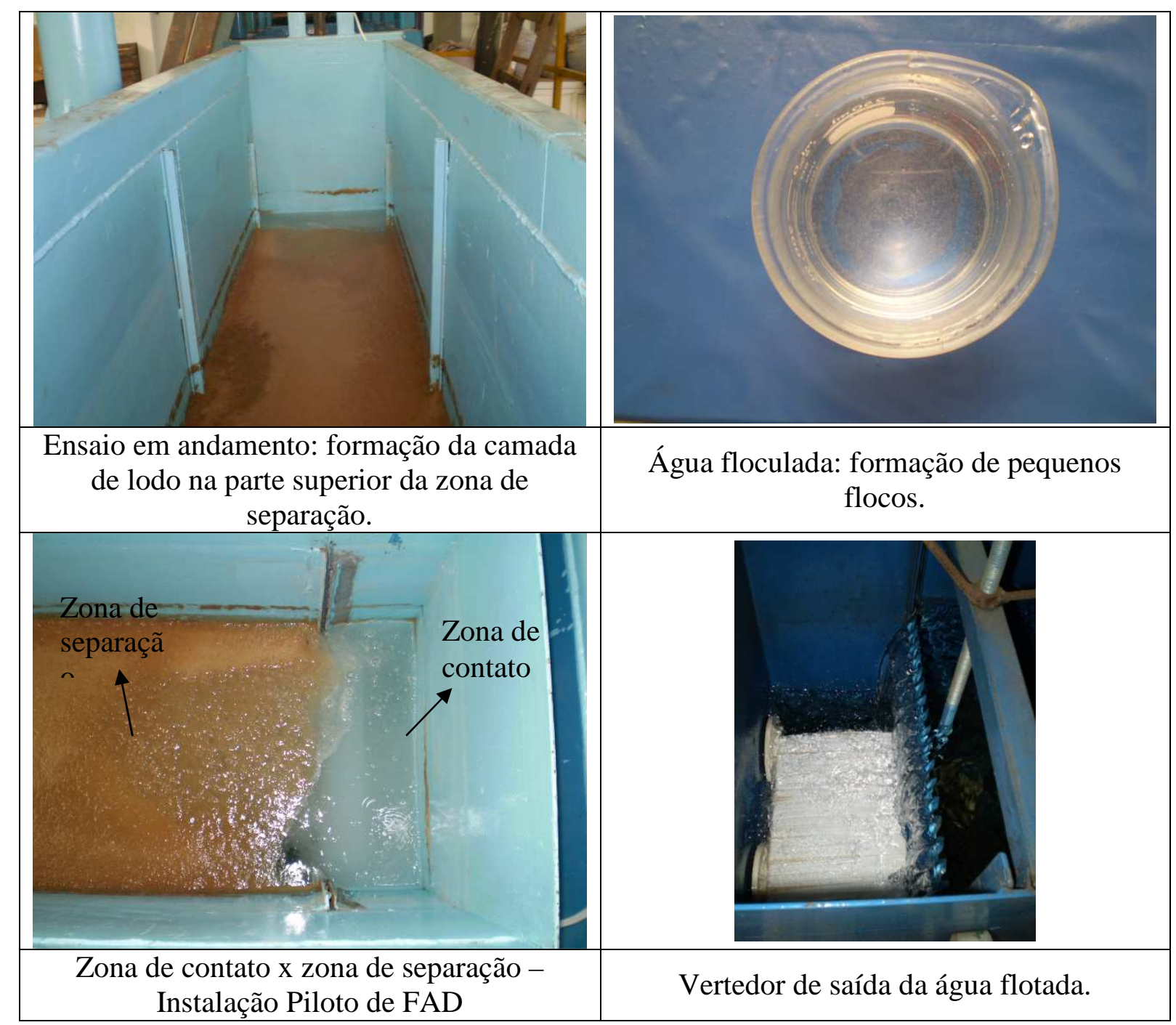

